Andrews University

Digital Commons @ Andrews University

\title{
A Study Of The Discriminative Function Of Six Variables In 9-12-Year-Old Males With Learning Disabilities
}

Kenneth M. Hanig

Andrews University

Follow this and additional works at: https://digitalcommons.andrews.edu/dissertations

Part of the Educational Psychology Commons, and the Special Education and Teaching Commons

\section{Recommended Citation}

Hanig, Kenneth M., "A Study Of The Discriminative Function Of Six Variables In 9-12-Year-Old Males With Learning Disabilities" (1989). Dissertations. 427.

https://digitalcommons.andrews.edu/dissertations/427

https://dx.doi.org/10.32597/dissertations/427

This Dissertation is brought to you for free and open access by the Graduate Research at Digital Commons @ Andrews University. It has been accepted for inclusion in Dissertations by an authorized administrator of Digital Commons@ Andrews University. For more information, please contact repository@andrews.edu. 


\section{INFORMATION TO USERS}

The most advanced technology has been used to photograph and reproduce this manuscript from the microfilm master. UMI films the text directly from the original or copy submitted. Thus, some thesis and dissertation copies are in typewriter face, while others may be from any type of computer printer.

The quality of this reproduction is dependent upon the quality of the copy submitted. Broken or indistinct print, colored or poor quality illustrations and photographs, print bleedthrough, substandard margins, and improper alignment can adversely affect reproduction.

In the unlikely event that the author did not send UMI a complete manuscript and there are missing pages, these will be noted. Also, if unauthorized copyright material had to be removed, a note will indicate the deletion.

Oversize materials (e.g., maps, drawings, charts) are reproduced by sectioning the original, beginning at the upper left-hand corner and continuing from left to right in equal sections with small overlaps. Each original is also photographed in one exposure and is included in reduced form at the back of the book. These are also available as one exposure on a standard $35 \mathrm{~mm}$ slide or as a $17^{\prime \prime} \times 23^{\prime \prime}$ black and white photographic print for an additional charge.

Photographs included in the original manuscript have been reproduced xerographically in this copy. Higher quality $6^{\prime \prime} \times 9^{\prime \prime}$ black and white photographic prints are available for any photographs or illustrations appearing in this copy for an additional charge. Contact UMI directly to order.

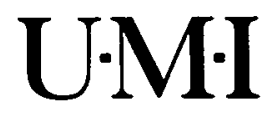

University Microfilms International

A Bell \& Howell Information Company

300 North Zeeb Road. Ann Arbor. Mi 48106-1346 USA

313/761-4700 800/521-0600 


\section{A study of the discriminative function of six variables in} 9-12-year-old males with learning disabilities

\section{Hanig, Kenneth Matthew, Ph.D.}

Andrews University, 1989

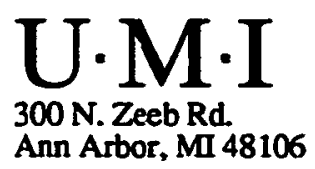

Reproduced with permission of the copyright owner. Further reproduction prohibited without permission. 


$$
\begin{aligned}
& \text { Andrews Universicy } \\
& \text { Graduate School of Education }
\end{aligned}
$$

\title{
A STUDY OF THE DISCRIMINATIVE EUNCTION OE SIX VARIABLES IN 9-I 2-YEAR-OLD MALES WITH LEARNING DISABILITIES
}

\author{
A Dissertation \\ Presented in Partial Fulfillment \\ of the Requirements for the Degree \\ Doctor of Philosophy
}

by

Kenneth M. Hanig

Reproduced with permission of the copyright owner. Further reproduction prohibited without permission. 


\section{A STUDY OF THE DISCRIMINATIVE FUNCTION OF \\ SIX VARIABLES IN 9-I 2-YEAR-OLD MALES WITH LEARN ING DISABILITIES}

by

Kenneth M. Hanig

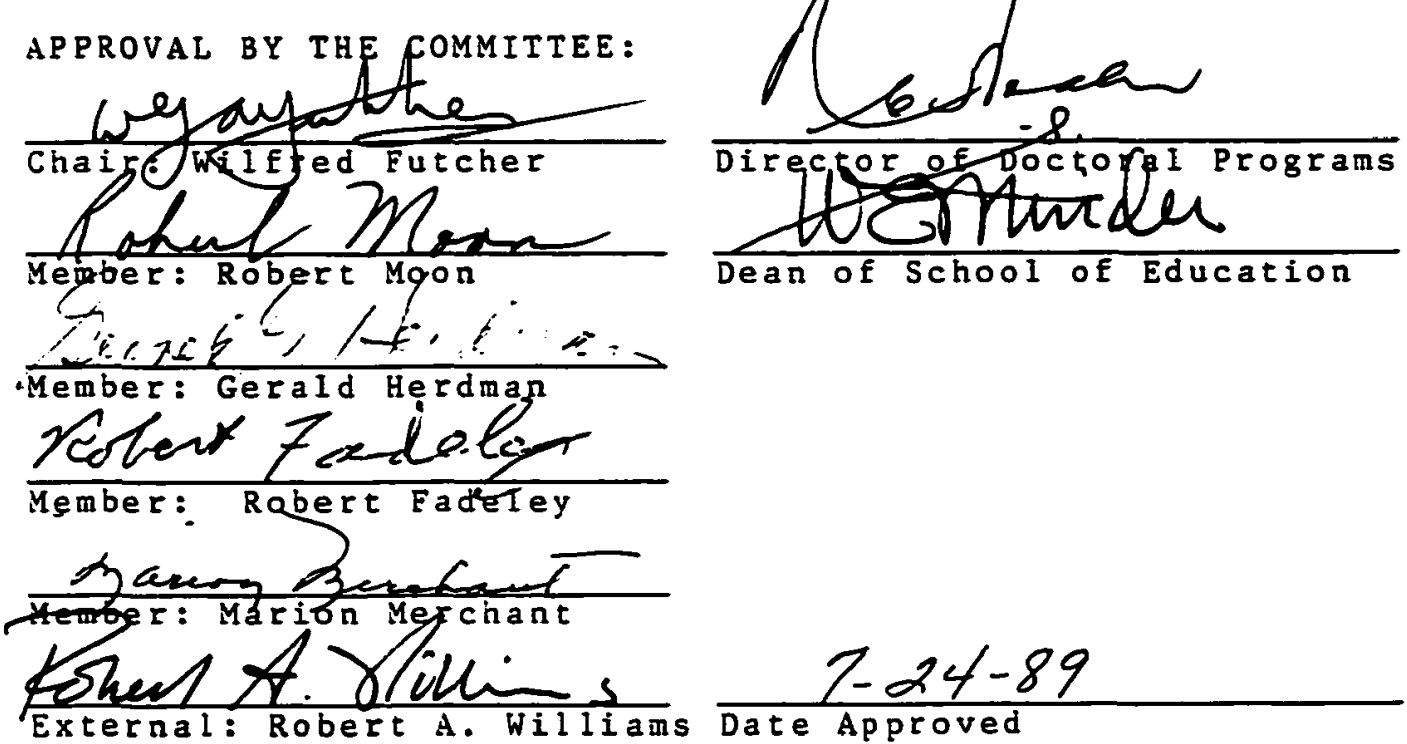

Reproduced with permission of the copyright owner. Further reproduction prohibited without permission. 
ABSTRACT

\section{A STUDY OF THE DISCRIMINATIVE FUNCTION OF SIX VARIABLES IN 9-I 2-YEAR-OLD MALES WITH LEARNING DISABILIIIES}

by

Kenneth M. Hanig

Chair: Wilfred Futcher, Ph.D. 
used in a project prior to this. Using measures such as Sentence Repeat, Synonyms, Digits Forward/Backwards, Design Copy, Nonsense Words, and Visual Patern Matcinin, this project studied the responses of an LD sample to these subtests and their ability to discriminate anong a verbally impaired sample, a spatially impaired sample, and a control group.

\section{Method}

Six subtests were developed, which, according to the literature, measured auditory discrimination and memory (Sentence Repeat); auditory and verbal compreinension and general verbal background (Synonyms); inmediate auditory memory, attention, concentration, jouble tracking, and reversal of mental operations (Digits Eorward/Backwards); visual perceptual-motor Eunctioning (Design Copy); lexical processing (Nonsense Words); and visual memory and visual-perceptual learning (Visual Pattern Matching). The basic null hypothesis was that there is no linear combination of six variables wich siznificantly discriminates among the three groups. The instrument was subjected to a pilot study before the final data collection took place. The data were analyzed using one-way analysis of variance, multivariate analysis of variance, and discriminant function analysis. 


\begin{abstract}
Results
Two sujtests dominated in their ability to discriminate among the groups--synonyms and Digits Forward/Backwards. Both the verbal and spatial groups were found to have shared deficits, but differed significantly from the control group on most of the neasures. The null hypothesis was rejected.

Conclusion

The y-12-year-old males in this sample with learning disabilities expressed deficits only in verbally related areas--specifically auditory/verbal comprehension and short-term auditory memory, attention, and concentration. Based on the literature and data gathering experience, it was also revealed that students should not be placed in LD programs based on one test, and a home visit should take place.
\end{abstract}


TABLE OF CONTENTS

LIST OF TABLES • • . . . . . . . . . . . . . .

Chapter

I. INTRODUCTION. • . . . . . . . . . . . . 1

Statement of the Problem. . . . . . . . . 3

Purpose... . . . . . . . . . . . . . 4 4

Hypothesis... . . . . . . . . . . 5

Assumptions................ . . . . . 5

Rationale................... . . . . . 6

Definition of Terms . . . . . . . . . . . . 8

Delimitations of the study.......... 10

Limitations................. . 11

I. REVIEW OF THE LITERATURE. . . . . . . . . . $\quad 14$

Introduction. . . . . . . . . . . . 14

The Problem of Definition......... . 17

The Problem of Classification... . . . . 25

Cerebral structures and Deficits... . . . 29

Piaget's Contribution........... . . 40

Measurement of Cerebral Deficits. . . . . 42

Research Focus............... . 49

III. RESEARCH DESIGN • . . . . . . . . . . . . 52

Overview. . . . . . . . . . . . . . . 52

Population and Sample.......... . . . 53

Problems in Determining Placement..... 56

Variables... . . . . . . . . . . . 57

Instrumentation................ . . . . .

Procedures.................. . . . . . . . 10

Further Delimitation. . . . . . . . . . . 73

Nul 1 Hypothesis . . . . . . . . . . . . . . 74

IV. PRESENTATION AND ANALYSIS OF DATA • • • . . 75

Introduction. . . . . . . . . . . . 75

Sample................... . . . . . . 76

Procedural problems............ . . 77

i i

Reproduced with permission of the copyright owner. Further reproduction prohibited without permission. 


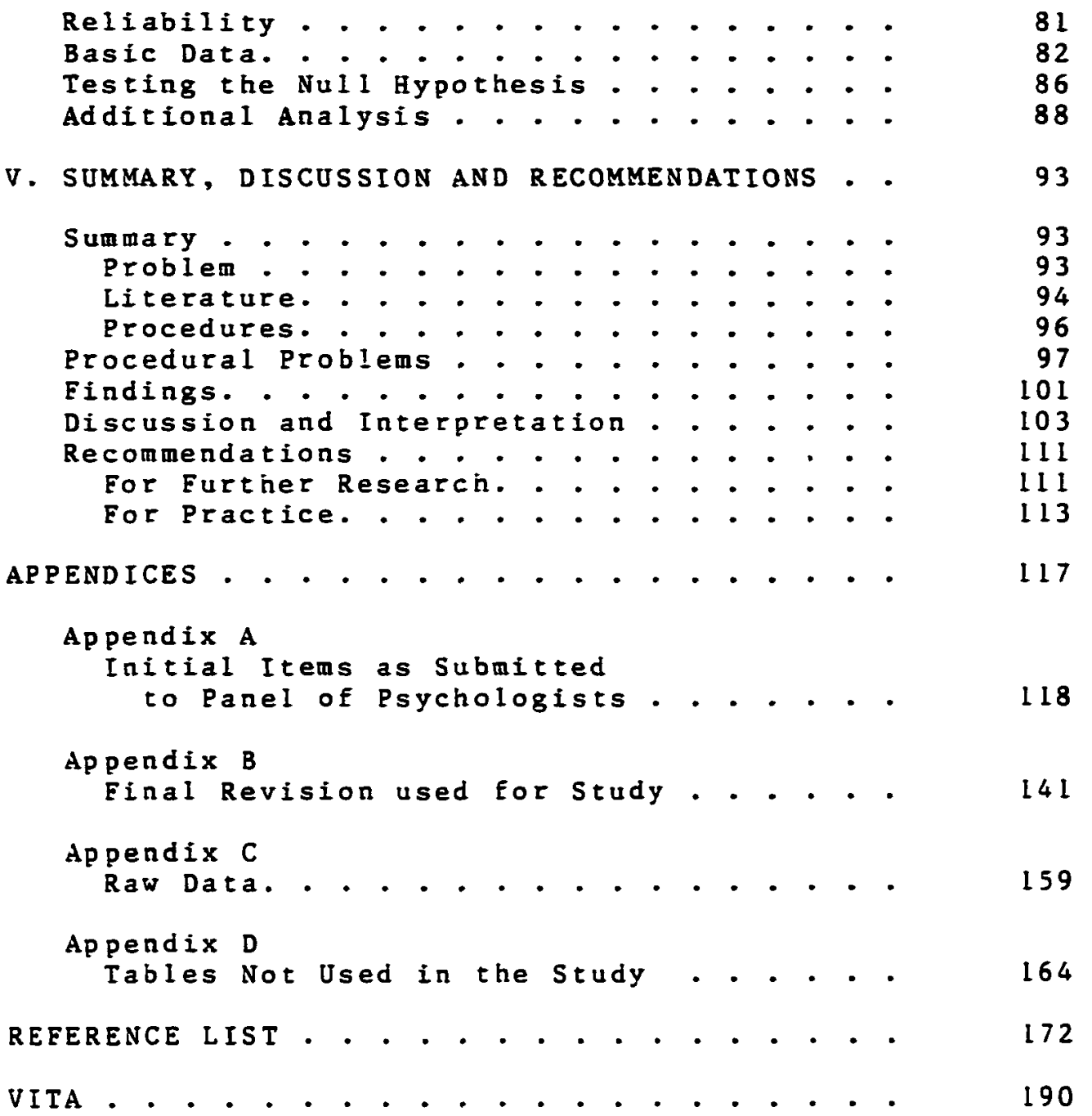


CHAPTER I

\section{INTRODUCTION}

It is difficult to do a thorough and comprehensive evaluation of the psychological aberrations of the human brain (Boll, 1978). An area in which this is especially difficult is that of central processing deficits or learning disabilities (Rourke, 1981). Scull and Brand (1980) have described how early work has evolved into such tests as the Brigance Diagnostic Inventory of Basic Skills, the Detroit Tests of Learning Abilities Revised, or the Kauffman Tests of Educational Achievement which purport to measure these deficits. In practice, measures that have been developed for other purposes, such as the Wechsler Intelligence Scale for Children-Revised, the Bender Visual-Motor Gestalt Test, the Developmental Test of Visual-Motor Integration, and the Illinois Tests of Psycholingustic Abilities have also been used in diagnosing central processing disorders (Miller, 1980; Rourke, ed., 1985; Rourke, Fisk, \& Strang, 1986 ; Stevenson, 1985 ; Wallbrown, Blaha, \& Vance, 1980$)$. 
Moreover, since researchers have attempted to show that learning deficits are related to cerebral dysfunctions (Boll \& Barth, 1981; Rourke, Fisk, \& Strang, 1986), these measures have been evaluated for their capacity to delineate cortical loci of the specific disorder (Rourke, I981; Rourke, Fisk, \& Strang, 1986). However, it is clear that more research is needed to clarify lateralized cerebral hemispheric functions and identify the sources of brain-behavior disturbances as they are related to the educational handicap of a learning deficit, such as a central processing disorder (McNeil \& Hamre, 1974). Many researchers have found that neurological dysfunctions are related to learning disabilities (Gazzaniga, 1973; Hynd, Hayes, \&now, 1982; Rourke, 1981 , 1985; Rourke, Fisk, \& Str.ng, 1986; Sattler, 1982). Yet, clarification of the extent of so-called "soft signs," indicating neurological conditions and thus the assumption of a learning disability, has not been firmly established (Rie\& Rie, 1980). When a client who has been referred to a psychologist has been involved in an accident and has sustained a head injury, the probability that a learning deficit will occur is 
rather high (Lishman, 1978). One of the most dramatic realizations of a neurological deficit resulting in learning problems is impairment due to a cerebral vascular accident (CVA) or "stroke." The resulting hemiparesis, speech disorders, memory dysfunctions, etc., are well covered in the literature (Mohr, Leicester, Stoddard, \& Sidman, 1971; Silverstein, Lehrer, \& Mones, I960; Vitale, Pulos, Wollitzer, \& Steinielber, 1974; Williams, 1979). For example, a 55year-old male smoker, who is 25 pounds overweight and in a stressful occupation (e.g., industrial plant manager), suffers a CVA in the left hemisphere. Right-sided hemiparesis and speech loss are the most immediate and recognizable deficits to the observer. Other deficits may eventually arise, such as memory loss, difficulty or absence of computational skills, and perhaps total incapacitation requiring extensive recovery--such as was the case of Woodrow Wilson.

\section{Statement of the Problem}

The problem addressed by this study is the difficulty of clearly identifying a learning disability in a child for the purpose of placement ina program for the learning disabled. The need for more discriminative powers to clarify the diagnostic category of learning disabilities in schools and elsewhere is clearly 
present. Many studies have described the lateral preference patterns as discriminative of learning disabilities (Dean, Schwartz, \& Smith, 1981; Hartlage \& Telzrow, 1983; Rourke, Fisk \& Strang, 1986). The evidence for a neurological condition in at least onethird of the children with learning deficits is also wel I known (Black, 1976). This has been found at the Level of the cerebral hemispheres (Rourke, Yanni, MacDonald, \& Young, 1973; Proceedings of the 8lst Annual Convention of the American Psychological Association, Montreal, CA, 1981). The need for more discriminative power is further evidenced in a "state of the art" review of the literature by Benton and Pearl (1978). They concluded that a satisfactory understanding of specific reading disabilities had not been achieved, though the cluster of ACID (Arithmetic, Coding, Information, and Digit Span subtests of the WISC-R) may be a promising development in analyzing the reading scores and deficits (Joschko \& Rourke, 1985).

\section{Purpose}

The purpose of this study was to combine variables in a test that would begiven in the course of an evaluation by a psychologist/psychometrist, from a referral seeking an evaluation for the appropriateness 
of a student for a learning disabilties program in the schools. Six variables were combined for the purpose of discriminating laterality and assisting in the writing of an individualized educational program (commonly referred to as IEPs) separating learning disabled groups from normal groups of students and contributing to an understanding of how information is processed in the cerebral hemispheres.

\section{Hypothesis}

The hypothesis proposed was: There is a linear combination of six variables which significantly discriminates among four groups of children: a braindamaged sample, a sample of spatially learning disabled, a sample of verbally impaired students, and a control sample.

\section{Assumptions}

In this study, the following assumptions were made:

1. A central-processing disorder reflects a minimal amount of neurological dysfunctioning (Hammil, Leigh, McNutt, \& Larsen, 1981).

2. Cereoral nemispineric dysfunctions result in specific learning disorders which can be operationally defined (Geary, Jennings, Sciultz, \& Alper, 1984). 
3. The significant impairment of such neuropsychological processes of memory, attention, etc., can be demonstrated in learning tasks (Selz \& Reitan, (979).

4. Factors such as biochemistry, emotionality, environmental deprivation, injury, metabolic activity contribute to the development of learning disabilities (Brazelton, Tronick, Adamson, Als, \& Weise, 1975; Hynd, Hays, \& Snow, 1982:

5. Measures such as the WISC-R, Children's Checking List, the Peabody Picture Vocabulary Test-Revised, Matching Familiar Figures Test, Children's Embedded Eigures Test, etc., reveal significant differences among the vectors of means for learning disabled (LD), behavior disordered, and normal children (Wynne \& Brown 1984).

6. Learning disabilities describe deficits in cognitive functioning and are seen in subject-related areas in curriculum as impeding a student's progress in school (Sattler, 1982 ).

\section{Rationale}

One of the most common measures used by psychologists to classify LD students is the Wechsler Intelligence Scale for Children-Revised (WISC-R).

Within this measure, the verbal-performance split, where 
the verbal scale is "significantly" lower than performance, is often used to discriminate LD students from other groups (Kaufman, 1979). As Rourke (1981) notes, the utilization of pattern analysis can aid in the determination of one subject having reading problems as opposed to deficits in other areas. Others challenge this view. Miller (1980) indicates that the use of verbal-performance discrepancies used in the placement of children with learning disorders is not supported by previous research (Bloom \& Raskin, 1980; Kaufman, 1979; Sattler, 1982). In fact, in two studies by Miller ( 1978 ), scores for learning-disabled students were not particularly outside normal scoring variations. Other evidence against the use of such discrepancies is found in Vance and singer (1979).

In other studies, the diagnostic content of "scatter" on WISC-R profiles has also led to the conclusion that caution must be used in interpretation due to the similarity of such profiles among various clinical groups (Kaufman, 1979). In one study, it was found that depression could affect the information processing of the cerebral hemispheres (Tucker, Stenslie, Roth, \& Shearer, 1981). In addition, there is some criticism regarding the reliability in the content sampling and scoring procedures of such measures 
(Holroyd \& Wright, 1965).

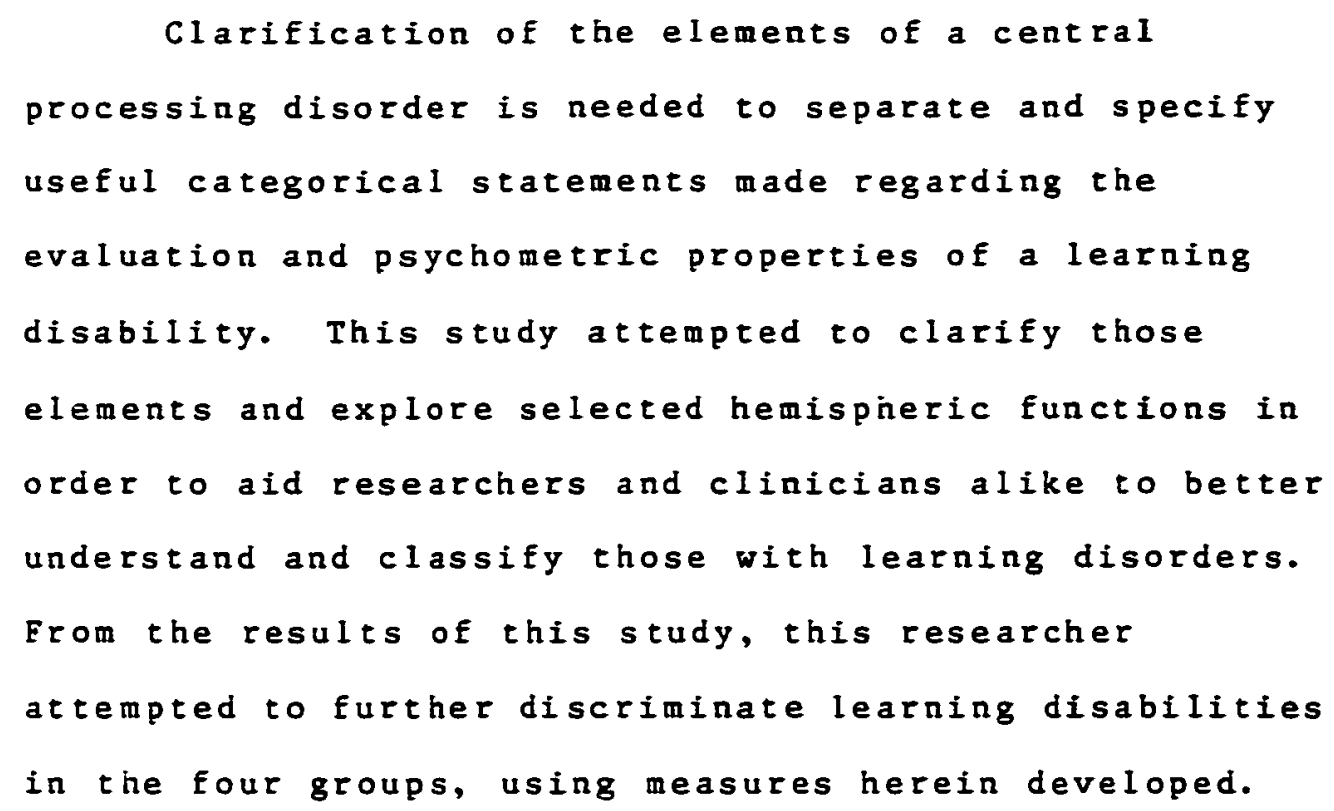

\section{Definition of Terms}

In order to aid the reader and clarify specific terms used in this study, a number of terms are defined. These defiaitions are taken from the Dictionary of Behavioral Science, New York: Van Nostrand, 1973, except where otherwise noted:

Agnosia: The loss of memory of familiar objects. This condition can involve any sensory system, and is often the result of cortical damage.

Aphasia: Impaired ability to speak, write, or to understand the meaning of words, due to brain damage.

Apraxia: Impairment or loss of ability to perform purposeful movement, caused by lesions in the motor area of the cortex, but with no sensory impairment or paralysis. 
Ataxia: Incoordination of voluntary muscular action.

Brain Disorder (Dysfunction; also Cerebral Hemispheric Dysfunction): Disorders that are caused by or associated with impairment of functioning of brain tissues and that generally manifest symptoms such as: impairment of coordination; impairment of orientation, memory impairment; impairment of intellectual functions including calculation, knowledge, learning comprehension; impairment of judgment; shallowness and lability of affect.

Cortex: The outer layer of an organ; the cerbral cortex inen used without qualification.

Dominance, hemisphere: One hemisphere of the brain controls movement of the body more than the other hemisphere, resulting in handedness.

Dyscalculia (acalculia): A form of aphasia that involves the loss of ability to carry out even simple arithmetic operations.

Dysgraphia (agraphia): The inability to express thoughts through writing or written symbols, caused by brain

lesion.

Dyslexia: A reading disorder characterized by the inability to understand what one reads either silently or aloud.

Lateralization: The tendercy for dominance of one side of the brain over the other in most functions.

Learning Deficit: A specific learning disability (e.g. auditory discrimination).

Learning Disability (also, Central Processing Disorder): "A disorder in one or more of the basic psychological processes involved in understanding or in using language" (from Indiana State Board of Education, 1978).

Learning Disabled: A term referring to one who has a learning disability.

Neuropsychology: "A study of brain-behavior relationships." (Small, L. Neuropsychodiagnosis in Psychotherapy, New York: Brunden/MAZ, 1973). 
Pattern Analysis: A technique for the search of clusters of items which belong together according to a particular criterion.

Scatter: The degree to which a distribution of measurements or scores are closely grouped around the mean or dispersed over a wide range, most commonly measured by the standard deviation.

School Psychologist: A psychologist spectalizing in problems associated with elementary and secondary educational systems, wio utilizes psychological concepts and methods in programs or actions which attempt to improve learning condition for students.

WISC-R: Wechsler Intelligence Scale for ChildrenRevised.

\section{Delimitations of the Study}

This study focused on 9-12-year-old males within four groups; one sample was drawn from a brain-damaged population; anotier from a verbally impaired (LD) population; a third from a spatially impaired (LD) population; and the fourth group consisting of a normal sample or control group. Nine-to-twelve year-olds were the focus of this study, since it is from this group that LD cases are referred for initial evaluations to school psychologists. Though learning disabled characteristics are found in females, only males were used since the frequency of learning disabilities in females is low. In terms of learning disabilities, males usually score about $1 / 6$ of a standard deviation lower than females (Ackerman, Dykman, \& Oglesby, 1983; Lawson \& Inglis, 1984). 


\section{Limitations}

Measures, such as the WISC-R as well as others

(Wide Range Achievement Test-Revised, Bender Visual-

Motor Gestalt, and others), are used by a case

conference comittee, consisting of the teacher, parent,

school personnel, and evaluation specialists to

determine an appropriate placement. However, as Cherkes

and Ryan (1985) note, results are often used to confirm

expectations. Even the Individualized Educational

Program, devised by a case conference committee, has

been called in question regarding its utility and

purpose in planning day-to-day educational instruction

(Dudley-Marling, 1985 ).

of most importance in a placement decision is the use of psychological tests, which are assumed to detect learning disabilities. Traditionally, psychologists have assumed that verbal-performance splits indicated dysfunctioning, and that these dysfunctions were related to learning disorders (Kaufman, 1979; Sattler, 1982). However, the use of WISC-R verbal-performance split has been called into question, especially relating to its validity and reliability (Berk, 1982; Kaufman, 1979; Sexton \& Street, (985), but the practice continues (Berk, 1983).

The method of placing a student in an LD 
program hampers the study of learning disabilities because of potential wrong placement. The assumption is that a student is learning disabled if he or she falls below expected grade levels on tests. Traditionally, a two-year difference between present grade level and tested grade level has been used to aidin a placement decision (Harris aing, 1982). Because criterionrelated validity of psychoeducational tests for reading ability (WRAT, PPVT-R, DTLA-R, etc.) accounted for over $70 \%$ of the variance in reading groups consisting of LD students (Webster, 1985), it would appear that the use of criterion-related tests would aid in a placement decision.

It was hoped that this study would aidin delineating the measures which taken together would assist in classifying students correctly and explain test results adequately thus contributing to the rormation of useful individualized educational programs. Having yet one more measure to compare to the WISC-R Verbal-performance results, or other measures, could aid in making sounder educational decisions, adding validity to placements and programs.

Practicing school psychologists would have additional measures to utilize in their assessments and would be able to offer case conference comittees valid 


\begin{abstract}
and reliable data to enhance placement decisions and IEP programing. Perhaps the measures would also aid in clarifying a difficult and cumbersome definition that tends to misclassify students, depriving some of the necessary instruction needed and locking others into programs of Iittle worth for their specific deficits. The need for such a measure is clear. Even if the hypothesis of this study was not supported, other researchers could build upon what was at tempted here and pernaps light a brighter candle.
\end{abstract}


CHAPTER TWO

\section{REVIEW OF THE LITERATURE}

\section{Introduction}

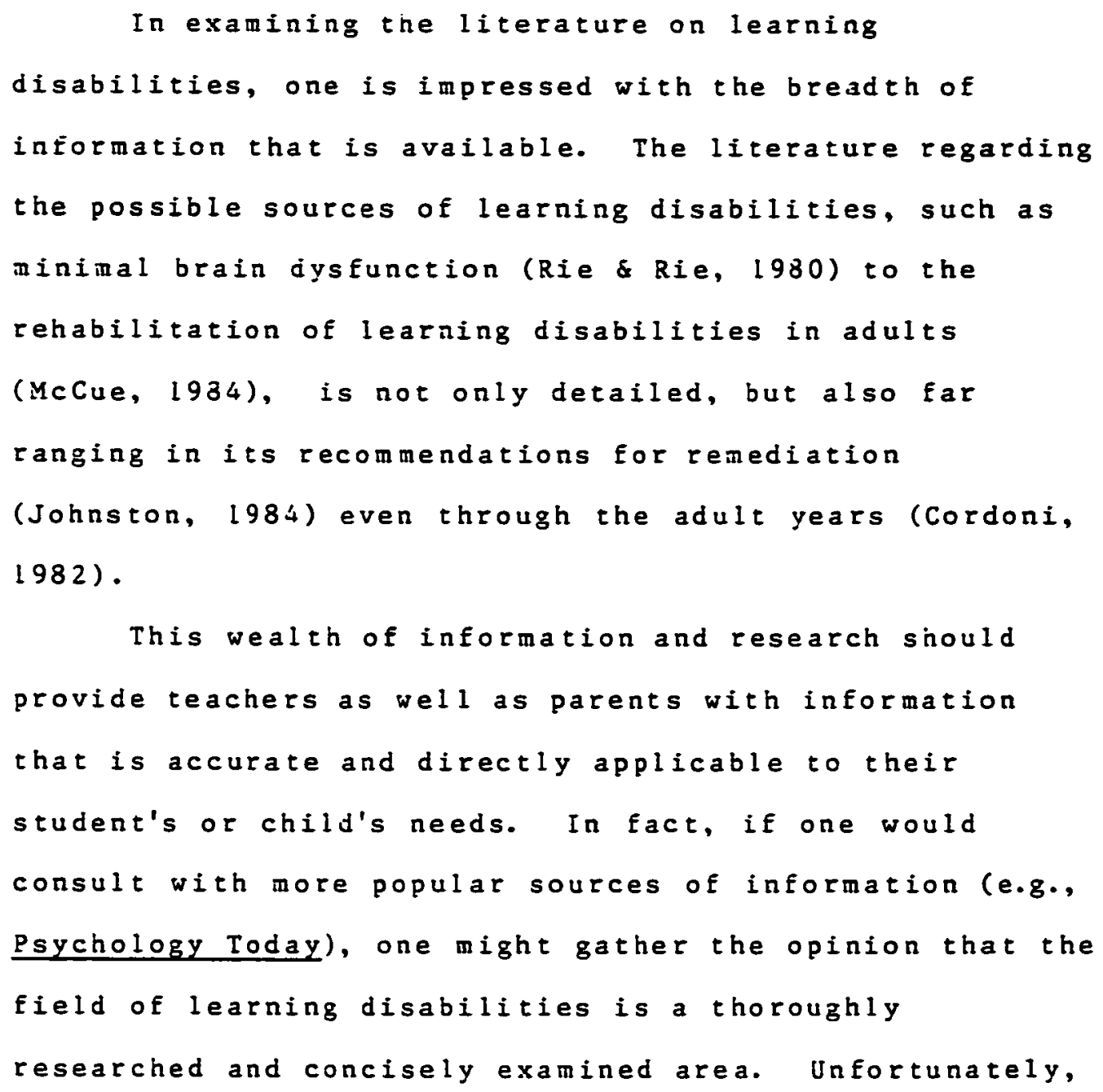

14 
this is not the case. As with any area of research, much is needed by way of defining what it is one wants to discover before recommending any approach to solving a problem based on tiat research. This seems to be the point at which the field of learning disabilities finds itself today (Graden, 1986). The difficulty in just defining what is a learning disability can be very elusive. Many areas can be expressive of learning deficits; figure-ground problems, sequencing, visual discrimination, memory, attention and concentration, systematic planning, kinesthesis, sensation, as well as others are just a few that have been explored (Mclue, 1984). In addition, other behaviors are descriptive of one witn a learning disorder attributable to minimal brain dysfunction, such as digestive problems, bedwetting, episodes of high fevers, hyperactivity, awkwardness, running away, poor "third dimension sense," persevering activities, and many others (Anderson, Holcomb, \& Doyle 1973). It is no wonder that many parents consult popular learning disabilities literature and read that their child's behaviors could indicate anything from the "common cold" to a serious problem in learning or perhaps some "hidden" neurological condition. The parent becomes worried and consults with a teacher, who in turn has read the same 
material, as well as confusing professional articles. The teacher, in turn, refers the case to the school psychologist. The psychologist as well may be perplexed over the information, but using the results of the most reliable research at his or jer disposal, diagnoses the condition.

Fortunately, research is becoming more sophisticated and specific (Groff, 1986; Mckeever, 1977). In Groff's (1986) summarization, many references now deal with dichotic listening (Bogen, Fischer, \& Vozel, 1965; Broadbent, 1952; Koomar \& Cermak, 1931); visual half-field testing (Bakker, 1979; Broman, 1978; Leong, 1980); and learning and memory (Bower \& Hildegard, 1981; Levitt, 1981; Travers, 1967). New recommendations are being offered to teachers in dealing with remejiation of problems due to learning deficits (Matthews, 1974; McNeil \& Hamre, 1974). These and other studies should help teachers and parents better understand learning disorders, as well as aid them in teaching strategies to help children learn better and more efficiently.

However, some problems remain. Clearly, the problem of definition is one of the most confusing areas of learning disorders. The first section of this review discusses a few of these problems. A second section 
discusses the area of classification criteria. If one is to conduct a study of learning disabilities, the identification of criteria for inclusion of subjects in the study is a problem.

The third area reviewed is that of structures and deficits. Though much has been done regarding brainlearning relationships, researchers are still attempting to clarify what organic structures are impaired due to learning deficits. The fourth section deals with Piaget's contribution toward the formation. of a model for understanding learning deficits. The last two sections deal with measurement of cerebral deficits, and the focus of future research as well as the focus of this study.

\section{The Problem of Definition}

It has been difficult to do a thorough diagnostic evaluation regarding a learning disability with any degree of confidence (Morris, 1988; Fiscier et al., 1986; Rourke 1981;). This difficulty has been complicated by the confusion of what, by definition, constitutes a learning disorder. This confusion stems, in part, from an inadequate diagnostic criterion by which to classify children with processing deficits (Graden, 1986; Fisk \& Rourke, 1979; Rourke, 1981). This can be demonstrated 
by the following definition of a learning-disabled child:

Children with special (Specific) learning disabilities exhibit a disorder in one or more of the basic psychological processes involved in understanding or in using spoken or written language. These may be manifested in disorders of listening, thinking, talking, reading, writing, spelling, or arithmetic. They include conditions which have been referred to as perceptual handicaps, brain injury, minimal brain dysfunction, dyslexia, developmental aphasia, etc. They do not include learning problems which are due primarily to visual, hearing, or motor handicaps, to mental retardation, emotional disturbance, or environmental disadvantage. (P.L. 94-142, Federal Register, p. 424)

Most states define a learning disability as a disorder in one or more of the psychological processes involved in understanding or in using language, and excludes children who have learning problems due to vision/ hearing problems, motor handicaps, or cultural disadvantage. Other states define a learning disability as a perceptual or communicative disorder, classify handicapped students with an "identifiable learning disability" who have a severe discrepancy between educational ability and measured intellectual ability, witnout quantifying what a severe discrepancy is. Other states refer to "average or above average" IQ, or "normal or near normal" intelligence. New Mexico indicates that those who have learning disabilities have average to superior IQ's. In no definition for learning 
disabilities, as defined by the states, is there a reference to a number for "normal or near normal" intelligence. Some states, such as Louisiana, include attentional deficit disorder, where most states do not. Some states, for example Maine, speak of a "specific learning function" as an "imperfect ability to listen, think, speak, read, write, spell, or do mathematical calculations." Other states, such as New Jersey, refer to "neurologically or perceptually impaired" as a learning disability, witn "perceptually impaired" defined as a disorder in understanding! oregon makes the prediction that these students "are or will become extreme underachievers." Vermont has a "specialty" category for the learning disabled "which results from a minimal brain injury or damage, a developmental lag of cerebral nervous system, or many other unknown causes." However, a recent study in Minnesota indicated that criteria were often abandoned to serve referred students who were having achievement problems" (LD State Update: Minnesota, 1987 ).

Perhaps the problem with the definitions above is one of clarity. For example, stating that "They do not include learning problems which are due primarily to visual, hearing, or notor inandicaps, etc.," may cause confusion. If one learas through visual and auditory 
processing, or motor means, and learning problems in these areas are not included, then what constitutes the learning disability in one or more of these modalities? Perhaps it might be clearer if, as Ayres (1972) specifies, learning-disabled children demonstrate inadequate sensory integration, which is manifested by immature postural actions, poor visual tracking, poor orientation in space, and a tendency toward distractability. In addition, elaboration on a biological cause would help focus on these characteristics, as did Duane (1979) who stated that the biological basis of developmental delay is dependent on individual rates of myelination, neuronal migration, and synaptic development or variations in neurochemistry.

Lerner (1984) indicated that there were at least Five components that should be included in a definition of learning disabilities: neurological dysfunction, uneven growth patterns, difficulty in academic and learning tasks, discrepancies between learning and potential, and the exclusion of other causes. She also categorizes characteristics that need to be included in a definition of learning disabilities; disorders of attention, disorders ó motor zilities, disorders of perception, disorders of written language, disorders of mathematics, and disorders of social/emotional behavior. 
Though she does not "define" LD, she at least highlights the major areas that need to be taken into consideration.

However, Banbury (1986) states that definitions reflect a user's specific orientation. While some professionals define the disorder as a maturational imbalance, a developmental delay, a neurological or organic impairment, or a discrepancy between expected potential and actual performance, others explain the disability by exclusion, that is, by stating that these learning problems are not caused by deficits in intel lectual, sensory, emotional, or environmental areas. Banbury further states that while some specialists consider etiology irrelevant, others focus their attention on causative factors, citing heredity, prenatal or perinatal problems, high fevers, head injuries, toxins, anoxia, malnutrition, or food aditives. With all of this conflicting information, it is not surprising that defining a learning disability is the most difficult task facing the teacher or parent in trying to decide what is best for the student. There are authors, though, who add to the confusion over definition by stating that all of these terms are confusing and unnecessary. Menkes (1980) states that terms applied to this situation (learning 


\begin{abstract}
disabilities) variously emphasize an assumed neurological basis ("minimal cerebral dysfunction"), a supposed perceptual deficit ("word blindness"), or the seemingly isolated character of the disorder ("dyslexia"), which is also often termed selective or specific, and aypotnesized to be "organic" or "developmental." Such terms are distracting, according to Menkes. He furtiner notes that preoccupation with the orain basis of the difficulty may lead to investigations wich do not help in planning a child's future. He further indicates that the term learning disability refers to the selective failure that arises from irregularity of cognitive development, but not failure due to imperfect control of attention. Other authors, such as Leggett (1986), though, attempt to be more practical in their orientation toward what constitutes a learning disability and offer guidelines on not only definition, but assessment and procedures in determining the disability.

However, even what logically seem to be practical orientations toward definition and selection criteria can cause difficulty. For example, one criterion for the identification of a learning disabled child states: A child who is learning disabled shall exhibit, when first identified, a severe discrepancy between
\end{abstract}


normal or near normal potential and academic achievement in at least one of the areas of basic reading skills, reading comprehension, written expression, expressive language, mathematical reasoning, or calculations, or listening comprehension. (Indiana State Board of Education, (978)

Such a criterion suffers from a lack of clarity and/or operational precision. Some "clarified definitions" are "agreed upon" by committee (Hammill et al., (987). They are then reconsidered by yet another comittee (National Joint Committee on Learning Disabilities, 1987), discounted and criticized as "catchall" classification (Ames, 1985), leading to the conclusion that theremay not be such a disorder to begin with (Graden, 1986). Following such guidelines and directions as to what constitutes a "severe discrepancy," or what is "normal or near normal," or even if the category exists at all, it is difficult at best for those employed in school psycnology settings (Kosc, 1987). Further, these criteria do not refer to a solid body of evidence, which implicates brain dysfunction or neurological disturbances in many central-processing disorders (Brown \& Campione, 1986; Reitan, 1974; Rourke, 1985). As Aaron (1981) observed, much is based on belief, and some studies, such as relating birthdate to learning disabilities (Polloway \& 
Smith, 1986), are on the fringe of numerology rather than psychology.

What one can say about the problem of definition is that it is a multifaceted area and that there seem to be many components that constitute a learning disorder. Definitions that sumarize the expression of a learning disorder may lack specificity and clarity. If the definition is too focused (Ayres, 1972), the definition becomes too technical. Lerner ( 1984 ) highlighted different areas to be considered in a definition. Banbury ( 1986 ) states that the definition may only reflect a user's specific orientation. Menkes ( 1980 ) indicates that there is too much preoccupation with distracting terms and Leggett ( 1986 ) attempted to be more pragmatic in his approach to definition and criteria. Yet, when attempts are made to be more practical in terms of selection of students for LD placement, "clarified definitions" seem only to be "agreed upon" by committee (Hamill et al., 1987), leading to the conclusion that there may not even be such a disorder (Graden, 1986). This lack of agreement on a definition of a learning disability leads to great ambiguity in identification and placement. A student idenzified as learning disabled in one state may not qualify in another. 
The Problem of Classification

Graden (1986) seems to highlight some of the more difficult problems associating learaing disabilities with any criterion or definition. Regarding decision making on $L D$, Graden found that the major conclusion reached by the University of Minnesota's Institute for Research on Learning Disabilities was that there was no defensible system for declaring students eligible for LD services. Many systems do exist. There are those which rely on norm-based tests (Indiana Council of Administrators of Special Education, 1987), measures which assess problem-solving styles and information processing (German, 1983), studies using subtest scatter on measures such as the WISC-R (Taylor, Partenio, \& Ziegler, 1983), those which examine cultural and motivational factors (Licht, 1983), some which deal with the interrelationship between various tests (Prasse, Siewert, \& Breen, 1983; Scull\& Brand, 1980), and those which deal with specific disabilities and eligibility criteria, such as the system of Aviezer and Seymour (1980). Other authors criticize some systems which use grade-and-age equivalency scores in their system of criteria and placement (Bennet, 1980). Graden (1986) Found that once a student is 
referred, decision-making teams engage in a "search for patiology" (Coles, 1988) to determine what is wrong with the student. Graden also cited examples of "assumptions" that were made regarding learning deficits that could be explained through environmental, behavioral, or other variables. The most important criterion for selection, according to Ysseldyke, Thurlow, Graden, Wesson, Algozine, and Deno (1983), was that the student has been referred for consideration for placement in an $L D$ program in the first place.

others, however (Rourke, 1975), use a rigid set of criteria to classify learning-disabled students. These are that disabled learners: ( 1 ) have deficiencies in at least one school subject area, (2) have WISC full-scale IQs in the normal range (i.e., $90+$ ), (3) are free of primary emotional disturbance, (4) have adequate visual and auditory acuity, (5) come from environments where socioeconomic deprivation is not a factor, (6) have had only the usual childhood illnesses, (7) have attended school since the age of 5.5 or 6 years, and ( 8 ) speak English as their primary language. By "deficiencies in at least one school subject area, "Rourke indicates functioning in the student's academic achievement at no higher than the 20 th percentile. If the student meets 
the above criteria, he could be considered a candidate for evaluation.

Aaron ( 1981 ) also indicates that not all LD children exhibit the same pattern of deficits and, consequenty, that they constitute a heterogeneous group. McCue et al., (1984) suspect that those with learning deficits have only "subtypes" of deficits and not a "syndrome." Thus, as Lubar and Deering (1981) state, children experiencing visual perceptual abilities confuse 'd' and ' $b$ ' or ' $p$ ' and ' $q$ '. A word such as "was" becomes "saw." In addition, they point out that these children are often poor at copying geometric forms, designs, or performing block design problems. Though these constitute subtypes of deficits, they would not, alone, indicate a learning deficit. In 1977 , Rutter, who studied 86 dyslexic children with reference to language abnormalities, motor incoordination, constructional difficulties, and right-left confusion, found that none of these children showed all these characteristics; more than one-fourth of the children nad only one. Yet an article by Mauer (1984) listed 76 characteristics "typical" of learning disabled students. To aid in general classification, though, Pirozzolo (1979) provided evidence that two groups do exist; those with audiolinguistic disorders and 
visuospatial dyslexics. More recently, Spreen and Haff (1986) and Lyon, Stewart \& Ereedman (1982) have identified other subtypes, though the category of deficits was small. Aaron ( 1981 ) also extended this same concept in his own earlier work noting that learning disabled children tend to overutilize cognitive strategies to the exclusion of others, resulting in serious imbalances. As an example, he states that some children possess better than average or superior visual memory, and relatively poor auditory memory, whereas other children show the exact opposite profile. More recent studies (Mckinney, 1985) argue against the "single syndrome theory" and demonstrate the feasibility of creating more homogenous diagnostic groups within this broad and ill defined category of exceptional cinildren. Thus the debate continues.

Many difficulties exist in associating learning disabilities with any criteria or definition. Graden (1986) found there was no defensible system for classifying learning disabled children, and many studies examining various systems have not clarified the issue. Decision-making teams seem to "search for pathology," yet other authors establish a rigid set of criteria even before a student is to be evaluated for learning disabilities (Rourke, 1975). Some authors are examining 
patterns in cognitive deficits, seeming to suggest that learning deficits may be more of a "subtype" deficit rather than a syndrome. Some have even suggested that these subtypes may be relatively small (Lyon, Stewart, d Freedman, 1982). Other researchers, arguing against the "single theory syndrome," advocate the creation of more homogenous diagnostic groups (McKinney, 1985).

What can be said about the problem of criteria is that the field is very active, and the different forms and approaches to research of criteria are indeed rich and varied. By debating the issues of selection criteria and researching the effects of measures as they relate to learning disabled students, researchers get a clearer picture of these deficits and offer children a more comprehensive treatment approach 0 solving and improving their learning capabilities. Aside from selection criteria, though, is the issue of the deficits themselves, i.e., what are the "subtypes?" To what cerebral structures do they relate? By examining these two questions, the issue of a need for specific criteria becomes more critical.

\section{Cerebral structures and Deficits}

The fundamental problem may not be the definition of a central-processing disorder. Rourke's eight criteria todetermine if a student is eligible to be 
evaluated for laarning deficit are a positive contribution. Even Graden's observations have led to a more enlightened dialogue on what constitutes a learning disability. The difficulty lies in the deficits themselves, as Aaron ( 1981 ) and Pirozzolo (1979) indicated.

Development of neuronal pathway connections has been one focus of research (Rourke, Bakker, Fisk, \& Strang, 1983). Neuronal structures are connected by outgrowths of cell bodies (dendrites, which carry information away from the cell body) and synapses (functions between neurons). The neurons, their branches, and their interconnections develop at a rate winch depends upon their location and function (Rourke, Bakiker, Fisk, \& Strang, 1983). As growth procedes, the differentiation of the hemispheres is emphasized in observed responses to verbal and spatial stimuli in the environment (Lezak, 1976). Pathways become established unless there is interruption due to injury (Boll \& Barth, 1981). It is speculated that intact areas of the brain can easily take over pathway functions which had been programmed to be handled by the newly damaged areas. Once the association of functions to brain areas has been accomplished, however, such plasticity may no longer exist, and the function served by the damaged 
area is permanently impaired (Boll Barth, 1981). Structured multisensory methods using small discrete learning modules to remediate deficits is a promising approach. Language impaired children seem best served in classrooms that are structured to address specific linguistic handicaps in a direct fashion. Learning disabled children require sufficiently challenging environments which involve experiences that will help further the development of neuropsychological strengths (Rourke, Bakker, Fisk, \& Strang, 1983). The apparent success of such methods which stress accurate pathways and multisensory approaches is consistent with the current concepts of how the mind learns if optimal patnways are unavailable.

Lubar and Deering (1981) note two groups of disabilities: input and output deficits. Input deficits include the general categories of visual perceptual disabilities, auditory perceptual disabilities, and tactual perceptual disabilities. Two types of output deficits are also noted--both being integrative deficits (Silver, 1981). The first of these is in sequencing, for example, seeing 23 as 32 , and reading it as sucn. The second output deficit involves the motor system and may include both fine and gross motor deficits. 
Classifications of deficits abound. For example, in the area of dyslexia, Goldberg and Schiffman (1972) Ifst the following conditions synonymous with dyslexia: primary reading disability, specific developmental dyslexia, congenital word blindness, strephosymbolia, specific reading disability, and developmental lag. Benton (1975) described the characteristics of the medical and educational aspects of dyslexia as falling into two major categories. The first category referred to neurological correlates, which included awkwardness of movement, visual or auditory perceptuai problems, incomplete knowledge of body laterality, directional confusion, difficulty with body image, speech defects, concentration problems, and poor impulse control. The second category, educational correlates, included difficulties with mathematics primarily related to word problems; difficulty copying arithmetic problems from the blackioard; spelling problens; problems with semantics; letter reversals; transposition and inversions; sequencing problems; problems following oral directions; and deficits in left-right orientation. Measurement of these deficits and the biological cerebral operations associated with them has been the focus of much research in neuropsychology (Joschko \& 
Rourke, 1985; Mcileil \&amre, 1974; Rourke, Fisk, \& strang, 1986). The problem is especially acute in developing an approach that would have significance concerning the condition or operations of the brain (Boll, 1978; Rourke, Eisk, \& Strang, 1986), though traditionally research has focused on a biological understanding of these operations (Hartlage \& Telzrow, 1986; Rourke, Young, Strang \& Russell, 1986).

The biological tradition of identifying structures in relation to operations (e.g., the left temporal lobe being related to memory and language) has combined with the psychological approach. This has led to two trends in current research; the one being an emphasis on localization of function, and the second a definition of functions in terms of specific tasks (e.g., arithmetic, reading, writing, paired-associate learning, etc. Harris \& King, 1982). This research has led some to reevaluate positions on and interpretations of mental styles as they relate to hemispheric lines (Gazzaniga, 1977 ; Couts et a1., 1987).

Measurement of these deficits and the combination of the biological with the psychological is most evident in Lezak's (1976) description of neuropsychology and the concept of intelligence. She comments that as refinements in testing and data handing techniques have afforded greater precision and control over observations 
of intellectual behavior, it has become evident that the behavior that tests measure is directly referrable to intellectual functions, but that general intellectual impairment occurs due to the sumation and interaction effects of tissue destruction at many cerebral areas. The same observation has been more recently made by Rourke, Young, Strang, \& RusselI (1986) as well as Goldstein (1984). Goldstein states that the identifiable neurological deficits can produce learning disabilities, but it is not necessary to have an identifiable neurological deficit to have a learning disability. By "identifiable" Goldstein means something that a neurologist could detect on a routine examination. He indicates further that the neurological bases for learning disabilities are subtle variations from normal tiat are far from understood.

Though Lezak (1976) refers to "tissue destruction," the terms are not thoroughly defined. What is assumed is that the destruction may be due to a cerebral vascular accident or, perhaps, direct injury. However, what most children who are referred for an LD evaluation display is not a history of severe tissue damage. As Goldstein (1984) states, the neurological examination is usually normal. What is more likely is that the student presents a deficiency in reading or 
spatial relations, which relates to left- or righthemispheric functioning, respectively, and it is from a study of these two hemispheres and their related functions and deficits that central-processing disorders have their base.

As Groff ( 1986$)$ summarized in a review of the Iiterature, cerebral dominance was the idea that one hemisphere, frequently the left, ruled the other. Although such a view ignored the importance of the minor hemisphere, it was still quoted. Groff's insight is that Leong ( 1980 ) defined laterality as the consistent use of one side of the body. Thus, one side was preferred or dominant. Groff indicated that other researchers (Galaburda, LeMay, Kemper, Thomas, \& Geschwind, 1978) observed that the left hemisphere of the brain was usually larger than the right and that, when one was larger than the other, the brain was asymetrical. Groff discerned that enlargement of the left hemisphere appeared in Wernicke's area, which was important to language and was thought to be involved with the comprehension of speech. However, Gazaniga (1967) said that both hemispheres handled language about equally well until a child was four years old.

In addition, Wiengarten and Anisfeld (1981) found that a comprehension shift occurred after the age of 7 , 
and Pines (1973) believed that speech dominance was complete by the age of 10 . Carmen, Nashon, and Starinsky (1976) suggested that first graders had visual superiority for processing single letters, but that nonverbal configurations were processed in the right. Later, when material would be practiced, it would be processed in the left. Groff's review noted that young children might have some language in both hemispheres and might shift toward the left after age 7 . This bilaterality of young children might suggest that they learned to read first with their right hemispheres. Later, though, the shift was progressively to the left, developing the dominant hemisphere to the point that, as Corbalis (1980) and Herron (1980) indicate, $97 \%$ of right-handers process spech in the left hemisphere, and $60 \%$ of left-handers produce speech from the ieft hemisphere.

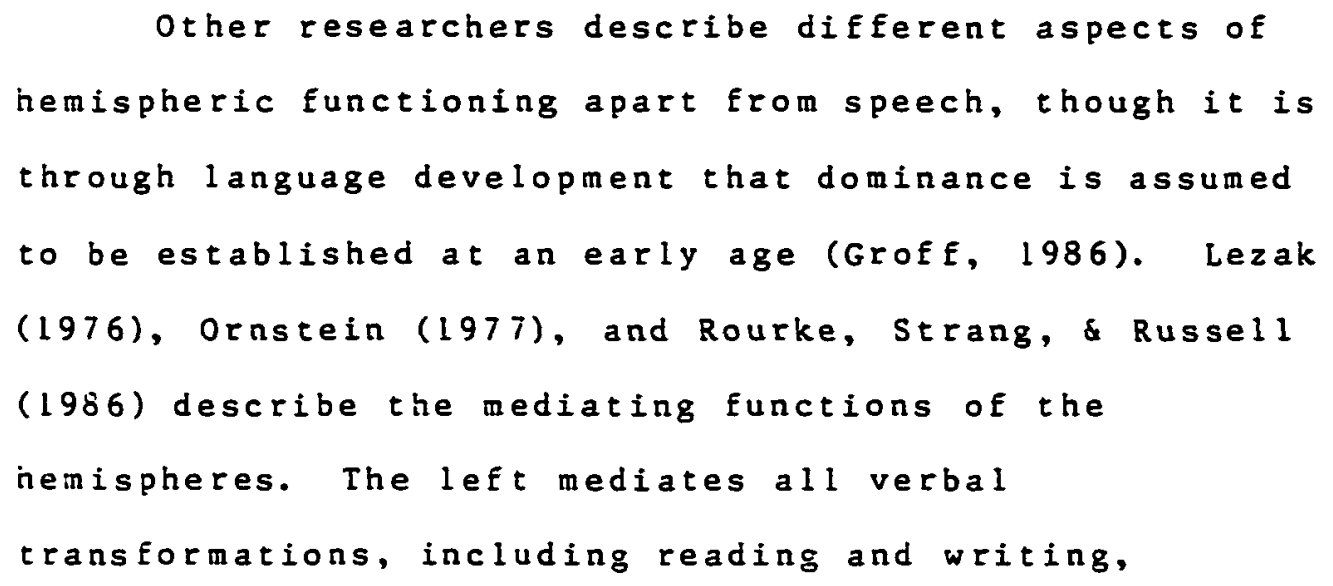


understanding and speaking, verbal ideation, and comprehension of verbal symbols. The right hemisphere jominates non-verbal, visual-spatial transformations, including the processing and storing of visual information, tactile and visual recognition of shapes and forms, perception of directional orientation and perspective, and copying and drawing of geometric and representational designs and pictures. 0thers have taken this further and associated factors such as adjustment, hyperactivity, depression, etc., with verbal or spatial deficits (Nussbaum \& Bigler, 1986).

Nevertheless, the consequence of studies has been toward the development of learning disabilities as inental style, without regard for neural development (Boll, 1978; Rourke, Fisk, \& Strang, 1986). As noted earlier in Groff's review, the brain grows and develops postnatally while the child is growing; and is not, as previously believed, fully developed at birth (Boll and Barth, 1981; Hartlage \& Telzrow, 1986). This idea is also supported through anatomical studies, wherein structures present at birth (e.g., planum temporale) are enlarged, seeming to indicate the site of future language functioning. Yet, the fibers connecting the two cerebral hemispheres (corpus collosum), which acts as a relay for neural impulses, are probably not 
functional at bitth (Gazzaniga, 1970).

Not taking into account anatomical studies in the consideration of learning deficits and relying on a nebulous categorization such as "mental style" obfuscates the issue. The result is that the accuracy of various tests to determine the presence or absence of a learning deficit is called to question, and placement decisions based on the variables noted in the tests become more a factor of intuition rather than accuracy. Al I tests for braindamage do not take into account that children from $9-14$ years use different cognitive strategies toward learning and are capable of different levels of comprehension, even in the absence of brain damage (Boll \& Barth, 1981). Some brief tests for brain dysfunction are employed in the assessment of brain damage in children and were most likely developed for quite another reason apart from cerebral dysfunction (Boll\& Barth, 1981).

Some researchers have made a positive contribution toward clarifying criteria for evaluation of a learning disability. But defining the deficits and their functional relationship to cerebral structure is the most promising approach in solving problems of definition. Grouping disabilities into operational categories such as input and output deficits, focusing 
on the cerebral operations associated with them, and specifying tasks can aid in the re-evaluation and interpretations of mental styles. However, not all cases are clear cut, indicating that a neurological deficit that is seen in examination has a correlate to a learning deficit. Rather, the neurological examination will be normal and only subtle variations in the hemispheres may be present. These variations seem to be far from understood. In examining the cerebral hemispheres, one can see that dominance is progressively determined in the left hemisphere, especially when mediated by language acquisition. Both the Ieft and the right hemispheres have basic tasks: the left concentrating on verbally based information and the right being dominant for spatial and visual recognition of forms. With all of this information, though, some researchers remain persistent in referring to learning deficits as a mental style. The result is that measures to assess a learning deficit lack accuracy, and placement decisions become ones of intuition. Research that continues to focus on brain-behavior relationships, and variables that relate to the hemispheric structures, may guide one toward a better understanding of learning disorders. 


\section{Piaget's Contribution}

Perhaps Piaget offers one of the most enlightened theories which combines the biological approach to neural development with observed behavioral correlates. Piaget's stages of development each fuse biological functioning with the resulting developmental psychological components. The sensory-motor state, roughly $0-2$ years of age, aims toward the development of reflexes, circular reactions (such as pursuing objects, voluatary movements, means-end relationships, etc.), and the internalization of schematic events (Piaget, 1977). These not only lay the groundwork for the development of a mature biological organism but also provide for rules with the child can use to explore and learn about his/her environment, thereby enriching his/her ability to function psyciologically and derive meaning from experience. The second stage, the preoperational, is a transition period from dependency to more socialized functioning. By engaging with the environment, and basing reactions on biological lessons learned in the previous stage, the child develops intuitive thought and can extract concepts from experience (Piaget, 1977).

The third stage, or concrete operations (roughly 7-8 to $(1-12)$, deals with the development of operational thought as it relates to logical thinking. The child 
can now relate parts to wholes, serialize, understand conversation, and learn reversibility. Language, by now, is predominane, and four operations come into focus: combinativity, reversibility, associativity, and identity or nullifiability. At the last, formal operations, stage, the child can now use propositional and combinatorial operations (Piaget, 1977).

Using Piaget's theory of development, one can easily see the development of cerebral functions, and if there are deficits, where they will occur. Any perinatal or postnatal complication interrupts the development of the sensory-motor stage, opening deficits in visual perceptual-motor areas. A lack of stimulation, environmental deprivation, toxic exposure, among others may hinder development further. Thus, inhibition toward pursuing objects may interfere with the ability toward discriminating, leading to problems in letter identification through visual means. Interference with means-ends relationships may hinder development of social judgment and comprehension. Deficits occurring in the stage of sensory-motor development further hinders preoperational and concrete stage development, waturing the deficit to an interruption of logical relationships and the perception of sequencing. Though these may be observable when the 
42

child interacts with the environment, such as a classroom situation, measurement of the variables can be difficult.

Measurement of Cerebral Deficits

Even though the theories of Piaget and others are useful in describing what is possibly observed in brainbehavior celationships, specific evaluation is elusive. The more accepted procedures use a number of measures or neuropsychological bateries, and simple and complex motor, sensory, and psychomotor abilities (Boll \& Barth, L981; Coutts et a1., 1987; Fischeret al., 1986; Talley, 1986). Much evidence supports these approaches. Many measures, such as the 25 studied by Herbert (1964) found that, though they could separate brain-damaged groups, no single test could demonstrate validity for the individual child, which was the focus of the batteries. Thus, even though no single test could demonstrate validity for an individual, they could at least separate brain-damaged from non-brain-damaged groups (Fisk \& Rourke, 1979; Fischer, Dean, \& Rattan, 1986). However, when not used for purposes other than separating the two sroups, the measures could provide information about deficits found in other groups (Boll \& Barth, 1981). Tests such as the Bender Visual-Motor Gestalt, the 
Background Interference Procedure, or the Minnesota Perception-Diagnostic Test could provide useful data about these groups, other than separating the braindamaged groups from the non-brain-damaged group. Used alone, though, i.e., only the Bender and no other measure, the tests offered no convincing validity as tests for brain damage. Other measures inad to be used in conjunction with them.

Areas examined in other studies (Bol1, 1972; 1974;

Boll d Reitan, (972), such as motor tests, have found significant differences between brain-damaged and nonbrain-damazed individuals. Learning disabled groups have not been included often in tests of motor persistence, when children were matcined for IQs, perhaps due to the observation that children with learning disabilities do not often exhibit lateralized motor and sensory deficits (Rourke, ly81). When these deficits are present, they are found to be clinically relevant (Rourke, 1981; Rourke, 1985; Kinsbourne \& Hiscock, $1981)$.

In the area of language disorders (e.g., speling, vocabulary, aphasia, etc.), research has included a learning-disabled population (Ernhart et al., 1963; Highinam \& Morris, 1987; Petrauskas \& Rourke, 1979; Rourke, 1981). However, differences have been slight (Boll, 
1974; Brown \& Campione, 1986). For example, using an LD group in comparing subtest profiles of the WISC-R and the K-ABC, the LD and a sample of borderline students' subtest ranks correlated significantly (Rho $=.90$, p. = $.01)$. However, the correlation between the distribution of ranks on these two instruments among the normal group were not significant (Rho $=.20$ and .10 , respectively). It was concluded that a subtest profile distinctive to an LD group was not evident (Naglieri, 1985). Factors such as age at injury (Graham, Ernhart, Thurstone, \& Craft, 1962) or length of time since the injury, with the age of the subject held constant (Teuber \&udel, 1962) have been shown to influence both level and pattern of deficits. Other variables such as type and location of lesions in the brain-damaged population have a differential and persistent influence on a child's ability developinent (Boll, 1974; Hartlage \& Telzrow, (986).

Studies examining the use of tests of psychoorganicity have been made to determine further applicability to a learning-disabled population. In Culbertson and Doberty's (1982) study, the Elizer Test of Psycho-organicity (ETPO) was examined in order to determine the validity of a second administration of the test ( 4 years later) with 6-1 l-year-old male subjects who were categorized as learning disabled, emotionally 


\begin{abstract}
disturbed, and unclassified. They were required to duplicate geometric and colored block designs and to memorize five-digit numbers. The ETPo successfully differentiated the groups, as identified by clinical judgment, thereby separating the learning disabled population from one that was emotionally discurbed. one of the most successful measures used in differentiating groups has shown that a satisfactory understanding of the nature of dyslexia, for example, has not been achieved, and that specific treatment and remediation methods of proven effectiveness have still to be developed (Benton \& Pearl, I978; Brown \& Campione, 1986). Further, in a review by Dumont (198I), it was Found that after research into learning disabilities, a consensus on even identifying characteristics of a learning disabled population had yet to be achieved. Ijentifying the characteristics of a learning disabled population is as elusive as ever (Graden, 1986). In a study by Harris and King ( 1932 ), children with learning problems and those with learning and behavior problems were more similar than different, yet differed significantly from children with no problems and with those with behavior problems only $(M=26.0$, with a significant $F$ ratio, $p<.001)$. Kosc $(1987)$ indicates, thougn, tinat learning disabilities should be strictly
\end{abstract}


distinguished from more educationally conceived learning .

Still, certain measures seem to reflect a degree of impairment which separates a learning disabled population from other groups or, at the very least, reflects a degree of understanding regarding the underlying processes within the cerebral cortex. For example, in a study by Telzrow and Harr (1987), comparing the WISC-R Performance scale with the Woodcock-Johnson Psychoeducational Battery, Tests of Cognitive Ability, and the Halstead Category Test, the WISC-R Perforinance scale and the Halstead Category Test seemed sensitive to nonverbal cognitive ability, particularly of a perceptual organizational nature, a right-hemispheric function. Tests which reflect verbal content such as vocabulary, antonyms, synonyms, etc., seem to tap remote memory for words and verbal comprenension, which is a left-hemispheric function (Lezak, 1981). Measures dealing with numerical repetitions such as digit span seem to reflect a degree of immediate auditory memory, attention, distractibility, double tracking, and the ability to store databits (Lezak, 1981). Tests of numerical repetition seem to be more sensitive to lefthemispheric functioning (Lezak, 1981). Measures of 
numerical repetition have also been found to be among the most sensitive to brain damage (DeWolfe, 1971; McFie, 1975; Woo-Sam, 1971). In addition, Smal1 (1973) suggested that deficiency in numerical repetition may also reflect a deficit in recent memory skills. One of the most traditional of the tests of perceptual visuo-graphomotor type are those of design copy, such as the Bender Visual-Moror Gestalt. These tests not only seem to reflect a certaindegree of visual-motor ability but also visual comprehension, visual assinilation, fine-motor coordination, and righthemispheric parietal lobe functioning (Lezak, 1981). However, these tests seem to be restrictive in interpretive ability, due to age norms, lack of standard scores which are reliable above 8 years of age, and the developmental differences between ages (Sattler, 1982). Matching exercises appear to be reflective of visual memory, recognition memory, visual-verbal discriminative ability, and lexical processing (Wallace, 1980; Lezak, 1981). Visual-pattern matching seems to tap visual memory, visual learning, symbolic facility, and recognition memory for symbol patterns, mostly right-nemispheric functions, with some assist from the left hemisphere (Lezak, 1981). Other measures, such as the innesota Multiphasic Personality Inventory, have been used to differentiate right-hemispheric brain- 
damaged patients from left-iemispheric brain-damaged patients and non-brain damaged subjects. The size and placement of the projective drawings (Gasparini, Shealy, \& Walters, 1980) have also been used to differentiate those groups. However, few studies have included a learning disabled population. In a recent study by Pollak ( 1986 ), where a learning disabled population was used with the Human Figure Drawing test, it was found that research on human figure drawings contributed little to the understanding of learning disabled children. Results of these studies or others have been generalized to the learning disabled population under the intuitive rationale that since learning disabled subjects most likely reflect a neurologically impaired condition, data derived from studies dealing with neurologically impaired subjects can be applied to learning disabled groups as well. The problem with this is that the learning disabled population reflects functioning in the classroom environment and not the hospital setting. Much information exists in terms of the measurement of cerebral deficits in brain-damaged populations. Thougin theories, such as Piaget's, are useful in describing brain-behavior relationships, the more accepted procedure is to use neurologically based evaluations in orier to determine the location and 


\begin{abstract}
extent of a deficit. Though most of the measures do well in discrininating brain-damaged from non-braindamaged groups, Iearning disabled samples have not been used often in those studies. Tests of language disorders, psycho-organicity, and measures to understand conditions such as dyslexia need to be developed further before specific treatments and remediation can be offered with any degree of certainty. Some measures do seem to separate learning disabled groups from others, but in specified areas. Measures using numerical repetition, nonverbal cognitive ability, matching exercises, and tests of perceptual visuo-graphomotor ability seem to identify deficits that can be localized

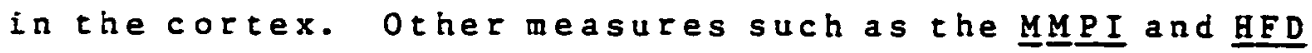
have met with less success in identifying LD groups from others.
\end{abstract}

\title{
Research Focus
}

Though much has been done, researchers are still attempting to find support for such a hypothesis that children with nyperactivity, EEG abnormalities, or learning deficits have a minimal amount of brain damage (Boll, 1978; Fisk \& Rourke, 1983; Prior \& Sanson, 1986; Rapoport, Donnelly, Zametkin, \& Carrougher, 1986 ; Shangraw, Seminer, \& Zarr, 1985 ; Zentall \& Zentall, 1986). These hypotheses assume a predictable continuum 
among behavioral effects of brain dysfunction, impairment, and subsequent damage. It is also assumed that there is a quantitative rather than a qualitative difference in the neuropsychology of brain-damaged children and related groups (Boll, 1978; Morrison, Hinshaw, \& Carte, I985; Pressman, Davey, \& Firestone, 1986; Sarazin \& Spreen, 1986; Shaywitz et al., 1986; Snow \& Hyd, 1985). It is important to consider age of onset, development, language facility, ability to comprehend, and other variables, as well as the age at which a subject is evaluated, which is generally 8 or 9 years of aze. As discussed by McNeil and Hamre (1974), research is needed in three areas: normal, developmental, and pathological, and the question for education is the normal development regarding brainbehavior relationsing and how to design a better curriculum for those groups suspected and determined through valid and reliable measures to have deficits in one or more areas which impede a child's learning. As found in the conclusions of McNeil and Hame, clarification of lateralized cerebral functions should aid in the discovery of these relationships and their accompanying deficits.

The field of learning disabilities covers an array of disorders that seem to relate to cerebral functions. 
Though research is becoming more sophisticated, problems such as definition of a learning disorder remain. There are also difficulties present in classification, with many criteria being used to place children in learningdisabilities programs that may or may not have validity. Researchers seem to classify children as having either audiolinguistic disorders or visuospatial disorder. In planning for remediation, some search for subtype deficits, while others try to create more homogenous categories. More studies are being done to clarify the location of deficits, be they input deficits or output deficits, in the neural structure. Based on this research, more precise instrumentation to measure the deficits continues to develop with varied results thus far. Using developmental theories such as Piaget's could lead to a more concisedefinition of a learning deficit, as well as aid in exploring the underlying cerebral patholozy or impairment in developmental structure.

Reproduced with permission of the copyright owner. Further reproduction prohibited without permission. 


\title{
CHAPTER THREE
}

\section{RESEARCH DES IGN}

\author{
Overview \\ As noted earlier, there is a need for a group of \\ discrimiative variables which will aid the practicing \\ school psychologist in not only differentiating the \\ types of deficits encountered in determining a placement \\ for a student who is suspected of being learning \\ disabled at referral but will also help in determining \\ the best approach in remediating his or her deficits. \\ These variables should discriminate within a given \\ school population and separate those who have learning \\ disabilities from those who do not have. In addition, \\ the variables should discriminate between normal and \\ neurologically impaired groups. Finally, the variables \\ should identify those areas reflective of a learning \\ deficit. \\ The variables used in this study were entitled \\ Sentence Repeat, Synonym, Digits Forward/Backward, \\ Design Copy, Nonsense Words, and Visual Pattern \\ Matching. The total time to administer the measures in
}


a "test format" was 40 to 45 minutes. The study was to help determine the necessary time to administer the measures, and the timing was to be clarified in a pilot study to be performed shortly before the formal administration of the instrument. In the pilot study, after the variables were reviewed by a number of practicing clinical psychologists the test was administered to five individuals from each group. The variables were developed with consideration given to content as well as criterion validity and test-retest reliability. Discriminant analysis was performed on the resulting data, which classified the subjects into the appropriate groups. The statistical analysis tested the hypothesis and the discriminant capacities of the variables.

\section{Population and Sample}

The subjects were to be drawn from four categories: (1) a normal group, (2) a brain-damaged group, (3) a sample that, in clinical judgment, had been identified as spatially disabled, and (4) a sample that was, by clinical judgment, classified as verbally disabled. It had been planned that Group 2, the braindamaged group medically diagnosed as having a neurologically impaired condition resulting in 
restricted learning, would be drawn from the Northern Indiana Children's Hospital in South Bend, Indiana.

This group was to represent all available 9-12-year-old males who received treatment at the hospital. If only a Eew were available, other subjects were to be secured by contacting South Bend area hospitals and physicians who were to refer additional subjects for the study. This group, however, was eventualiy eliminated from the study Eor reasons given on pages 65-66.

The remaining groups were drawn from the South Bend Commuity School Corporation, located in South Bend, Indiana. The city in the northwestern part of the state has a total population of approximately 242,400. The city has a past history of heavy industry and automobile manufacturing, which has given way to the development of service vehicles, farm tools, and a service economy. The school population consists of approximately 21,000 students, with the majority coming from blue-collar families involved in manufacturing, and a smaller population of white-collar service providers and manager. The average income for the former group is \$18-21,000 for the head of the household. For the latter group, the average income is approximately \$35,000. The minority percentage for the city is about $19-20 \%$, with a comparable percentage of minority children enrolled in the South Bend schools. 
The learning disabled groups consisted of the entire population of 9-12-year-old males currenty enrolled in the learning disabilities program of the South Bend Communty School Corporation, or approximately 87 subjects. Not all learning disabled students attend public school. A small segment is enrolled in parochial or private institutions. The learning disabled sample was to be split into two groups; the one group reflecting verbal impairment, and the other group reflecting spatial deficits. The control group (or normal sample) consisted of 9-12year-old males, approximately equal in number to the learning disabled group. An adjustment of numbers in the normal group would have had to be made once the size of the brain-damaged group was known.

In order to randomize the control group, class lists with the names of all 9-12-year-old males in the South Bend schools were secured. Excluding the names of students in the learning diabled groups, members of the control group were selected randomily in such a way as to equal in size the number of individuals in the learning disabled group.

Some difficulties with the groupings were expected. The brain-damaged group from the Northern Indiana Children's liospital (NICH) would be small, but adjustments were to be attempted to equate the number 
with the other three groups. However, the 9-12-year-oId range was restrictive, and the available subject pool may still have been smaller after adjustment. In addition, locating a sample which was impaired only in the left or right hemisphere would have been difficult at best. More likely it was anticipated that there would be a bilaterally impaired group, or subjects who were impared in the dominant hemisphere. If an adequate number of subjects were not available from NICH, patients treated on an outpatient basis would have been included, which, it was expected, would have confounded the data. However, sample adjustments were to be made if this condition occurred.

\section{Problems in Determining Placement}

It was suspected that some bias would enter the learning disabled groups. Research had shown that learning disabled placements were dominated by white, iniddle- and upper-middle-class students. It was expected that methods of placement decisions by case conference committees cited earlier, were likely to play a role in this bias. It was possible that the learning disabled sample may have included a number of students who had been misassigned.

Though selection of the learning disabled group was difficult and complicated by many factors, the 
selected group for this study originally included approximately 87 cases, 83 of whom agreed to participate. Of these, 2 were in second grade, I 7 in third grade, 22 in the fourth grade, 21 in the fifth grade, and 21 in the sixth grade. Sixty-two subjects were white, 18 were black, and 3 were of Hispanic background. Three of the subjects had been placed in the learning disabilities program in 1980, I9 In 1981, 10 in 1982,20 in 1983 , and 31 in 1984 . The average age of the subjects was 10.8, with a standard deviation of 1.19. Most of the students had been placed between April and october of the same year.

\section{Variables}

Subtests were developed for this study to measure tine following variables:

1. Auditory Discrimination (or Sentence Repeat)

a. Example: "See the brown dog carrying the bone,"

"My father bought a tree for the house," etc. In the final version of the test, the sentence "I rode the bus to school" was used.

b. Application: At the beginning of the test, the student was asked to listen to the sentence, and remember it for repetition later during the test. After administration of the second subtest, Synonyms, the subject was asked to repeat the 
sentence. The time between delivery of the statement and its repetition was approximately 2 minutes, depending on the subject.

c. Rationale: Part of the purpose of this measure was to identify laterality. This subtest has been found to be generally specialized in the left hemisphere (Fischer et al., 1986; Lezak, 1976; Small, 1973). Subjects were anticipated to have difficulty discriminating sounds, even when thresholds for sound perception remained within normal hearing range, and no aphasic disability was present. Auditory discrimination can be tested by having the subject repeat words or phrases spoken by the examiner (Lezak, 1976). Phrase repetition can reflect verbal apraxia (Lezak, 1976). It also captures the characteristics of the classroom situation (Boll, 1981). This measure taps verbal memory and recall, although disorders in this area do not tend to lower intelligence (Meyer, 1961; Meyer \& Yates, 1955; Milner, 1958; Neff\& Goldberg, 1960; Steplen \& Sherpinski, 1964).

2. Synonyms (a measure of auditory recall, verbal comprehension, and general verbal background. Lezak, (976).

a. Example: "Work, Circle, etc. (see Appendix B). On 
this subtest, the subject was given a word read from a Iist and was asked to give a synonym after he was given an example.

b. Application: The items were selected from the teacher's edition of Measure Me Sky, Reading program 720, which emphasizes decoding, comprehension, critical evaluation, and the use of ideas. The items selected ranged from the simple to complex, as identified in the pilot study.

c. Rationale: Verbal fluency and comprehension are important skills in learning classroom materials. Deficits in both past learned abilities to decode and comprehend are reflected in measures such as Synonym (Aaron, 1981). Response time to measures such as these can indicate the quality of verbal impairment (Lezak, 1976).

3. Digits Forward Digits Backward (measures immediate auditory memory, attention, distractibility, concentration, double tracking, and reversing mental operations. Lezak, 1976; Talley, 1986).

a. Example: In Digits Forward, a series of numbers, starting with two or three $(2-3,1-4-7$, etc.) are given to the subject, and he is usually allowed two trials to repeat the numbers. Then the forwards part of the exam is ended. In Digits 
Backward, the student is given a series of new numbers that he is required to reverse (e.g., I$3-4$, reverse, $4-3-1)$.

b. Application: On this measure, the student was required to do the same as described above. Numbers for the test were generated by a computer program for random numbers.

c. Rationale: It has been suggested that DF/DB reflects conclusive deficit of organic etiology (Costa, 1975) and is more sensitive to brain damage (Woo-Sam, 1971). It also has an impressive amount of subtest specificity across age ranges (Kaufman, 1979). The subtest is an adequate measure of cognitive processing (Kaufman, 1979) and is used because teachers and others cite distractibility and inatention as cornerstones of learning disabilities (Epstein, Cullinan, \& Rosenier, 1983; Talley, 1986).

4. Desizn Copy (measures visual-perceptual motor Eunctioning and right hemispheric functioning. Lezak, 1976).

a. Examples: Please refer to Appendix B.

b. Applications: On this variable, the student was given a sheet of paperand was presented with a figure, which he was asked to draw.

c. Rationale: This was the most "true" measure of 
right-brain functioning, because the left hemisphere has relatively minor involvement in the perception of shapes, forms, and patterns, whether by sight, sound, or touch, or in copying or drawing nonverbal figures (Bogen, 1969; Gazzanagia, 1970; Pellegrino et al., 1984). Permission was secured to use assorted figures from the Developmental Test of Visual-Motor Integration and the Bender Visual-Motor Gestalt. The measure was included because classroom work involves writing and spatial abilities as well as other fine-motor and spatial-analytic tasks.

5. Nonsense Words (measure of lexical processing. Lezak, (976).

a. Examples: CAMpol, GIFMAL, etc. See Appendix B for other items.

b. Application: On this measure, the student was givena list of nonsense words and was allowed to study them for 120 seconds. Once he had completed studying the 1 ist, he was asked to circle items he remembered from another list that also included nonsense words that were not on the original list and acted as distractors.

c. Rationale: Analytic-sequential and holistic simultaneous information processing operations are two fundamental strategies in the context of 
reading instruction (Bever, 1975). The measure is also more reflective of right-left hemispheric functioning, since the analysis seems to be carried out by the right cerebral hemisphere, with the phonetic analysis carried out by the Left (Geffin, 1978). Being able to process Iinguistic information is essential for reading instruction in the classroom. If a student has difficulty with discriminating sound, linking sound to letter and word recognition, etc., he will find reading difficult. In addition, nonsense words also add a measure of auditory discrimination in terms of sound and sound blendings (Lezak, 1976).

6. Visual-Pattern Matching (taps visual memory, perceptual processing, and visual-perceptual learning. Lezak, 1976).

a. Example: Please refer to Appendix B.

b. Application: The student was given a list of figures and asked to check the ones that he recalled after a short passage of time (approximately one to two minutes, depending on the student), matching them from a stimulus sheet. 
c. Rationale: Newcomb (1969) developed a similar measure and found a tendency for subjects with right-hemispheric lesions to take longer to respond than other brain-injured subjects, though she felt that a tachistoscopic presentation would give more significant results. An experimental version of the Benton Visual Retention Test seemed to discriminate significantly between apraxic and nonapraxic subjects with respect to the accuracy of perceptual recognition (Dee, 1970). In addition, apraxia appears to be more of a right-hemispheric disability (Dee, 1970). Three rationales are given for using Sentence Repeat, Synonym, Digits Forward/Digits Backward, Design Copy, Nonsense Words, and Visual Pattern Matching togetiner. One of the nost important rationales for the use of these measures in one presentation is that they tap into laterality, with the examiner in the field being able to point to data obtained on these measures as indicative of dysfunction in one hemisphere or the other. These measures do identify one hemisphere over the other. A second rationale is the identification of learning disabilities, with measures in the areas of classroom applications based on research. These measures contribute to that concept of classroom 
applications. The third rationale is that since these variables are given, in addition to others in a "normal testing battery," time factors become important. After a student has been evaluated for an hour and 15 minutes, another measure such as the Luria-Nebraska Neuropsychological Test Battery, which takes as much as six hours to administer, can be fatiguing, even if it is administered the following day. Using these six variables could eliminate the need to measure on still other variables that take much longer to administer and may not be directly applicable toward the development of an IEP. In addition, most school psychologists, for whom this "test" was developed, do not have the time, expertise, or resources to administer a more complicated battery. Using these six variables in combination would Bive psychologists additional confidence in identifying cerebral laterality and learning disabilities and may be used as a rationale for further long-term neuropsychological evaluation.

\section{Instrumentation}

The six variables used, i.e., Sentence Repeat, Synonyms, Digits Forward/Digits Backward, Design Copy, Nonsense Words, and Visual Pattern Matching, were designed to discriminate beween four groups: normal, verbally impaired, spatially impaired, and brain 
damaged. The length of time necessary to administer the test was assumed to be 30 to $40 \mathrm{minutes,} \mathrm{based} \mathrm{on} \mathrm{the}$ preliminary findings oE the pilot study, and anticipated speed of administration by other persons than the researcher. The process of development followed this pattern:

1. Items were developed for each subtest. In Sentence Repeat, only one item was used ("I rode the bus to school"). In synonyms, Is items were developed based on an original filot study that contained 40 possible items. For Digits Eorward/Digits Backward, items were generated through random selection, using a computer program for random number generation. In Design Copy, permission was obtained to use selected items from the Bender Visual-Motor Gestalt, and the Developmental Test of Visual-Motor Integration. The final number of items for the subtest was eight. In terms of Nonsense Words, from a possible pool of 40 items, 10 were finally used in the formal study. Finally, for Visual Pattern Matching, items were to be secured from the Raven's Progressive Matricies. However, permission to use selected items was denied by the publisher. Therefore, between 25 and 35 items were developed by the researcher and screened through the pilot study and examination by 
psychologists. From this preliminary pool of items, I 2 were finally used in the formal study.

2. After permission was secured or denied for various items on the measure, 12 board-certified psyciologists reviewed the variables, the items, instructions to the subjects, scoring, timing, etc. The evaluators judged each item based on its purpose, applicability, level of difficulty, what the item was purported to measure, the discriminative power of the item, etc.

3. After the subtests had been reviewed by the psychologists, the items were rewritten according to their recommendations. In Sentence Repeat, some of the 25 items were rejected because they were "Iinguistically awkward" (The secret agent's message was decodable; I swam to get back to the shore; sue greeted each of the people warmly, etc.); too difficult to recall (We read the poem on Monday, The taxicabs tooted and honked, The dog is brown with large white spots, etc.).

Some of the 40 items on the synonym measure were rejected because the answers to the word were too difficult, and"most 9-12 year olds would not come up with this answer" (items such as moody, temperamental, irritable, etc.). Some of the judges felt that some of the 9-12-year-old subjects would not be familiar with 
the item itself, or that the word had different meanings depending on the subject's experience (e.g., the words gauge, fragment, perceive).

None of the judges felt that the Digits Forward/ Digits Backward subtest was too difficult, nor did they feel that the Design Copy measure was inappopriate. Most favored the items and were familiar with the items since they were borrowed from other measures (Bender, VMI). Most of the judges wanted the 40 Nonsense Words items changed to easier terms (Bilo, Bosa, Poti, etc.), since they felt that too few students would remember the words, even after much study. In addition, they felt the terms were linguistically difficult and confusing, with some of the terms being very similar to each other (Bilo, Bosa; Tesa, Iuni; Taci, Tiso). Nonsense words were eventually used from another dissertation (Groff, $1986)$.

All but one of the judges felt that the concept of a Visual Patern Matching subtest was appopriate. The one judge whodid not feel that it was appopriate came to this decision because of its place in the series of subtests. He preferred to see this subtest come earlier in the test. Most also felt that the 30 items needed reworking since they were far too difficult (see the appendix). Items were eventually reworked, using the 
Revised Minnesota Paper Form Board Test (see appendix) as a guide, and all the judzes accepted the revision for the subtest.

The judges felt that the directions to the subtests were most appropriate and were similar to instructions given on other measures (e.g., Wechsler IQ tests). Some felt that the directions to the visual Pattern matching subtest were too long. They were shortened to highlight the main task for the measure. 4. After the items had been rewritten, a pilot study was conducted using five subjects from each group, with the exception of the brain-damaged group due to the inaccessibility of subjects. The subject pool available at the Northern Indiana Children's Hospital was extremely limited conly one possible subject), and other patients at $N I C H$ were severely disabled and unable to respond to items. After contacting physicians in south Bend and surrounding areas, it was found that (1) patients did not receive a "confirmed" neurological diagnosis, patients were unable to be discriminated for either left-or right-hemispheric impairment, i.e., most of the patients had bilateral impairments, (3) most were well beyond the 9-l2-year-old age limit (average age was over 40), (4) the possible pool of 
9-12-year-old males was extremely small (3) and, (5) records were not open to the researcher and permission was denied from parents and/or physician for reasons of confidentiality. Thus, the braindamaged group was reluctanty eliminated from the pool of subjects, and only three groups were included in the formal study. Five students from each of the verbally impaired, spatially impaired, and control groups were selected for administration of the pilot test. The test was judged not only on the difficulty or ease of the items but also with respect to how the items were arranged, the ease of using the instrument, the time factor involved in administering the test, and how the subjects seemed to respond to the measures, i.e., if they felt that the test itself was easy/difficult, confusing/clear in terms of the directions, etc. Notations on these factors were made for the final revision of the measures.

5. Once the pilot study had been concluded on the remaining three groups (i.e., normal, verbally LD, and spatially LD), the subtests were rewritten in their final form. Special permission forms had to be developed to be sent to the superintendent for 
elementary education, special education directors, principals of the schools from which the students were to be evaluated, and parents. Securing permission took much time due to scheduling difficulties with the administrators. All of them requested that the researcher meet with them and explain in detail the reason, purpose, rationale of tine study, how the testing was to affect the students, and frankly, if the study would place the corporation in a bad Iight. Allaying their fears took quite a bit of time, especially since it included meeting with one school board member who did not want the study conducted at all. Administrators had to be convinced of the advantages of the study.

\section{Procedures}

After permission had been secured from administrative parties, the school principals had to be contacted and, in many cases, convinced that the study could be done in their schools. Later, however, they changed their minds and refused permission for further testing in their schools. After completing a few of the cases for the pilot study, two principals complained to the superintendent, who in turn asked that the research not be conducted in the school buildings. This 
researcher was to cease all operations of the study. Again, all administrators were contacted and reassured that the study would not be conductedin the school buildings after school hours but in the student's homes. This added another time factor to the study. Even though parental permission was easily secured either in writing, orally, or both, the students had scheduling conflicts that needed to be addressed. It was interesting to note that although the administrators were apprehensive about the study, the parents seemed to embrace it enthusiastically and would discuss it at length. All parents were interested in the results of the study, and to keep them informed brief results were sent to them at the researcher's expense. Before the final data collection, a number of volunteers were contacted through Indiana University at South Bend, the University of Notre Dame, Saint Mary's College, Bethel College, and general solicitation at Lake Michigan College (South Campus in Niles, Michigan). Two volunteers were trained to administer the test, but these ceased to participate after two weeks. The researcher and one other person were involved in the final data collection.

1. Once permission had been secured, the formal data gathering began. The testing process was periodically 
checked (once per week) to make sure the research assistant was following proper procedures, to note progress being made, to correct any scheduling difficulties, and the like. Some subjects were not at home when they were scheduled to be evaluated, and telephone calls had to be made to reschedule them. (One subject had to be rescheduled five times.) Nevertheless, during the hour-and-a-half review sessions with the research assistant, questions were raised and answers were sought.

2. Since it was planned that the test-retest reliability of the measure would need to be evaluated, the same test was administered two to four weeks (on the average) after the first administration. At times, the test was administered after a time period a few days longer than four weeks due to scheduling problems with the parents.

3. One measure of ten used in the South Bend Communty School Corporation is the California Test of Basic Skills (CTBS). Scores from the CTBS were to be correlated with the research measure to obtain a measure of criterion-related validity. However, permission to use the scores was denied due to confidentiality. It was argued that since the CTBS 
is part of the student's file and not a matter of public record, the corporation could not allow the scores to be used. When it was noted that scores are usually published once per year in the local newspaper, the response was that they were total scores and not individual scores, which were not a mater of public record. However, since the researcher was employed as a school psychologist for the corporation and the psychological records were separate from the student's "regular" file, the WISCR scores could be used (with permission of the director of psychological services and the parents). Those and only those scores were made available. Permission was obtained Erom all parties, and WISC-R scores from the spatially and verbally LD groups were used. The wISC-Rs had been administered to only five of those in the control group. Permission had to be secured from the private psychologists and the parents before those scores could be used in the study.

\section{Further Delimitation}

Because of the problems encountered in securing the data, having to test in the nomes rather than the schools and under difficult circumstances, and because of the fact that two different persons administered the 
pre-test and the postest, this report deals only with

data secured from the pretest. Posttest data are

included in the appendix.

\section{NuIl Hypothesis}

The hypothesis examined in this study was: There

is no Iinear combination of the six variables, which

significanty discriminate among the three groups. The hypothesis was tested by multiple-discriminant analysis, with alpha set at .05. 


\section{CEAPTER FOUR}

\section{PRESENTATION AND ANALYSIS OF JATA}

\section{Introduction}

This chapter is divided into several sections.

Following a brief review of the subtests, the participating sample is described. The third section deals with a number of procedural problems. The major section of the chapterdeals with the basic data and is divided into a number of sections.

The results of this study deal with scores on six measures: Sentence Repeat, Synonyms, Digits Forward/ Backwards, Design Copy, Nonsense Words, and Visual Pattern Matching. In Sentence Repeat, the subject was given a sentence at the beginning of the testing period and was to repeat the sentence after the snyonyms subtest. For the synonyms subtest, the subject was to respond with an appropriate synonym for a term given to nim by the exaniner. In the Digits Forward/Backwards subtest, the subject was simply torepeat a group of digits in a forward presentation under two trials, and in a reverse sequence using different numbers, also under two trials. 
For the Design Copy measure, the subject was asked to copy designs presented to him on $3 \times 5$ index cards. For the Nonsense Words measure, the subject was asked to circle the correct item after a brief presentation of a group of nonsense words by the examiner. Visual pattern Matching followed a format similar to that used for Nonsense Words. The responses were scored, and the data were subjected to different statistical treatments as presented below.

\section{Sample}

dt the time of the study, the entire population of y-12-year-old males in the South Bend schools was solicited to participate in this study. The population consisted of 87 possible subjects from special education program for learning-disabled students in South Bend. of tinis possible pool of subjects, 37 were finally secured for the study. Table 1 gives the breakdown of the subjects by number, percentages (in parenthesis), and ethnic background. Of the total sample of 72 subjects, 26 were included in the verbally impaired group, only 11 were members of the spatially impaired group, and 35 were included in the control group. It is noted from the table that the control group consisted almost entirely of white subjects, whereas the other two groups had only $46 \%$ and $36 \%$ white members. This was in 
Table I

Sample by Study Group and Ethnic Origin

\begin{tabular}{clcccc}
\hline Group & White & Black & Hispanic & Total \\
\hline & No. & $\%$ & No. $\%$ & No. $\%$ & No. $\%$ \\
\hline Verbal & $12(16.7 \%)$ & $12(16.7 \%)$ & $2(2.8 \%)$ & $26(36.1 \%)$ \\
Spatial & $4(5.6 \%)$ & $6(8.3 \%)$ & $1(1.4 \%)$ & $11(15.3 \%)$ \\
Control & $34(47.2 \%)$ & $1(1.4 \%)$ & 0 & $35(48.6 \%)$ \\
Total & $50(69.4 \%)$ & $19(26.4 \%)$ & $3(4.2 \%)$ & 72 \\
\hline
\end{tabular}

contrast to previous research findings mentioned on page 53. The subjects were in the second through sixth grades, and the average age was 10.8 , with a standard deviation of 1.19. The subjects in the verbally and spatially impaired groups had been evaluated by the Psychological Services Department and placed in the learning disabilities program between the months of April and october. Two students in the control group were of upper-middle-class backgrounds. All others in the control group were lower-middle to middle-class students.

\section{Procedural Problems}

Not all 87 of the 9-12-year-old students attend school in the South Bend Communty School Corporation. 
A small percentage attend parochial or private schools in South Bend and did not want to participate in this study. Of those students who do attend school in the South Bend system, some refused to participate in the study due to concerns over confidentiality. Though the parents were familiar with the learning disabilities program, they still felt that the label of learning disability was a "stigma" about which they did not want others to know. Other parents felt that their son was not being serviced appropriately, and that including their son in the project was not in their best interest; these were not included in the study.

Further procedural problems arose in the data collection. First, the data were to be collected in the school buildings, but later had to be collected in the students' homes. While collecting the data in the students' homes, the researcher became very aware of many sources wich may have contributed to the students' alleged "learning disability." Many homes were chaotic, having multiple distractions to impede any student's ability to respond to the subtests.

Another procedural problem was the scheduling of appointments in the homes. It was not at al i unusual to have to reschedule an already confirmmed appointment. Although inany parents expressed an interest in a telephone contact to have their son included in the 
study, they were less cooperative about having theit son participate when the appointment was actually set. It was later found that many of the parents were not so resistive to this particular study as much as to the LD program itself. Many of the parents were not clear as to what a learning disability was, nor of the program in which their son participated. After collecting the data from each student, the researcher tried to clarify terminology and to review the individualized education program prescribed for the sons of any parent who had placement reports.

Though it was difficult to establish appointments for initial testing, the appointments for the retesting went more smoothly. Most parents were cooperative and many were interested in the results of the study. Because of that interest, the examiner provided the parents with a short explanation of the findings of the study. Most data gathering had to be done between 4:00 and $8: 00$ p.m., because most students had extra-curricular activities (e.g., sports). In addition, most of the parents worked and did not return home until after 4:00 p.m. Some parents interested in the testing process asked if they could observe.

Some problems arose before the data collection actually took place in order that the data collection 
could be completed in a reasonably short period. It had been planned that volunteers from various colleges in the South Bend area would be used to assist with the data collection. Only two students volunteered and were trained. However, even they dropped out after only two weeks. Another assistant and the researcher examined al 12 cases. The researcher administered the initial test, and the assistant gathered the data in a retest situation two to four weeks later, depending on the scheduling. Since all parents of the subjects were contacted by letter and telephone, they had the researcher's telephone number and could call to rearrange the schedule if necessary. This did occur and, in a few cases, the second testing could not be given until a few days beyond the four-week period. Due to some extenuating circumstances, some of the data were not collected in the home. Some of the students were tested at local libraries, communty centers, at the University of Notre Dame library, or the library at the Indiana University at South Bend. Though these arrangements took some time, the officials from these universities, commuity centers, or libraries were most cooperative. Therefore, as stated in Chapter 3 , the study was further delimited. Only the pre-test data collected by the researcher himself are dealt with in this report. 
81

It would have been interesting to correlate the distribution of scores obtained in this study with scores on the California Test of Basic Skills (CTBS). But, since permission to use the scores was denied due to issues of confidentiality, this was impossible. The use of CIBS scores would have enabled this study to obtain a measure of criterion-related validity, and a comparison of WISC-R scores with scores obtained in this study would have been interesting. However, only two students in the control group had been given the WISC-R. Permission to use scores from the WISC-R for the other groups was denied.

\section{Reliability}

As was stated in Chapter 3, the original design included pretest-postest reliability estimates. This was not pursued for two reasons. In the first place, the difficulty encountered in testing, and the disparity between the pretest and posttest situations led to a decision to exclude posttest data from the study. Secondly, the pretest-post test procedure is not recommended for estimating the reliability of measures of variables on which differential growth is likely to occur between the two administrations (Anastasi, 1976). A commonly used measure of reliability for instruments where growth is likely to take place is 


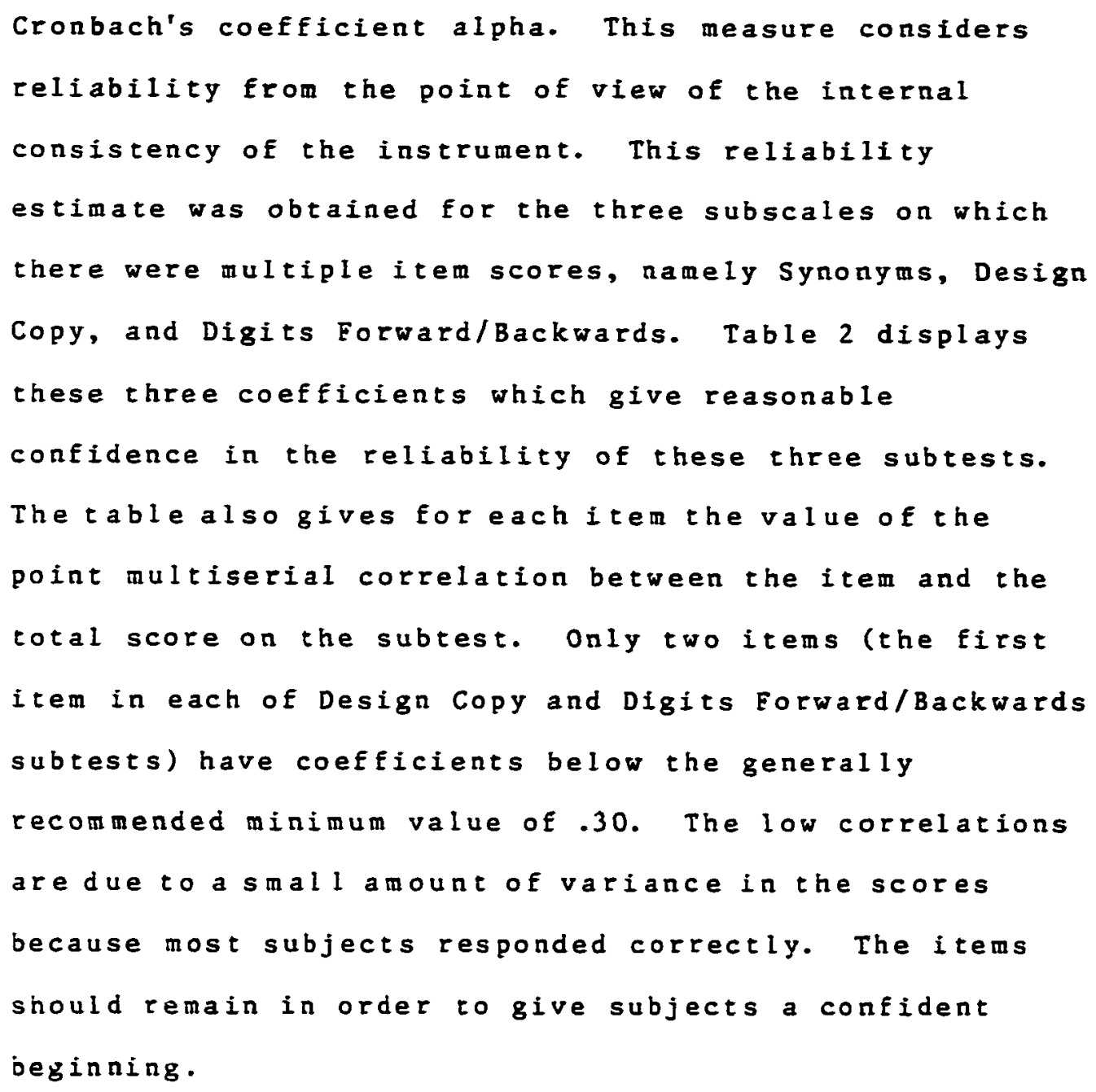

\section{Basic Data}

Table 3 shows the means and standard deviations for each of the three groups on each of the six subtests. It is apparent in the table that the groups scored somewht differently on several subtests. Before testing the multivariate hypothesis, the group means were compared by analysis of variance for each of the 
Table 2

Internal Consistence Reliability

\begin{tabular}{|c|c|c|c|}
\hline $\begin{array}{c}\text { Reliability } \\
\text { Coefficient } \\
\text { Alpha }\end{array}$ & .79 & $\begin{array}{l}\text { Design } \\
\text { Copy } \\
.063\end{array}$ & $\begin{array}{c}\text { Digits } \\
\text { Forward/ } \\
\text { Backwards } \\
.73\end{array}$ \\
\hline Item & \multicolumn{2}{|c|}{ Point-Multiserial } & Correlations \\
\hline 1. & .63 & .09 & .15 \\
\hline 2. & .37 & .40 & .32 \\
\hline 3. & .51 & .50 & .63 \\
\hline 4. & .50 & .52 & .69 \\
\hline 5. & .39 & .54 & .71 \\
\hline 6. & .50 & .61 & $.6 \mathrm{I}$ \\
\hline 7. & .50 & .74 & .57 \\
\hline 8. & .64 & .65 & .38 \\
\hline 9. & .59 & - & .48 \\
\hline 10 & .52 & -- & .61 \\
\hline 11. & .52 & -- & .57 \\
\hline 12. &.+1 & -- & .33 \\
\hline 13. & .45 & -- & -- \\
\hline 14. & .56 & -- & -- \\
\hline 15. & .56 & -- & -- \\
\hline Test-Retest & .50 & .24 & .61 \\
\hline
\end{tabular}

Reproduced with permission of the copyright owner. Further reproduction prohibited without permission. 
Table 3

Means and Standard Deviations for All Variables

\begin{tabular}{|c|c|c|c|c|c|c|}
\hline \multirow[t]{2}{*}{ Subtest } & \multicolumn{4}{|c|}{ Group } & \\
\hline & $\begin{array}{l}\text { Verbally } \\
\text { Impaired } \\
\qquad \underline{X}\end{array}$ & $(26)$ & $\begin{array}{l}\text { Spatial } \\
\text { Impaire } \\
\underline{x}\end{array}$ & $\operatorname{d}^{l y}\left(\underline{S}^{1} 1\right)$ & $\begin{array}{l}\text { Contr } \\
\left(\begin{array}{l}35 \\
\times\end{array}\right.\end{array}$ & 01 \\
\hline $\begin{array}{l}\text { Sentence Repeat } \\
\text { [Pussible Range } 0-2 \text { l }\end{array}$ & 1.1923 & 0.939 & 1.4545 & 0.820 & 1.0571 & 0.780 \\
\hline $\begin{array}{l}\text { Synonyms } \\
\text { [Possible Range 0-30] }\end{array}$ & 12.2692 & 3.207 & 18.2727 & 4.502 & 19.2286 & 6.390 \\
\hline $\begin{array}{l}\text { Digits forward/ } \\
\text { backwards } \\
\text { [Possible Range } 0-21\end{array}$ & 8.3079 & 2.112 & 9.0909 & 2.587 & 11.4857 & 3.60 \\
\hline $\begin{array}{l}\text { Design Copy } \\
\text { [Possible Range } 0-16\rfloor\end{array}$ & 12.4231 & 2.369 & 12.0909 & 1.921 & 12.2571 & 2.356 \\
\hline $\begin{array}{l}\text { Nunsense Words } \\
\text { [Possible Range } 0-2 \mid\end{array}$ & 1.5385 & 0.647 & 1.8182 & 0.603 & 1.6857 & 0.583 \\
\hline $\begin{array}{l}\text { Visual Pattern } \\
\text { Matching } \\
\text { [Possible Range } 0-2]\end{array}$ & 1.4231 & 1.206 & 1.3636 & 0.505 & 1.4000 & 0.497 \\
\hline
\end{tabular}


six separate tests. Table 3 shows the results of these analyses.

Table 4 indicates that only two measures significantly separated the three groups. Test of the differences for each pair of groups in these cases

Table 4

Analysis of Variance

\begin{tabular}{lcc}
\hline Variable & F & P \\
\hline Sentence Repeat & 0.3730 & .6900 \\
Synonyms & 14.4936 & $<.0005 *$ \\
Digits Forward/Backwards & 8.956 & $.0003 *$ \\
Design Copy & 0.0881 & .9158 \\
Nonsense Words & 0.9132 & .4060 \\
Visual Pattern Matching & 0.0203 & .9799 \\
Total Test & 12.2265 & $<.00005 *$ \\
d.f. for all tests $=2$ and 69. & \\
\hline
\end{tabular}

indicated that, on subtest 2 , synonyms, the verbal group scored significantly lower than either of the other two broups, but no significant difference was noted between the spatial and control groups. On subtest 3 , Digits Forward/Backward, both the verbal and spatial groups scored significantly below the control group. 


\section{Testing the Null Hypothesis}

The null hypothesis that the centroids of the three groups are not significantly different was tested by multivariate analysis. This yielded an F of 3.4135 , with 12 and 128 degrees of freedom, and a p of .0004 . Hence, the null hypothesis was rejected. The group centroids are significanty different. Because the hypothesis was rejected, discriminant analysis was used to study the relative importance of the six subtests in discriminating among the groups.

The function of discriminant analysis is to identify a new dimension along which the groups are maximally separated. The discriminant analysis yielded one significant discriminant function $(p=.0002)$. The group means on this function were control $=4.041$, spatially impaired $=2.963$, and verbally impaired $=$ 1.308. Table 5 gives the standardized weights of the six measures to identify the function. It is common practice to note any variables whose weights are at least half of the maximum weights. From the table, the major contributors to the separation of the groups are subtests 2 and 3 , with some lesser contribution from subtests 5 and 4. The interpretation of the function is that, on a syndrome defined as higher scores on synonyms and Digits Forward/Backward, the groups are placed in the order control group, spatially handicapped groups, 
Table 5

\section{Discriminant Function}

\begin{tabular}{|c|c|c|c|}
\hline Variable & Name & Standard Discr. & Function \\
\hline 1. & Sentence Repeat & -2.2104 & (5) \\
\hline 2. & Synonyms & +11.7046 & (1) \\
\hline 3. & $\begin{array}{c}\text { Digits Forward/ } \\
\text { Backwards }\end{array}$ & +7.1782 & (2) \\
\hline 4. & Design Copy & -3.8431 & (4) \\
\hline 5. & Nonsense Words & -4.0355 & (3) \\
\hline 6. & $\begin{array}{l}\text { Visual Pattern } \\
\text { Matching }\end{array}$ & -1.773 & (6) \\
\hline
\end{tabular}

and verbally impaired group. The discriminant program uses the discriminant function to predict the group to which any individual most probably belongs. This classification is found in Table 6 , which indicates that of the original 35 subjects in the control group, 22 (63\%) were correctly placed in that group by the discriminant function, 7 were wrongly placed in the verbally impaired group, and 6 were wrongly placed in the spatially impaired group. Of the 26 subjects in the verbally impaired group, 18 (69\%) were identified as belonging to that group, 2 werewrongly placed in the control group, and 6 were wrongly placed in the 
Table 6

Classification Matrix

\begin{tabular}{lcccc}
\hline Group & Control & Verbal & Spatial & Total \\
\hline Control & 22 & 7 & 6 & 35 \\
Verbal & 2 & 18 & 6 & 26 \\
Spatial & 3 & 2 & 6 & 11 \\
Total & 27 & 27 & 18 & \\
\hline
\end{tabular}

spatially impaired group. In the spatial group with 11 subjects, 3 were wrongly placed in the control group, 2 In the verbally impaired group, and only $655 \%$ were correctly placed in the spatially impaired group. overall, 46 of the 72 subjects, or $64 \%$, were correctly placed. This indicates a moderate degree of discriminate validity. The test was more successful in identifying verbally impaired ( $69 \%$ success) than spatially impaired ( $55 \%$ ) children.

\section{Additional Analysis}

In studying the results of the discriminant analysis, it is evident that some variables are more effective than others in separating the three groups, and correctly assizning individuals to groups. It was, therefore, of interest to observe how effectively a 


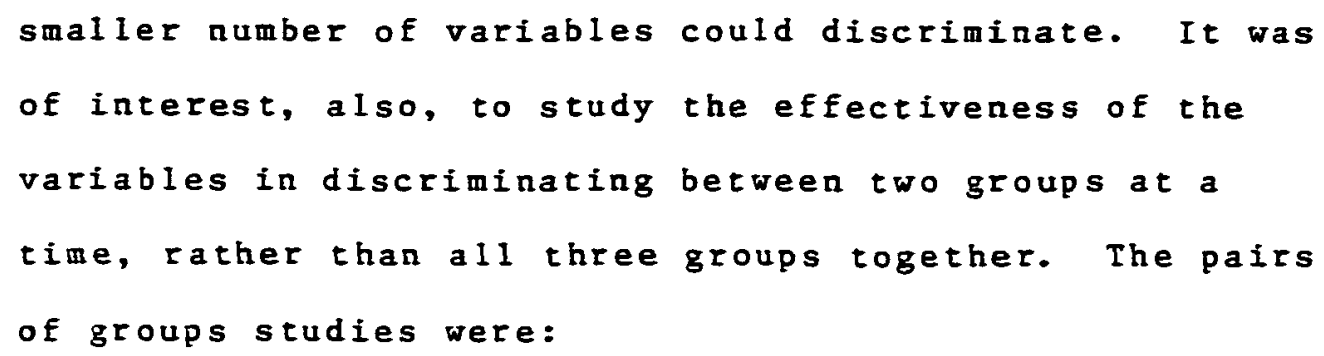

Table 7 gives the results of the discriminant

function analysis in twelve conditions--using six

variables, Eour variables, or two variables to

discriminate between each of the four pairs listed above. The four variables used for the second set of tests were Synonyms, Digits Forward/Backwards, Design Copy, and Nonsense Words. The two variables used for the third set of tests were Synonyms and Digits Eorward/Backwards. From the table it is evident that either six, Eour, or two variables can significantly discriminate between control and handicapped, between control and verbally handicapped, and between verbal and spatial groups. None of the combination of variables was able to significantly discriminate verbally from spatially handicapped subjects.

Reproduced with permission of the copyright owner. Further reproduction prohibited without permission. 


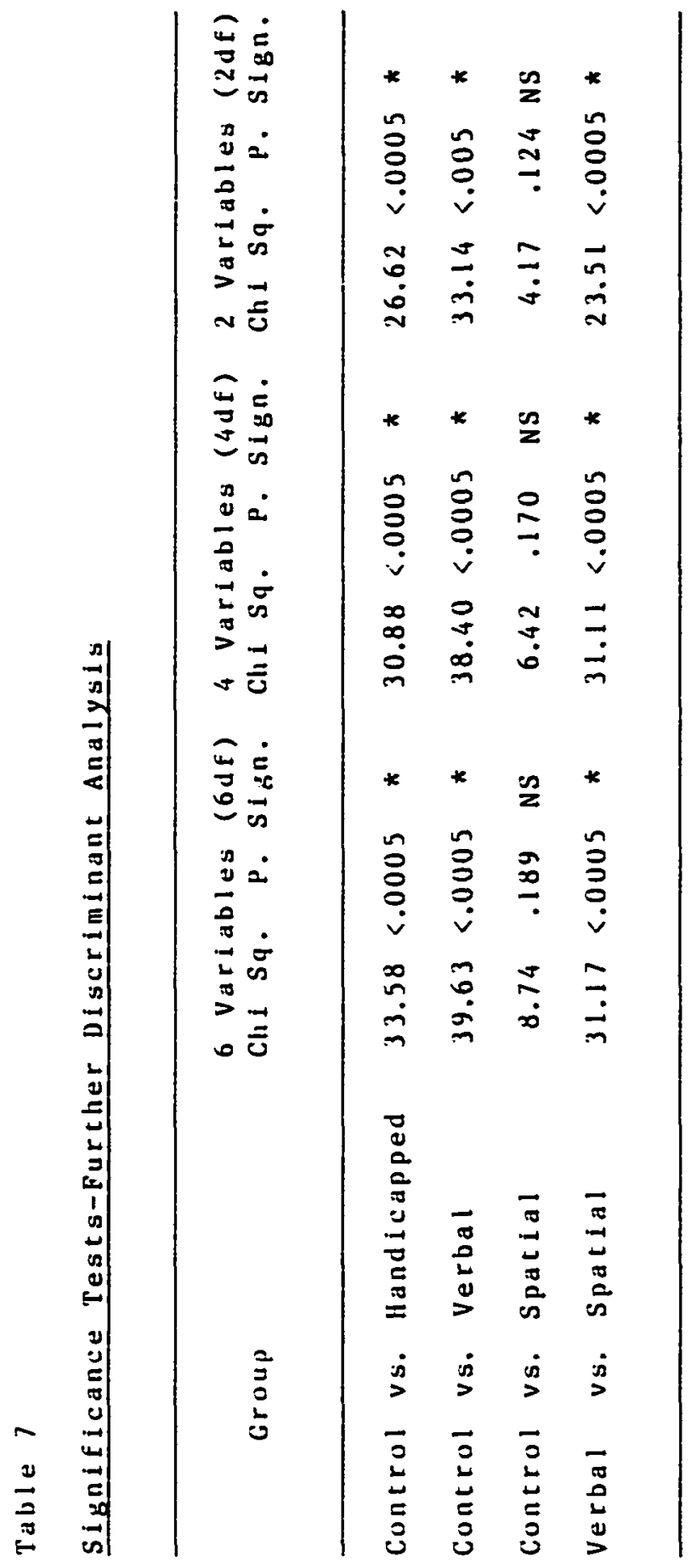

Reproduced with permission of the copyright owner. Further reproduction prohibited without permission. 
As before, the discriminant function was used to predict the most Iikely group membership for each subject. Table 8 sumarizes the results. For each of the four pairs of groups, the column of the table show what percentage of the members of each of those two groups were correctly assigned and what percentage of the subjects in tie two groups together were correctly assigned. These data are, again, given for discriminant functions involving six, four, and two variables. For the three pairs of groups for which the discriminant analysis was significant, Table 8 shows an encouraging increase in the percentage of correct placements in comparison to the data of Table 6. In is clear that some of the variables are capable of discriminating with gratifying success. When using either six or four variables, the synonyms and Digits Forwards/Backwards variables were mainly responsible for the discrimination. The only exception to tinis was in the situation where four variables were used to discriminate between the verbally and spatially handicapped groups. In this case, the Digits Forwards/ Backwards variable did not make a contribution. 
Table o

Group Assignment by Discriminant Function

\begin{tabular}{|c|c|c|c|c|c|c|c|c|c|c|c|}
\hline \multirow[b]{3}{*}{ Group I } & \multirow[b]{3}{*}{ vs. } & \multirow[b]{3}{*}{ Group I I } & \multicolumn{4}{|c|}{ Percentage } & \multicolumn{3}{|c|}{ Correctly placed } & & \\
\hline & & & \multicolumn{3}{|c|}{$\begin{array}{c}6 \text { Variables } \\
\text { Group }\end{array}$} & \multicolumn{3}{|c|}{$\begin{array}{l}4 \text { Varlables } \\
\text { Group }\end{array}$} & \multirow[t]{2}{*}{2} & \multicolumn{2}{|c|}{$\begin{array}{l}\text { Variables } \\
\text { Group }\end{array}$} \\
\hline & & & I & I I & All & 1 & I I & $A \mid 1$ & & I I & Al 1 \\
\hline Control & vs. & Handicapped & 77 & 73 & 75 & 71 & 81 & 76 & 71 & 78 & 75 \\
\hline Control & vs. & Verbal & 74 & 85 & 79 & 71 & 92 & 80 & 71 & 85 & 77 \\
\hline Control & vs. & Spatial * & 69 & 55 & 65 & 57 & 73 & 61 & 49 & 73 & 54 \\
\hline Verbal & vs. & Spatíal & 81 & 82 & 81 & 81 & 82 & 81 & 81 & 82 & 81 \\
\hline
\end{tabular}

* The discrimination was not statistically significant. 
CHAPTER 5

SUMMARY, DISCUSSION, AND RECOMMENDATIONS

This chapter is divided into three sections: the first sumarizes the problem, Iiterature, procedures, and the findings; the second discusses findings as related to the literature; and the third section deals with recommendations for future research and for practice.

\section{Summary}

\section{Problem}

This study focused on the interaction of six subtests in 9-12-year-old males with learning disabilities. Though learning deficits due to cerebral injury are documented, the need for more discriminative power to clarify the diagnostic category of learning disabilities exists. The purpose of the study was to combine subtests in such a way as to help in diagnosing learning disabilities, assist in the writing of individualized educational programs, and separate learning disabled from normal groups. 


\section{Literature}

The concept of learning deficits is not new.

Banbury ( 1986$)$, Boll (1981), and others have identified a number of factors which seem to be related to the development of learning deficits such as closed-head injury due to falls, brief oxygen deprivation, educational neglect, poor parenting, or other such factors.

Researchers such as Boll and Barth ( 1981 ), Coutts et al. (1987), Talley (1986), and others have counseled against using tests which were designed for a purpose other than identifying learning disabled from other groups. Strategies such as verbal-performance splits or scatter on the WISC-R have not been found to be effective in identifying learning disabled from other broups.

Defining learning diasablities has been of much concern to many researchers. Many characteristics of the learning disabled are noted in definitions of the disorder, but may only reflect the specific orientation of the "user" (Banbury, 1986). Some definitions lack operational clarity. Yet, classifying students into learning disabled programs confounds the issues of definition and placement (Graden, 1986). Some jefinitions and placements rely on description and 
identification of cerebral dysfunction in hopes of lending more substance to the decision to place a student in the program based on measurement of cerebral deficits (Boll \& Barth, i981). The contribution of theorists such as Piaget gives some structure to the argument of definition and classification.

$$
\text { Regarding definition, an array of deficits may }
$$

encompass the description of learning disorders of "processing deficits." Though it is understandable that, due to fear of their child's failure in school, parents may consult popular periodicals for an answer to their child's learning problem, formal research is just as confusing. For example, one research study may focus on attention problems as the source of a learning disorder; yet another finds memory as the main deficit which indicates learning disabilities. Researchers, such as Groff (1986) and Mckeever (1977) are now beginning to offer more specific insights to the disorier and are clarifying definitional aspects. other researchers such as Lerner (1984) have also helped to clarify defiaitional problems. There appear to be at least five components contributing to a definition of learning disorder: neurological dysfunction, uneven growth patterns, difficulty in academic and learning tasks, discrepancies between learaing and potential, and the exclusion of other 


\begin{abstract}
causes. The differences of opinions observed in research studies seem to be the degree to which a student exhibits difficulty in learning or academic tasks, or how great a discrepancy is necessary to indicate that a student is learning disabled.
\end{abstract}

\title{
Procedures
}

The first step used in this study of the discriminative function of six subtests in 9-12-year-old males was the development of six measures which not only tapped certain learning tasks, but also involved those tasks which, put together, were those most likely to be observed in a classroom setting. Sentence Repeat was developed as a measure of auditory discrimination and memory. Synonyms was developed to tap not only the student's verbal background but also verbal fluency, long-term verbal memory, and verbal comprehension. Digits Forward/Backwards was used as a measure of auditory memory, attention, and double tracking. Design Copy was used as a measure of visual-perceptual functioning, and Nonsense Words was used as a measure of lexical processing. Visual Patern Matching taped visual memory and perceptual processing. After the development of the subtests, the measures were scrutinized by 12 licensed psychologists, who gave recommendations for improvements. A sample of 
37 learning-disabled students was used; 35 "normal" students acted as a control group. Five verbally and five spatially impaired subjects as well as five from the control group were used in a pilot study. After the pilot study, the subtests were assessed by the 12 psychologists before the final group of items was developed. Permission to conduct the tests was secured from the school system and the parents. After some procedural problems were stablized, the data collection began. Seventy-two students were tested using the six subtests. Of these, 35 were in the control group, 26 in the verbally impaired group, and 1 in the spatially impaired group.

\section{Procedural Problems}

Although tests may shed some light on the interactive processes that are involved in learning, the human element is also part of the discriminative process in identifying learning disabled from other groups. Different tests can yield conflicting results. Grade expectations and differences between where a student is performing and where he should be performing, etc., are often the factors that are considered by case conference comittees in their decision to place a student in a learning disabled program.

The method by which a student was placed in a 
learning disabilities progran was a significant factor in this study. Though placement was not the focus of this study, the method of placement into the learning disabled program by the school system was of concern to the researcier. Case conference committees often place cnildren in different prograns because the referral question indicates an evaluation for learning disabilities, parental pressure, and administrative concarns--among other reasons (Graden, 1986). The school system used for tis study was not an exception to this problem. That ss not to say that all of those involved in placing the students into the learning disabled program did so Elippantly. Many students, who are referred for evaluation, aly have scores that indicate that they nay have a learning deficit, or may be only "slow learners" who are in aeed of extra tutorial help. Like nost school corporations, the one used in this study has limited funding available for programs such as extra tutorial classes. Children who are having difficulty in class may be placed into learning fisability programs because that is all that is available for the student (Graden, 1986). In fact, most of thestudents in this study had IQs in the middle 80 s to low $90 \mathrm{~s}$, and did not show extzeme differences between their IQ and standard scores on tn achievement measure, tnus failing to meet the criteria used in Indiana to 


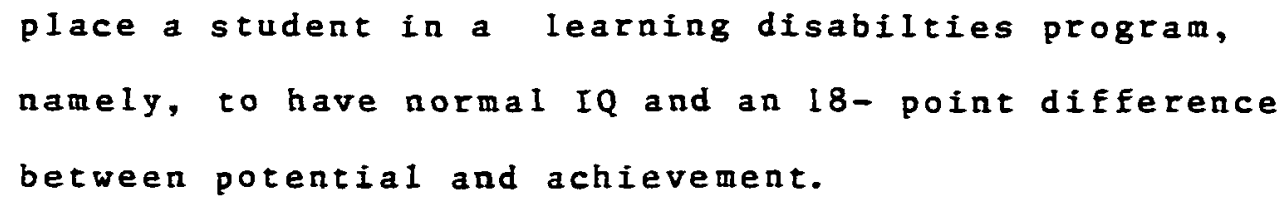

This type of placement procedure contaminates any study conducted on a sample of learning disabled students. One does not have a "pure" group on which to collect data, unlike, for example, if one were to do a study on mildiy mentaliy retarded students, where an important PIacement issue is if they have IQs under 70 but higher than 55. With this particular learning disabled group, normal or "near normal" intelligence was loosely defined. In addition, Indiana requires that for placement in the learning disabilities program there be at least an 18-point difference between the full-scale IQ on a measure such as the WISC-R and an achievement test such as the WRAT-R. Some students were placed with IQs as low as 76 , and as little as 2 points difference between the full-scale IQ and the achievement measure standard score. From the school corporation's standpoint, the student needs the help and should get the assistance. Yet, collecting data from students placed according to such criteria leads to confusing results and is inconsistent with the spirit of 94-142. Some of what constitutes a learning disability and placement decisions also rests on a lack of awareness on the part of the comittee members as to the uniqueness 
of the student's environment and taking that uniqueness into consideration in placement decisions. As noted above, during the data collection for this report, some of the students' homes seemed to be chaotic, with multiple distractors. Though these distractors may have affected the students' responses, one cannot help but think of the affect of the student's environment on his performance in the classroom. Placing the student in the learning disabilities program and expecting him to increase his skills without considering the environment to which he returns after school is only addressing a part of the problem. Making a decision to place the student into the learning disabilities program without considering his environment may deprive the student of services, such as those of a social worker. A class for the learning disabled was not meant to be a "cure-all" for every problem. This report has shown that the category of learning disorders is a very heterogeneous one. By simplifying the disorder and its etiology, one may contribute to the deficit rather than remediate it. One may also focus on the wrong factors causing the learning disorder, confounding the remediation. If anything, as MeCue (1984) notes, many areas can be expressive of a learning deficit. Measuring and defining those areas must be unique to the individual student. 


\section{Eindings}

Analysis of the variance indicated that only two subtests significantly separated the three groups. on the synonyms subtest, the control group and the spatially impaired group both scored significantly higher than the verbally impaired group. No significant difference between the means of the first two groups was evident. On the Digits Eorward/Backwards subtest, again, the control group scored significantly higher than the verbally impaired or spatially impaired groups. Ine group means did not differ from eachother on the remaining subtests--those being Sentence Repeat, Design Copy, Nonsense Words, and Visual Pattern Matching. Since multivariate analysis of variance indicated that the centroids of the three groups were significantly different, the nuil hypothesis was rejected, and discriminant analysis was used to study the relative importance of the six subtests in discriminating among the groups. The major contributors to the separation of the groups were the synonym and Digits Forward/Backwards subtests, with lesser contribution Erom Nonsense Words and Design Copy. The interpretation of the function was that on a syndrome defined as higher scores on synonyms 
and Digit Forward/Backward, the groups are placed in the order of control group, spatially handicapped group, and verbally impaired group. Of the original 35 subjects in the control group, $63 \%$ were successfully placed in that group by the discriminant function. of the 26 subjects in the verbally impaired group, $69 \%$ were correctly placed in that group. Of the 11 subjects in the spatially impaired group, only $55 \%$ were correctly placed in that group by the discriminant function. Further analysis was undertaken to study the effectiveness of the six variables in separating four pairs of groups--control vs, all handicapped, control vs. verbally handicapped, control vs. spatially handicapped, and verbally vs. spatially handicapped. For these same four pairs of groups, the discriminating ability of four variables (Synonyms, Digits Forward/ Backwards, Design Copy, Nonsense Words) was studied and also the discriminating ability of the two more successful variables, namely synonyms and Digits Forward/Backwards. No set of variables could successfully discriminate between the control group and the spatially handicapped. All other discriminations, however, were significant. In these cases the percentages of correctly placed subjects ranged from $71 \%$ to $92 \%$. 


\section{3}

\section{Discussion and Interpretation}

Researchers such as McNeil and Hamre (1974) and Rourke, Fisk, and Strang (1986) have focused on causative factors, assumed neurological dysfunction, developmental contributors, or environmental influences. What can be said about the definition of learning disabilities is that learning disabilities is a multifaceted area and many measures seem to indicate a learning deficit. One report such as this could not begin to focus on all aspects of the disorder. What could be expected is that the research may continue to identify, classify, and describe the factors of the disorder which would aid in clarifying the definition and contribute to the uniqueness in measuring these factors in individual students. In turn, this would lead to better strategies for remediation. As noted earlier in this chapter, the school corporation used in this study is not unique in the problem of definition and eligibility for learning disabilities services. As noted in Chapter 2, there is lack of agreement among states in defining the term. Decision-making skills of committees seem to be far from objective (Ames, 1985; Jarason \& Doris, 1979; Graden, 1986; Hammill et al., 1987; Ysseldyke, Thurlow, Graden, Wesson, Algozine, \& Deno, 1983). Attempts at the solution of the problems of definition, interpretation of test results, and the use of test results to 
formulate an eligibility statement and individualized educational program seem to be in their infancy. In Eact, most learning disabled students still cannot be reliably distinguished from other low-achieving students in school settings (Ysseldyke, Algozzine, E Eps, 1982). Some researchers (Jarason \& Doris, 1979) have gone so far as to state that decision-making teams conduct a "search for pathology" in their orientation towards placement for special learning disabilities services. Other researchers, notably Rourke (1975), have focused on more rigid criteria, which may be useful for inclusion of subjects for research but may be impractical in the daily administration of special education programs for learning disabled students. Researchers, such as Lezak (1976) and McCue (1984), have focused on specific deficits and how they relate to the classroom experience of the student. Two general classifications have been identified by Pirozzolo ( 1979$)$ : audiolinguistic disorders and visuospatial dyslexia. Even though specificity may be lacking in the Eindings on research into learning disabilities, many new paths are being explored and the field is very active.

Though a search for specific deficits continues, a body of research highlighting cerebral structures and 
105

associated deficits is slowing building a description of the underlying neural pathwas of the deficits. Two trends in this type of research are developing: an emphasis of localization of function and a definition of function according to specific tasks. Measurement of deficits in terms of their neurological components is apparent in the field of neuropsychology. It has been found that identifiable neurological deficits can produce learning disabilities (Joschko \& Rourke, 1985; McNeil \& Hamre, 1974; Rourke, Fisk, \& Strang, 1986), yet having such identifiable neurological deficit does not mean that there has to be a learning deficit (Goldstein, 1984). The term "identifiable" is defined as something that a neurologist could detect in a routine examination (Goldstein, 1984). The subtle neurological variations that may produce a learning disorder seem to be far from understood. It is of little wonder, then, that teachers, school administrators, parents, and sometimes school psychologists find the field of learning disabilities difficult to deal with and subsequently try to simpify the disorder to something "managable." Research into the laterality of learning disabilities also seems to be an active approach in investigating the contribution of cerebral structure to cerebral functioning on learning tasks. Some research (Galaburda et al., 1978) has studied the actual 
structural size of certain areas of the brain, the site of specific language disorders, language dominance, speaking/writing, and cerebral growth as contributors and loci of learning deficits. Tests which seem to tap these areas, such as the Luria-Nebraska Neuropsychological Test Battery, seem to be successful in this approach to identifying both site and dysfunction. other tests have also been found to be useful, but a learnign disabled population has not always been included. Measuring deficits in other populations and applying their results to learning disabilities groups, with the assumption that the results do apply to the learning disabilities group as well, appears to be changing. Researchers, such as Naglieri ( 1985 ), are using the WISC-R in new ways in the research of learning disability groups. In addition, others (Graham, Ernhart, \& Craft, 1962 ) are taking into account measures such as age of cerebral injury, length of time since an injury, environmental factors, etc. Measures which tap skills in vocabulary, the use of antonyms and synonyms, verbal comprehension, numerical repetition, visuographic reproduction, matching exercises, and the like appear to be adding to the body of knowledge on what constitutes a learning disorder.

The field of learning disabilities is rich and diverse in which to do research. Solving problems of 
definition, classification, measurement, and remediation seem to be in its infancy. Some tests may or may not have validity; some used in one context cannot be used in another. Though some tests seem to be strong indicators of localization, they do little to contribute toward an understanding of the underlying process of the deficit. Tests which do measure the deficits and attempt to understand the underlying process of the disorder may not be instruments which are successful in localization. Children with learning disorders seem to fall into one of two categories: those with audiolinguistic disorders and those with visuospatial dyslexia. Continued research in the field may lead to a more concise definition of learning disabilities, clarify placement decisions, and describe the underlying cerebral pathology as well. The field of learning disabilities is one of both complexity and diversity. Based on the research already done in the field, there is a need for more comprehensive and individualized evaluation in identifying a student's unique disability.

Two of the subtests used in this study appear to distinguish the groups--synonyms and Digits Forward/Backwards. As noted by Lezak ( 1981 ), tests which reflect verbal content such as vocabulary, antonyms, synonyms, etc., seem to tap remote memory for 
words and verbal comprehension. Measures which deal with numerical repetitions such as digit span measures seem to reflect a degree of immediate auditory memory, attention, distractibility, double tracking, and the ability to store data bits (Lezak, 198I). On both ineasures, the verbally impaired group had the most difficulty, with the spatially impaired group doing somewhat better, and the control group doing the best on the two measures. Both Synonyms and Digits Forward/ Backwards successfully discriminated among the groups. of the original 35 subjects in the control group, $63 \%$ were correctly placed into that group using the discriminant function; $69 \%$ were successfully placed into the verbally impaired group; and $55 \%$ in the spatially impaired group. It would appear then that the two measures are moderately good discriminators for Jetermining a learning disability.

Yet, theseareonly two measuresin a vast network of interrelated parts that constitute a learning deficit. While these two measures are able to identify groups with reasonable success, it is not good practice to base the decision of a learning deficit for an individual on one or tro measures when a "single-test" approach has very limited value (Golden, 1978). If anything, it is essential that an individualized 
approach be implemented in order to evaluate any change in the function being assessed (Lezak, 1981). Though Synonyms and Digits Forward/ Backwards successfully discriminated the groups, one could not base a diagnosis of a learning disability in an individual student solely on those two measures.

Combining these six measures, which measured different factors regarding learning deficits seems only to touch on a limited group of deficits. Lesser contributions to discriminating the groups were made by the Nonsense Words and Design Copy subtests. However, based on information referred to in Chapter 2 (Lezak; Rourke et al.), one could assume that more of the subtests would have discriminated among the groups. Lerner (1984) identified five components which contribute to a learning deficit, namely, neurological aysfunction, uneven growth, difficulty with academic tasks, discrepancy between achievement and potential, and excluded other factors. She also mentioned contributing factors such as disorders of attention, motor abilities, perception, written language, mathematics, and disorders of social/emotional behavior. Both Hartlage and Telzrow (1986) indicate that there are subtypes of learning disabilities, and children display uni-ue styles of information 


\begin{abstract}
processing. Therefore, the six subtests may have been able to tap learning deficits, but may not have been able to do so completely for this group, due to the uniqueness of the disabilities. Perhaps a group of 8year-old-inales would have had deficits in measures such as Nonsense Words and Design Copy or variations of these measures. Nevertheless, the frustration of an assessment and research into what constitutes a learning disability is both the deficit's key to remediation and its mystery for identification. A learning disabilty may be elusive in its character, but at the same time, reinforces the view that the human mind is vastly complex and resistive to simplification. Clearly, both past research and this report show that more compehensive evaluation is necessary if one is to identify a child as learning disabled.

The results of the additional analysis provide encouragement for a further study of these variables. The fact that Synonyms and Digits Forward/Backwards had the greatest validity in identifying the three groups is most likely related to the fact that these two subtests contained respectively 15 and 12 separate item scores. The tests which had very little influence in discriminating, namely Sentence Repeat, Nonsense Words, and Visual Pattern Matching, each consisted of only one
\end{abstract}


111

single score. The unreliability of a single score would have contributed to a lack of discriminant validity. This may also explain the relative inability of the subtests to discriminate the spatially handicapped.

\section{Recommendations}

This study dealt with a Iimited number of subtests and could not include a significantly contrasting group such as a brain-damaged sample. Many areas in the study of learning disabilities are beyond the scope of one dissertation. Issues such as specific cerebral dysfunctioning on these six measures and specific remediative strategies for deficits expressed on these subtests were not explored. Much investigation remains for future research.

\section{For Further Research}

1. The items used in the six subtests need further refinement and classification in order to distinguish with certainty one group from another. Perhaps focusing on the four more successful subtests rather than all six in combination would add more discriminative power to the subtest, especially ones so promising as synonymn and Digits Forward/Backwards.

2. Others may wish to combine these measures in other 
ways in order to explore their ability to

distinguish learning disabled groups from other

populations. Perhaps placing Sentence Repeat at the end of the series, or eliminating or changing that subtest altogether, would aid in separating the groups more successfully.

3. Increasing the sample size of the groups and utilizing students from learning disabilities programs in other school corporations could help to clarify the role of the six subtests in distinguishing learning disabled groups from others. In addition, including other age groups or expanding the current sample of 9-12 to perhaps 8-13 would enlarge the groups and help the subtests distinguish among the groups.

4. In undertaking research in this field, other factors winth influence a child's performance in school and on these measures must be taken into account. Factors such as the home environment, the parents' attitude toward school and the learning disabilities program, dietary habits, economic factors, and others may account more for learning deficits than anything measured on tests.

5. The two measures which were expected to identify the spatially handicapped should be increased to contain 
I 13

more item scores on each test. This could result in

increased reliability of these subtests and hence

give them greater opportunity to possess validity in

identifying spatially handicapped.

6. Eurther study should be given to the ability of

various combinations of the variables to

discriminate among pairs of groups, particularly

with a larger sample and using subtests with an

increased number of items.

\section{Eor Practice}

1. Though parents may be responsible for a lack of support or failure to communicate their concerns to schools regarding special programs in which their son is encolled, the school needs to be more responsive to the concerns and needs of the parents. Too often the student must meet rather simplified guidelines of the program rather than having the program fit the student's needs. This report has shown that the uniqueness of the student must be taken into account to provide inim with an adequate remediation plan. If the school were to communicate more with the home, the parent may be more supportive of the school, and the student more motivated within the program.

2. Teacners and special-prozrams supervisors all need 
I 14

to focus on specific deficits rather than take a global approach to improving the learning environment and curriculum. This study and others (Rourke, I981) have found that those with learning disorders more frequently express subtype deficits rather than syndromes. Focusing on the subtype disorder enhances the student's success in the program.

3. Those whose responsibility it is to evaluate and aid others in placement decisions should focus on the specific deficits and organize their diagnostic tests toward not only identifying whether a student is learning disabled but in what area(s) that student is expressing deficits. More information that specifically clarifies the disorder enables case-conference committees to make good placement decisions and helps formulate useful strategies in aiding students with learning disorders.

4. It is essential that the student be looked at as an individual apart from the group; perhaps apart from what is considered the learning disabled group. This report has cited a numer of researchers who question the definition of learning disabled, upon which many learning disability placement groups are defined. To the extent that the student is referred and evaluated, case-conference committees must take 


\section{5}

take it upon themselves to take responsible action in determining adequate data information for placement and remediation. If the deficit does not "fit" the current program, then the program must be redesigned to meet the student's needs.

5. At tempts should be made to identify the cerebral functions of the hemispheres as they relate to the development of learning disorders. This study and others (Boll, Lezak, Rourke) have found that learning disorders seem to be expressive of more diffuse and bilateral disabilities rather than unilateral.

6. More precise tests which are reliably and validly associated with cerebral disorders need to be made available to those whose responsibility it is to place children in special learning environments.

The precise nature of learning disabilities remains a vague and vastly unexplored area. This project was begun with the opinion that learning deficits were products of inefficient teaching strategies, lack of concern on the part of schools to focus on remediation in the classroom, or well-meaning but inisguided concern for tiose who a few short years ago may have been called slow learners. This project inas not only disproven those false assumptions but also 
has clarified the need for more comprehensive evaluation, less simplified solutions, and an emphasis on the uniqueness of the learner. Though much work is needed in defining the disorder and in developing valid and reliable instruments to detect learning deficits and offering program remediation for those who express those deficits, the future seems to offer the possibility that these deficits will be identified and school will become a true learning environment for those with learning handicaps.

Reproduced with permission of the copyright owner. Further reproduction prohibited without permission. 
AP PENDICES

Reproduced with permission of the copyright owner. Further reproduction prohibited without permission. 
APPENDIX A

INITIAL ITEMS AS SUBMITTED

TO PANEL OF PSYCHOLOGISTS

Reproduced with permission of the copyright owner. Further reproduction prohibited without permission. 
Dear Dr. $\ldots \ldots \ldots \ldots$.

Thank you again for agreeing to review this instrument under development. While examining the items, directions, etc..., please wite clearly. other comments can be written on the reverse side of each page.

I will stop by your office, in approximately two weeks, to gather your review. If you wish to return it earlier, mail the review to my office, or call and I will come to pick it up. Thank you for your kind attention and criticism.

\section{DIRECTIONS}

\section{Subtest 1 : SENTENCE REPEAT}

There are 25 items, of which one will be used in the Einal version, with two sample items given to the subject before the test item. Next to each item, code accordingly:

S: sample item

E: easy item

D: difficult item

D/C: discard this item

I: include this item

Directions are also given for SENTENCE REPEAT. Merely check the directions you feel would be most adequate. If none of the directions are suitable, place a D/C next to the directions.

\section{Subtest 2: SYNONYMS}

There are 40 items, of which 15 to 20 will be selected in the final version. Next to each item, code as you did for the sentence Repeat subtest. Mark the Directions in a similar fashion.

Subtest 3: DIGITS FORWARD/BACKWARD (See sheet A)

Verysimilar to items in the WISC-R and WAIS-R. The different numbers were generated through a computer program for random number assignment. Merely note if more items should be included, and if the Directions for both DF/DB are appropriate. 
Subtest 4: DESIGN COPY (See Sheet B)

Eight items have been selected, by permission, from the VMI. Again, score the items as you did for Sentence Repeat, and comment on the Directions.

Subtest 4: NONSENSE WORDS

Please comment on the directions. Then, score the items as you did for sentence Repeat.

Subtest 6: VISUAL PATTERN MATCHING

Comment on the directions, and score the thirty items as you did for Sentence Repeat.

SCORING SHEET

Please comment on the scoring sheet; if the arrangement is adequate, easy to use on face value, etc...

Again, thank you for your cooperation. I will be looking forward to your comments.

Kenneth $M$. Hanig 
This file contains sample items developed for the Michigan Patterned Gestalt, Dissertation topic: "A Study of Cerebral Lateralization, Dysfunction, and Localization in 9-12-Year-0ld Males with Learning Disabilities."

Sample Items ( 2 provided)

SUBTEST I SENTENCE REPEAT: Measures auditory discrimination, auditory memory, verbal memory, etc...

1. The dog is brown with large white spots.

2. Crossing the ocean was difficult.

3. A marble left on the floor shows carelessness.

4. The secret agent's message was decodable.

5. The triangle is an unusual shape.

6. The bird spread its wings, and flew away.

7. Marianne made the decision to leave.

8. I found the hook in an empty jar.

9. I saw the boat sail a silent sea.

10. The principal is very strict.

11. I rode the bus to school.

12. I passed the test on Friday.

13. The sinip ias been deserted.

14. Last summer, we went sailing with friends.

15. I solved the problem with Sam's help.

16. I swam to get back to shore.

17. Sue greeted each of the people warmly.

18. Sue swung her hat about her head.

19. The taxicabs tooted and honked.

20. Stuart was afraid of the large dog.

21. We had bacon and eggs for breakfast.

22. We read the poem on Monday.

23. Janis went to the audition for the talent show.

24. Many stars are visible in a clear sky.

25. The job was completed on time.

\section{Directions for SENTENCE REPEAT}

A.

(E) "I am going to say a sentence, and ask you to remember it. During the course of the test, I will ask you to repeat the sentence. Do you understand?" (S confirms) "Good. Now, here is the sentence........... Would you repeat that for me now? (S repeats the sentence) Good! Now remember the sentence, because I will ask you to repeat it once more." (After SYNONYM subtest) E: "Now, let's try a few for practice." 
B .

(E) "I am going to give you a sentence to remember. Here is the sentence........ Can you repeat that for me now?" (S repeats the sentence) "Good! Now during the test, I will ask you to repeat it once more. Now, let's try a few for practice." (S repeats two of the sample items) $E$ : "Good, now let's go on to the first item."

c.

(E) "This is a test to see how well you do on a number of tasks. The first thing $I$ will ask you to do is repeat the following sentence, okay? (S confirms) "Good. Here is the sentence........ Could you repeat that for me now?" (S repeats the sentence) "Good! Now try and remember it, because I will ask you to repeat it once more during the test. Now, Iet's go to the first item."

II. SYNONYMS) (Taps auditory recall, verbal comprehension, and general verbal background.)

A. (Directions) (E): "I am going to say a word, and I want you to tell me another word that means the same thing. Okay?" (Subject confirms. If not, the examiner should define the word SYNONYM, and give an example. The examinersays, "Well, a synonym is a word that means the same thing, such as fast-speedy, or correct-right. Do you understand? Examiner then begins with the first item.)

B. (Directions) (E): "I am going to say a word, and I want you to tell me another word that means the same thing. Okay?" (Subject confirms.) If the subject does not understand, given an example (fast-speedy, correctright, house-home, stone-rock, etc...). Proceed to sample items if subject confirms or not.

\section{SCORING}

$0=$ incorrect answer

1 = Concrete answer. E can test the limits by asking questions, such as "Tell me another word that means the same as--.---.."

2 = Abstract answer.

Sample Items: 
$E$ : "Now, tell me another word for.........

I. car (automobile, stationwagon, limo, etc...)

2. join (assemble, pair, couple, hinge, cement, etc.)

3. man (male, gentleman, him, he, grandfather, father, etc...)

4. end (close, finish,stop, period, final, etc...)

5. Eunny (ridiculous, laughable, goofy, silly, etc..)

6. weak (feeble, lame, frail, worn, etc...)

7. curve (arc, cresent, arch, bow, bent, etc...)

8. Eall (drop, nosedive, crash, descent, etc...)

9. crush (squash, demolish, obliterate, smash, etc...)

10. secret (mystery, riddle, puzzle, hidden, etc...)

\section{Items}

1. End

(2) complete, terminate, closure, finish, terminal, etc...

(1) over, bottom, last, final, settle, close, stop, etc...

(0) bottom out, the bitter end, end of the rainbow, etc...

2. Loud

(2) noisy, blatant, bellow, deafen, etc...

(1) shout, clang, roar, racket, shrill, etc...

(0) silent, quiet, real loud, bang a drum, etc...

3. Right

(2) correct, proper, creditable, legitimate, etc...

(1) legal, merit, due, license, etc...

(U) okay, what's due to you, doing what's right, etc...

4. Wrong

(2) unfair, unreasonable, bad, unjust, unequal, etc...

(1) one-sided, shame, vice, illegal, etc...

(0) absolute, goes against the law, what you can't do, etc...

5. Duty

(2) obligation, responsibility, morals, ethical, etc...

(1) binding, an act, contract, etc...

(0) What you have to do, free time, entertain, etc... 
6. Soft

(2) Smooth, delicate, supple, tender, pliable, etc...

(1) weak, spongy, flabby, plastic, fur, etc...

(0) hard, feels like......, rough, etc...

7. Under

(2) below, low, beneath, down, etc...

(1) downstairs, underground, underfoot, etc...

(0) up, around, that way, etc...

8. Different

(2) unusual, strange, odd, curious, etc...

(1) apart, another, various, etc.... bizarre

(0) similar, great, large, etc...

9. Before

(2) preceed, front, lead, prior, etc...

(1) ahead, first, etc...

( 0 ) Iast, end, behind, etc...

10. Finish

(2) complete, end, terminate, conclude, final, etc...

(1) last, period, close, limit, etc...

(0) start, use, add, etc...

11. Detail

(2) minimal, few, minutiae, trifle, small, etc...

(1) little, drop, dab, dash, bit, etc...

(0) group, large, just a few, DK, etc...

12. Circle

(2) circumference, round, etc...

(1) coil, wheel, compass, etc...

(0) DK, square, box, round-a-bout, etc...

13. Fable

(2) story, tale, yearn, fiction, etc...

(1) Jack-and-Jill, poem, etc...

(0) DK, a story that's not true, etc...

14. Fantasy

(2) myth, romance, illusion, vision, etc...

(1) shadow, ghost, dream, whim, fairyland, etc...

(0) real, DK, a lot, bad, nighttime, etc...

15. Moody

(2) tempermental, irritable, sullen, etc...

(1) jumpy, static, jrouciny, etc...

(0) happy, up and down, DK, etc...

Reproduced with permission of the copyright owner. Further reproduction prohibited without permission. 
16. Route

(2) guide, itinerary, etc...

(I) handbook, map, road, etc...

(O) DK, travel, vacation, trip, etc...

17. Relationship

(2) correlate, relative, family, etc...

(1) married, aunt, brother, sister, friend, etc...

(0) DK, away, agree, etc...

18. Fact

(2) true, real, actual, certain, etc...

(I) strict, exact, sound, scientific, etc...

( 0$)$ DK, untrue, Iie, the earth is round $(Q)$, etc...

19. Imaginary

(2) nuIl, nonexistent, absent, extinct, nothing, etc...

(1) dream, lie, vanish, etc... unreal...

(0) not there ( $Q)$, can't find it, solid, etc...

20. Compare

(2) judye, contrast, simili, contrast, balance, etc...

(1) separate, criticize, measure, etc...

$(0)$ equal, tell the difference $(Q)$, same, etc...

21. Opinion

(2) viewpoint, bias, belief, conviction, view, etc...

(1) Faith, creed, belief, etc...

(O) DK, how you feel (Q), opposites, etc...

22. Begin

(2) start, initiate, onset, undertake, etc...

(1) prime, first, charge, etc...

(O) DK, start up (Q), Einish, etc.

23. Sequence

(2) series, progression, order, erc...

(1) train, following, etc...

( 0 ) come after ( $Q)$, DK, costume, etc...

24. Impossible

(2) difficult, absurd, unreasonable, etc...

(1) hard, can't do (Q), etc...

(0) DK, say you will (Q), disagree, etc...

Reproduced with permission of the copyright owner. Further reproduction prohibited without permission. 
25. Promise

(2) oath, pact, vow, pledge, etc...

(1) warranty, agree, swear, etc...

(O) DK, say you will (Q), disagree, etc...

26. Respect

(2) honor, esteem, reverence, etc...

(1) obey, Iike, nice, self-respect, etc...

(0) look up to (Q), DK, laugh at, see, etc...

27. Permission

(2) al low, permit, leave, favor, grant, etc...

(1) passport, release, Iicense, etc...

(0) DK, let go (Q), can do something (Q), etc...

28. Refuse

(2) reject, deny, decline, etc...

(1) of fend, grudge, etc...

(0) DK, give up on (Q), don't do (Q), etc...

29. Exaggerate

(2) Iie, fiction, magnify, expand, etc...

(1) bigger, larger, boast, etc...

(0) blow out of scale (Q), small, DK, etc...

30. Gauge

(2) judge, scale, rule, measure, etc...

(1) speedometer, barometer, etc...

(0) DK, Find the difference ( $Q)$, go fast, etc...

31. Invisible

(2) mysterious, indistinct, obscure, etc...

(1) ghostly, blur, dark, dim, etc...gone...

(0) DK, can't see it $(Q)$, etc...

32. Associate

(2) relate, relative, combine, join, mingle, etc...

(1) 1 ink, club, know, tie, etc...

(0) hang with (Q), leave, go, DK, etc...

33. Essential

(2) necessary, basic, needed, etc...

(1) real, important, etc...

(0) DK, have to have it (Q), unimportant, etc...

34. Fragment

(2) unfinished, extract, etc...

(1) piece, bit, part, etc...

(O) DK, just a part of (Q), etc... 
35. Discipline

(2) training, punish, detention, rul $\leq$, etc...

(1) obey, Eollow, spank, etc...

(O) DK, be mean, get to do what you want (Q), etc...

36. Frigid

(2) cold, freezing, unfriendly, aloof, etc...

(I) Erost, snowy, icy, chilly, etc...

(O) DK, warm, like the winter (Q), etc...

37. Melancholy

(2) depressed, gloomy, sad, upset, etc...

(1) down, blues, hopeless, dull, etc...

(0) down in the dumps (Q), DK, happy, etc...

38. Ominous

(2) Eoreboding, threatening, dangerous, etc.

(I) scarey, bad, afraid, etc...

$(0)$ something that gets you ( $Q$ ), DK, unusual ( $Q$ ), happy, etc...

39. Perceive

(2) observe, distinguish, aware, insight, vision, etc...

(1) eye, view, survey, see, etc...

(0) DK, look into (Q), unusual, strange, etc...

40. Vain

(2) conceited, pride, narcissistic, egotistic, etc...

(1) selfish, boast, bore, snobbish, etc...

(0) stuck on yourself (Q), DK, happy, sad, etc...

\section{SENTENCE REPEAT}

E. "Before we go on, I asked you to remember a sentence. Would you repeat it for me now?"

Scoring: 2 = complete recall

1 = partial recall

$0=$ no recall

III. DIGITS FORWARD/DIGITS BACKWARD (See at tached sheet of random numbers.) This subtest measures immediate auditory processing, attention, distractibility, concentration, double tracking, and reversal of mental operations. 
Directions for Digits Forward (E): I am going to say a group of numbers and you are to say them right after me, okay? (S answers affirmative) For example, if I say 3-47, what would you say? (S repeats the series. If he/she cannot, say "I said 3-4-7. Let's try this group: 4-2-3. If $S$ still cannot repeat, go on to item one.)

Scoring: Give both sets $A$ and $B$. If $S$ only answers $A$ or B correctly, score L. If both repeated correctly, score 2. If neither are repeated correctly, score 0 .

Directions to Digits Backwards (E): I am going to say a group of numbers that I want you to say backwards. For example, if I said $1-2-3$, what would you say? (s repeats 3-2-1. If not say, "Let's try another group. Remember to say them backwards. If I said 2-4-6, what would you say? If $S$ answers correctly or incorrectly, proceed to item 1 .

Scoring: Same as in Digits Forward.

IV. DESIGN CORY (Desizns are placed on cards.) This measure taps visual perceptual-motor functioning and right hemispheric processing)

Directions (E): I am going to show you some cards with designs on them. All you have to do is draw them on your paper, okay? Good. Here is the first one. (If $S$ does not understand, demonstrate the first item.) Give all cards to all subjects.

V. NUNSENSE WORDS (Measures lexical processing)

Directions (E): I am going to give you a list of

nonsense words to study for a few -inutes. I will then give you another list of nonsense. urds. Simply check of $f$ the ones you remember, okay? Good. Now here is the list. (Time $120^{\prime \prime}$ )

Scoring: The second 1 ist will have 15 words, ten of which the $S$ is to identify.

a. $0-2=0$ points.

b. $3-4=1$ points.

c. $5-10=2$ points.

Reproduced with permission of the copyright owner. Further reproduction prohibited without permission. 


\section{Items:}

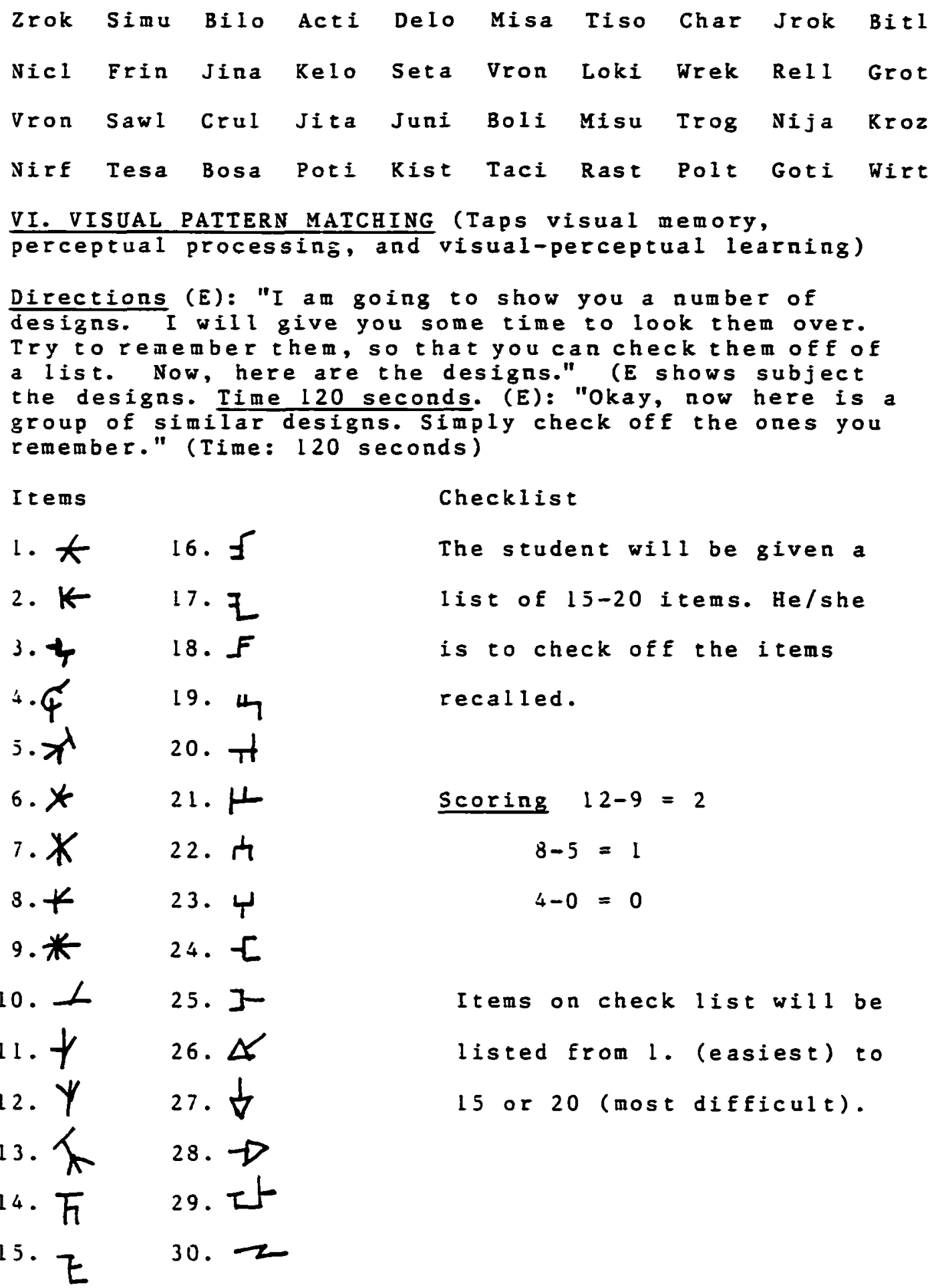


Sheet A

\section{DIGITS FORWARD}

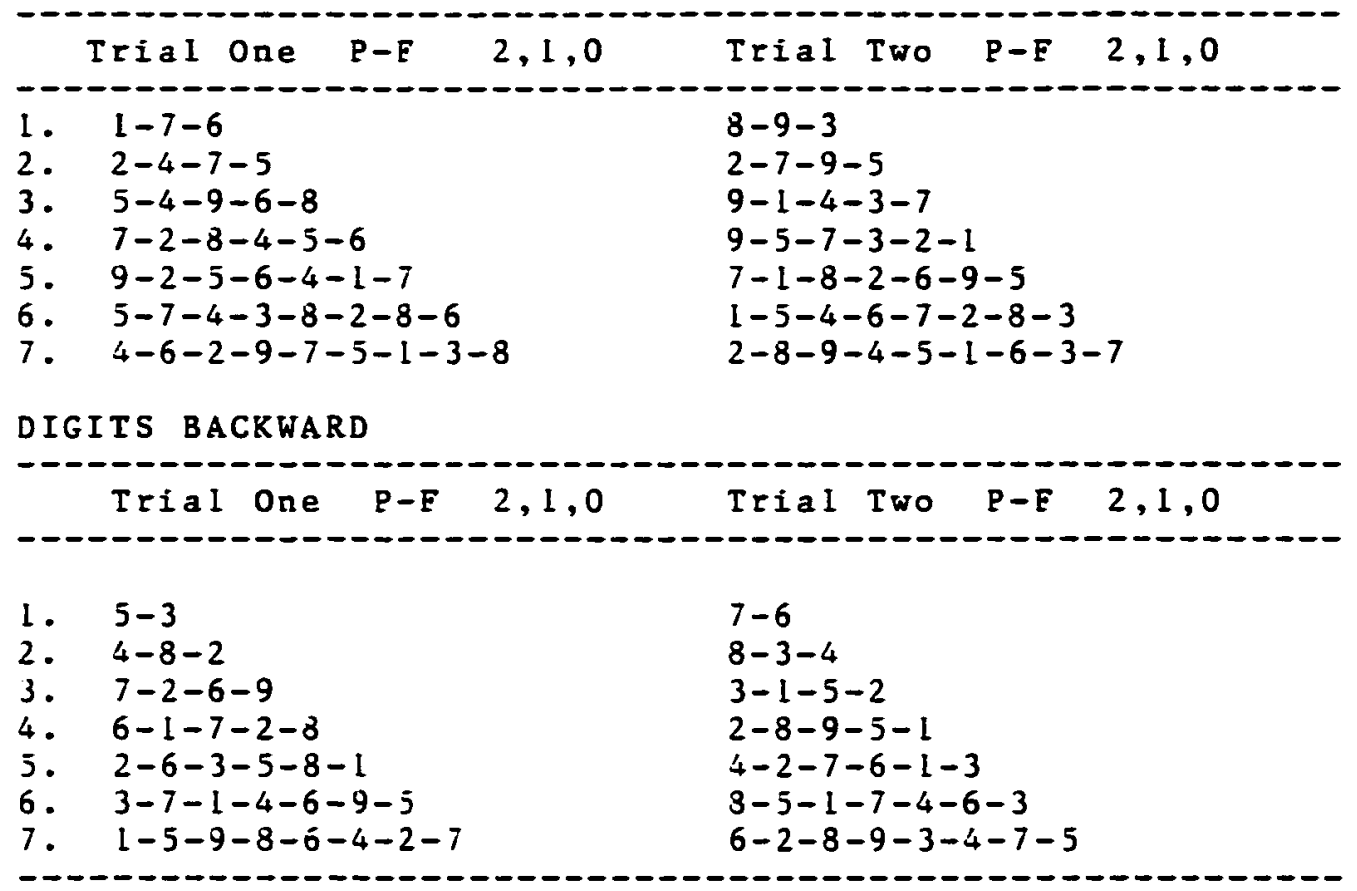

Reproduced with permission of the copyright owner. Further reproduction prohibited without permission. 

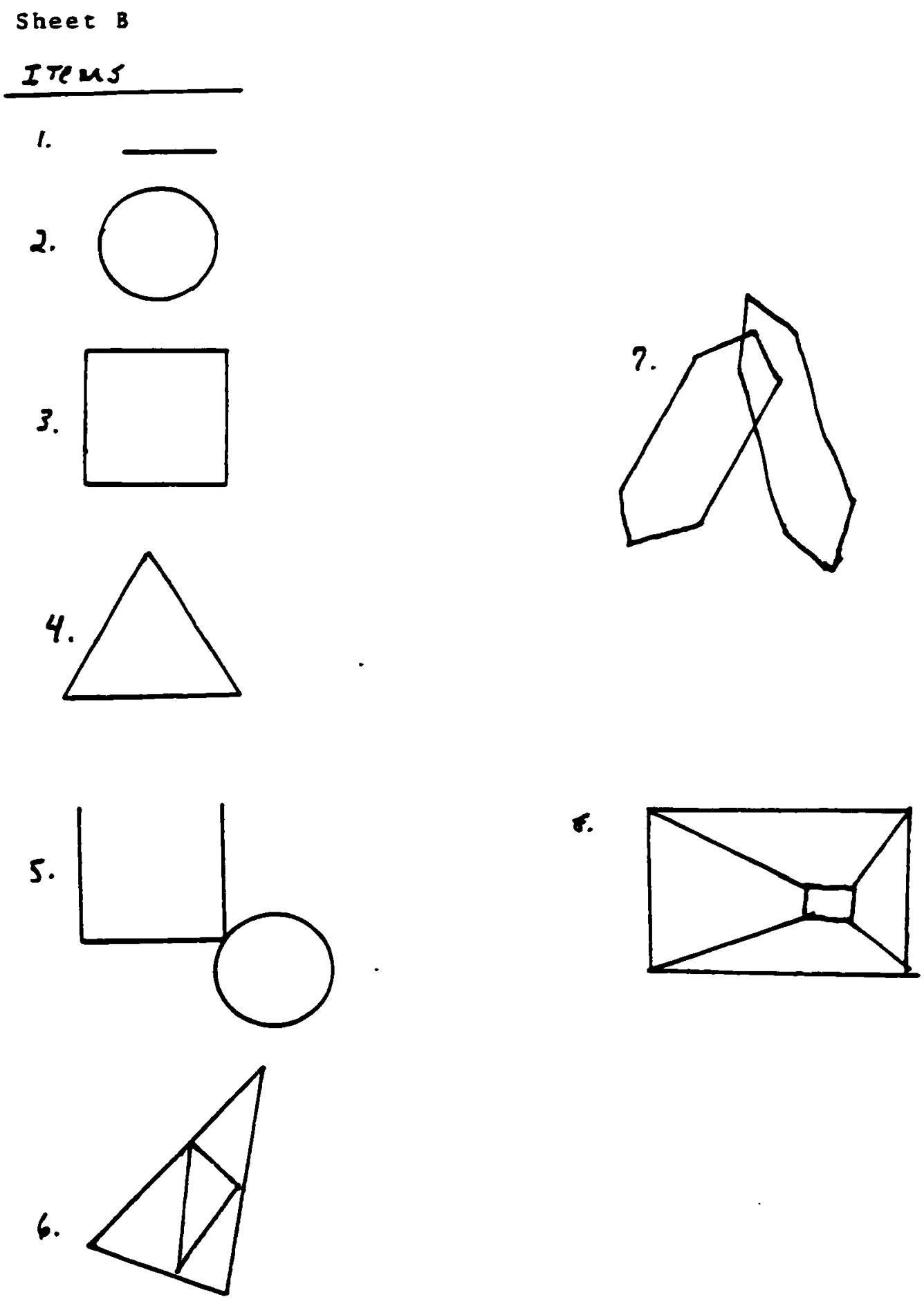


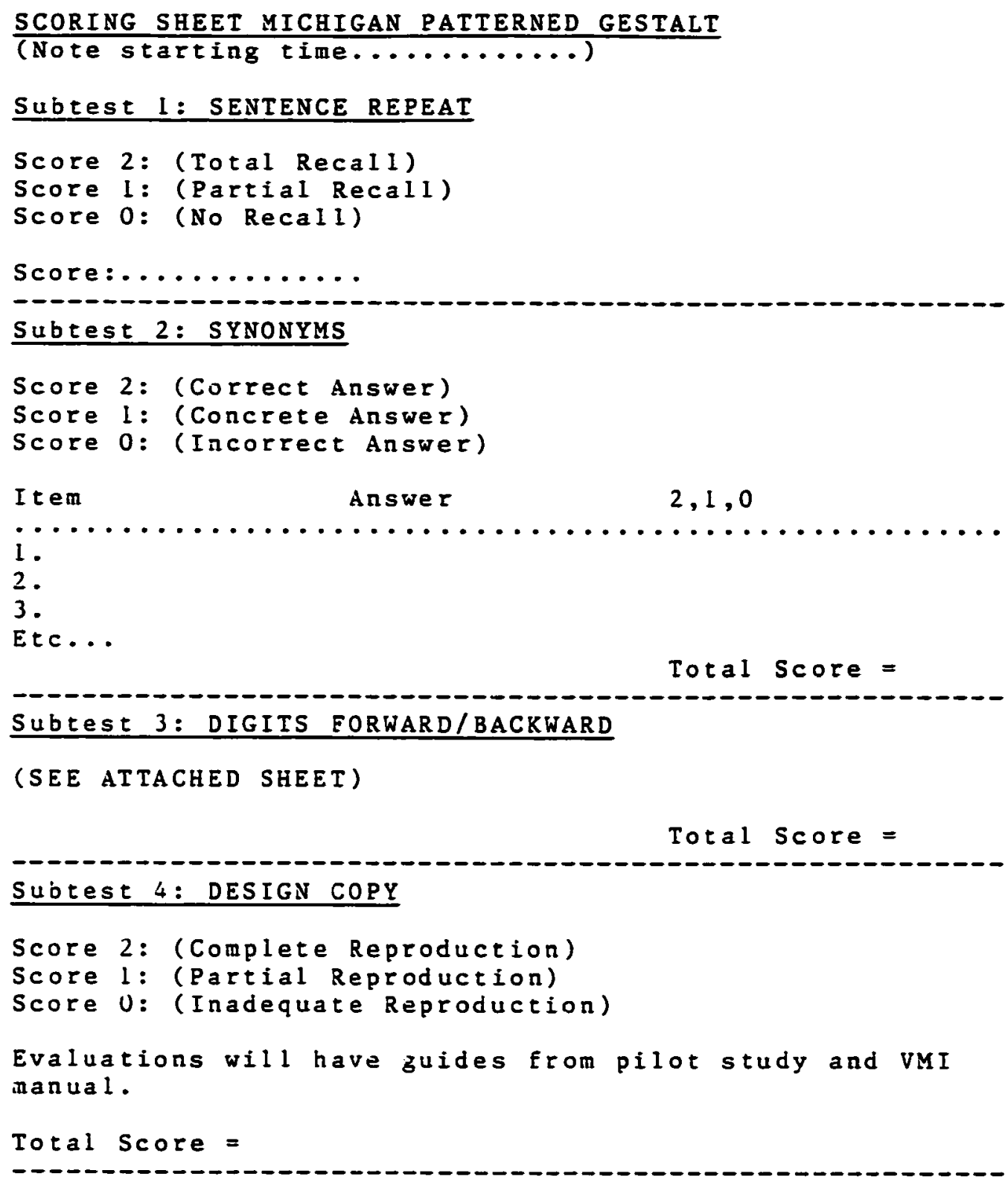




\section{Subtest 5: NONSENSE WORDS}

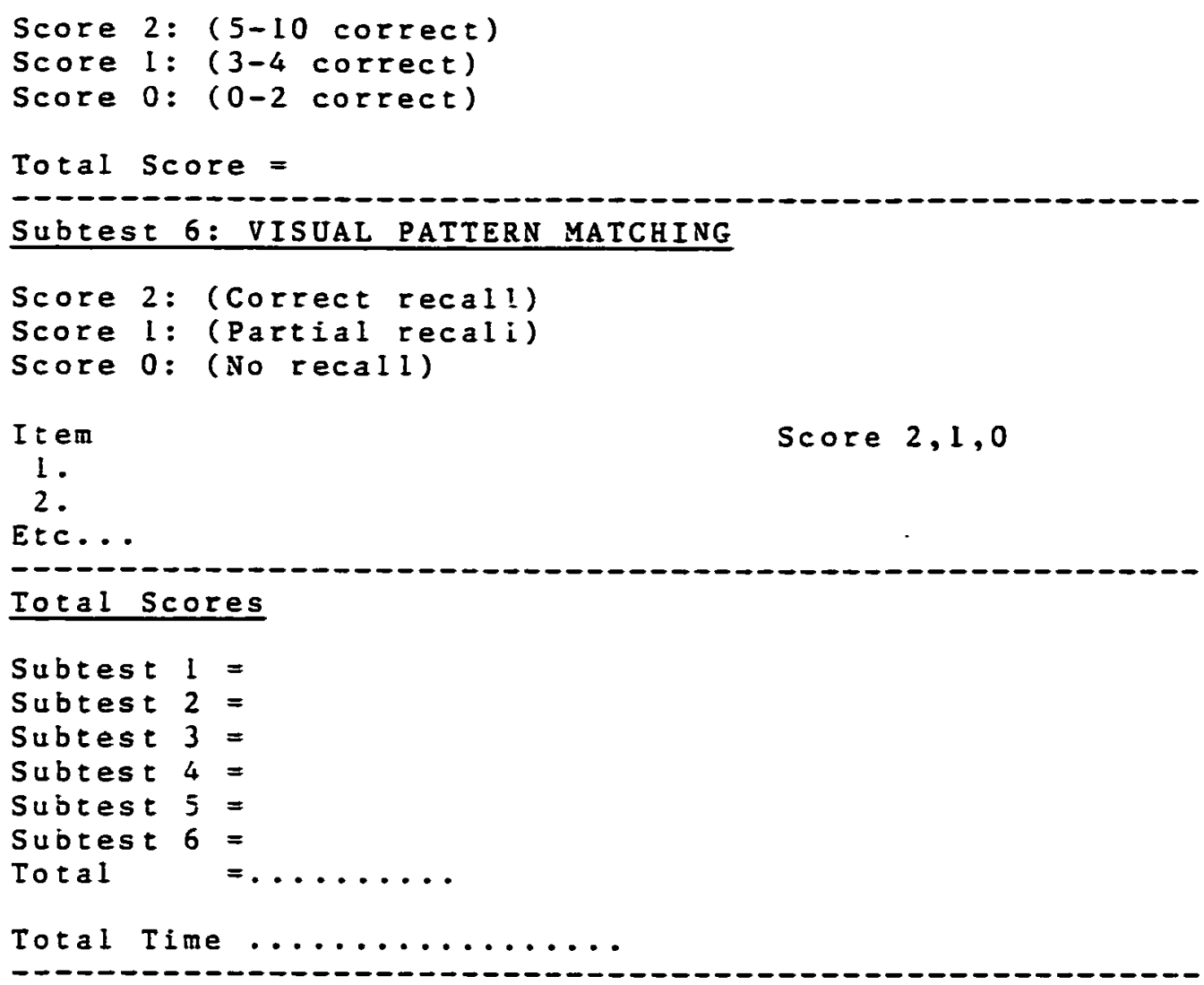


PILOT IEST: EXPERIMENTAL VERSION

\title{
SUBTEST I: SENTENCE REPEAT
}

\begin{abstract}
Directions: (E) "I am going to give you a sentence to remember. Here is a sample sentence: I RODE THE BUS TO SCHOOL. Can you repeat that for me? (S repeats the sentence. If not, say "okay. Let's try another. Listen carefully, and try to repeat the sentence: THE JOB WAS COMPLETED ON TIME." If the subject is still unable to repeat the sentence, at tempt the following sentence: "THE PRINCIPAL IS VERY STRICT." If the subject is unable to repeat the sentence after the third sample, discontinue the itme, and got to SUBIEST 2. "Good! Now during thes tst, I will ask you to repeat this sentence: CROSSING THE OCEAN WAS DIFEICULT. Can you repeat that Eor me? (Subject repeats the sentence). Good" Now let's go on with the rest of the test."

\section{SUBTEST 2: SYNONYMS}

Directions: (E) "I am going to say a word, and I want you to teli me another word that means the same thing. Okay?" (Subject confirms. If not, the examiner should define the word SYNONYM and give an example. Define a synonyin as a word that means the same thing, and give the following examples:

EX.: Car--automobile man--male, him, he, gentleman, etc...

(E) "Do you understand? Good. Now let's try a few. Give me a synonym for secret (riddle, puzzle, mystery, etc...). Good, now let's try Funny (ridiculous, laughable, goofy, silly, etc...) okay, now let's do some others (Ex. proceeds to first item)."

Scoring 2 = Abstract answer 1 = Concrete answer $0=D K$ (Don't know), incorrect, or other answer

Items What is another word for..........?"

1. END

(2) complete, terminate, closure, finish, terminal, etc...

(1) over, bottom, last, final, settle, close, stop, etc...

$(0)$ bottom out, the bitter end, end of the rainbow, etc... 
2. LOUD

(2) noisy, blatant, bellow, deafen, etc...

(1) shout, clang, roar, racket, shrill, etc...

(0) silent, quiet, real loud, bang a drum, etc...

3. RIGHT

(2) correct, proper, creditable, legitimate, etc...

(I) Iegal, merit, due, Iicense, etc...

( 0 ) okay, what's due to you, etc...

4. WRONG

(2) unfair, unreasonable, bad, unjust, etc...

(1) one-sided, shame, vice, illegal,etc...

(0) absolute, goes against the law, can't io, etc...

5. DUTY

(2) obligation, responsibility, morals, ethical, etc...

(1) bindinz, an act, contract, etc...

(0) have to do, free time, entertain, etc...

6. SOET

(2) smooti, delicate, supple, tender, etc...

(I) furry, spongy, flabby, plastic, etc...

(0) hard, feels like......, rough, etc...

7. UNDER

(2) below, low, beneath, down, etc...

(1) downstairs, underground, etc...

(O) up, around, that way, etc...

8. DIEFERENT

(2) unusual, strange, odd, curious, etc...

(1) apart, another, various, bizarre, etc...

(U) similar, great, large, etc...

9. BEFORE

(2) preceed, front, lead, prior, etc...

(1) ahead, first, etc...

(O) last, end, behind, etc...

10. FINISH

(2) complete, end, terminate, conclude, final, etc...

(1) last, period, close, limit, etc...

(0) start, use, add, etc...

Reproduced with permission of the copyright owner. Further reproduction prohibited without permission. 
II. CIRCLE

(2) circumference, round, etc...

(1) wheel, compass, ball, etc...

(0) DK, square, box, round-a-bout, etc...

12. $\mathrm{FACT}$

(2) true, real, actual, certain, etc...

(1) strict, exact, sound, scientific, etc...

(0) DK, untrue, Iie, etc...

13. BEGIN

(2) start, initiate, onset, undertake, etc...

(I) prime, first, charge, etc...

(0) DK, start up (Q), opposites, etc...

14. IMPOSSIBLE

(2) difficult, absurd, unreasonable, etc...

(1) hard, can't do (Q), etc...

(0) won't do (Q), easy, crazy, etc...

I5. REFUSE

(2) reject, deny, decline, etc...

(1) offend, grudge, etc...

(0) DK, give up, don't do, etc...

\section{SENTENCE REPEAT I}

(E) "Before we go on, I asked you to remember a sentence. Would you repeat it for ne now?"

Scoring: 2 = Total recall

1 = Partial recall

$0=$ No recall, or incorrect recall

SUBTEST III: DIGITS FORWARD/DIGITS BACKWARD (SEe attached sheet "A" for items)

Directions (E): "I am going to say a group of numbers, and you are to say them right after me. Okay? ( $S$ affirms) For example, if I say $1-6$, what would you say? (s repeats. If he/she cannot, say, "I said 1-6. Let's try this group: 4-2" If s still cannot repeat, go on to item one.j"

Scoring: Give both sets $A$ and $B$. If $S$ only answers $A$ or B, score 1 . If both are repeated correctly, score 2. If neither are repeated, score 0 .

Reproduced with permission of the copyright owner. Further reproduction prohibited without permission. 
Directions (Digits Backwards) (E): "I am going to say a group of numbers that I want you to say backwards. Eor example, if I said $3-8$, what would you say?" (S repeats 8-3. If not, say, "Weli, you would say 8-3. I said 3-8, so to say it backwards, you would say 8-3. Let's try another. Remember to say it backwards: 7-2." If $S$ answers correctly or incorrectly, proceed to item one.)

Scoring: Same as Digits Forward.

SUBTEST IV: DESIGN COPY (Designs placed on cards. On this form, see attached sheet "B".)

Directions: (E): "I am going to show you some cards with designs on them. Al I you have to do is draw them on your paper, okay? Good. Here is the first one." (If s does not understand, demonstrate the first item.) Give all cards to all subjects.

\section{SUBTEST V: NONSENSE WORDS}

Directions (E): "I am going to give you a list of nonsense words tostudy for a minute. I will then give you another list of nonsense words. Simple circle the ones you remember, okay? Good. Now, here is the list." (Time I $20 "$ )

Zrok Simu Bilo Vron Sawl Delo Misa Trog Rast Kist Grot Seta Jina Tesa Tiso

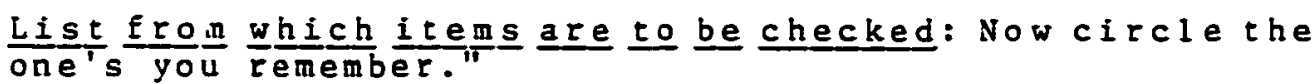

Zrok Simu Bilo Acti Delo Misa Tiso Char Jrok Bitl

Vicl Frin Jina Kelo Seta Vron Loki Wrek Rell Grot

Sawl Crul Jita Tuni Boli Trog Nija Kroz Nirf Tesa

Bosa Poti Kist Taci Rast Polt Goti Wirt Riga Loni

Scoring: The $S$ is to identify ten of the fifteen words. a. $0-2=0$ points

b. $3-4=1$ point

c. $5-10=2$ points.

SUBTEST VI. VISUAL PATTERN MAICHING (See attached sheets
"C"and "D.") 


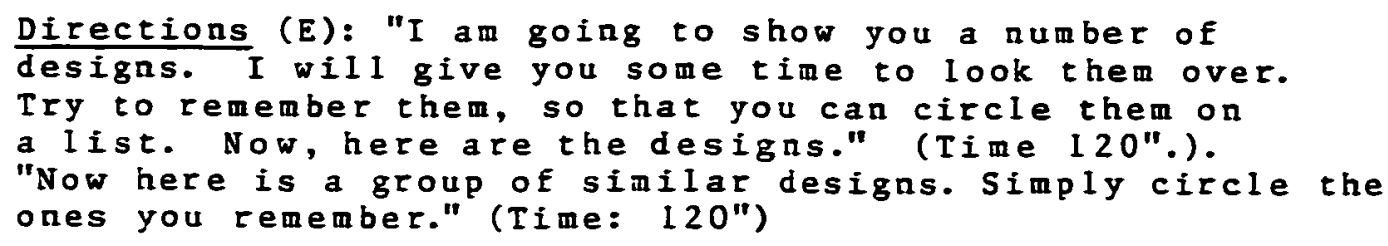


Sheet A

\section{DIGITS EORWARD}

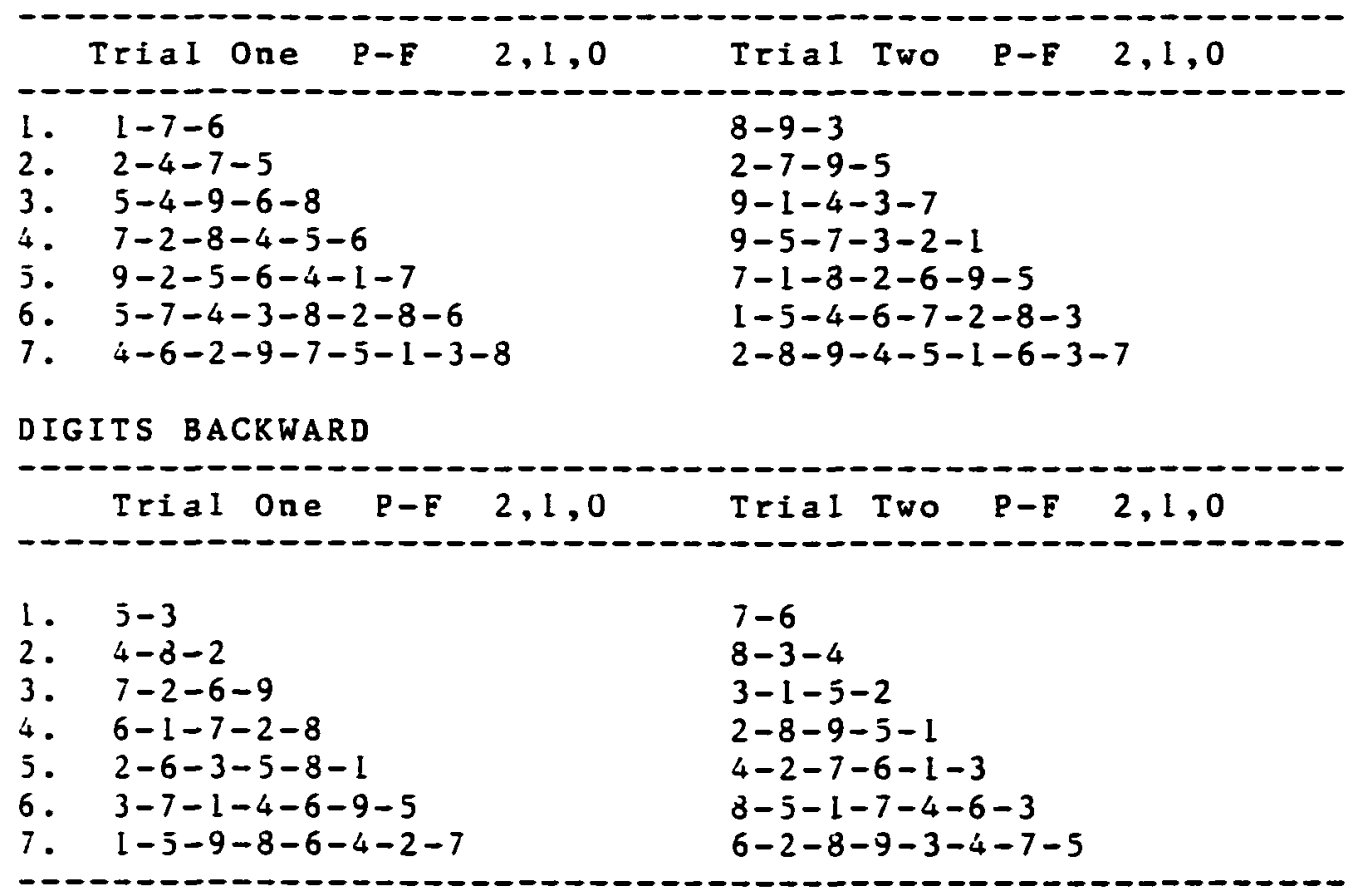

Reproduced with permission of the copyright owner. Further reproduction prohibited without permission. 
Sheet $B$

ITens

I.

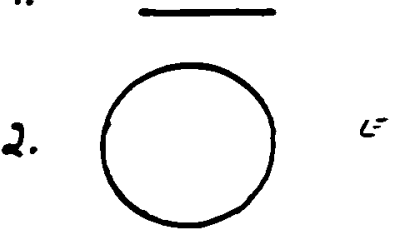

3. $\leqslant=$
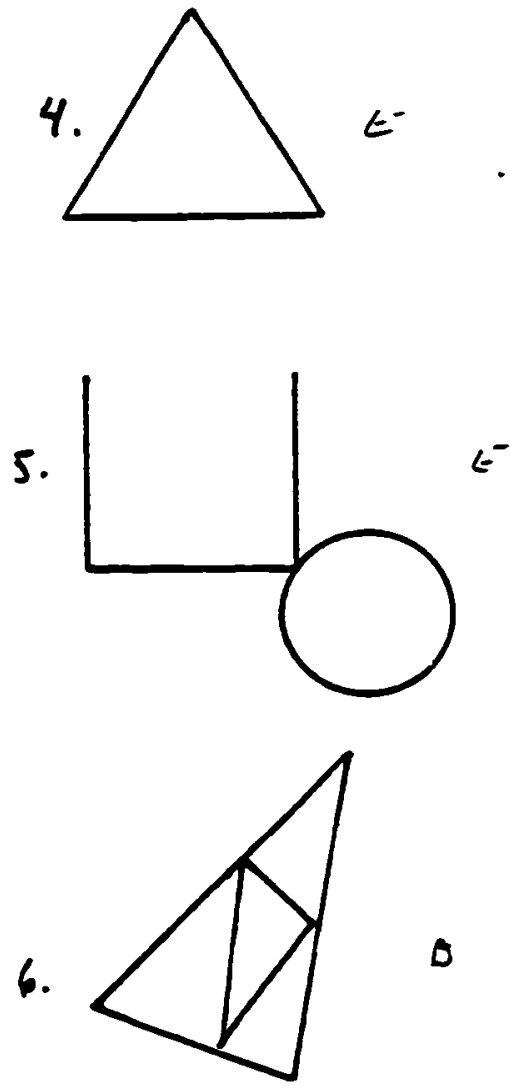

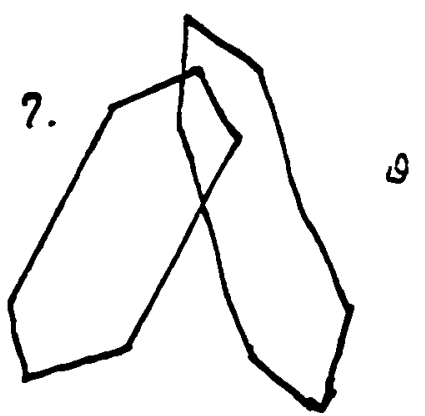

$\gamma$.

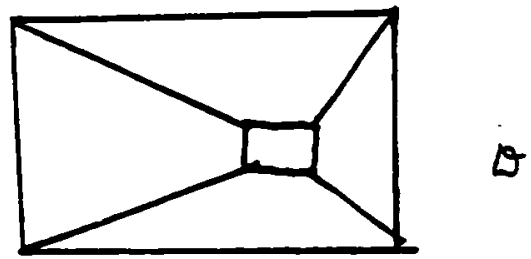


APPENDIX B

FINAL REVISION USED FOR STUDY

Reproduced with permission of the copyright owner. Further reproduction prohibited without permission. 
FINAL REVISION: FORMAL DATA COLLECTION

\section{SUBTEST 1: SENTENCE REPEAT}

Directions: (E) "I am going to give you a sentence to remember. For example: CROSSING THE OCEAN WAS DIFFICULT. Can you repeat that for me?

(Subject repeats the sentence. If not, say "okay, let's try another. Listen carefully, and try to repeat the sentence: THE JOB WAS COMPLETED ON TIME." If the subject is still unable to repeat the sentence, attempt the following sentence: "THE PRINCIPAL IS VERY STRICT." If the subject is unable to repeat the sentence after the third sample, discontinue the item and go to SUBTEST 2.)

"Good! Now during the test, I will ask you to repeat this sentence: I RODE THE BUS TO SCHOOL. Can you repeat that for me? (Subject repeats the sentence). Good! Now let's go on with the rest of the test."

\section{SUBTEST 2: SYNONYMS}

Directions: (E) "I am going to say a word and I want you to tell me another word that means the same thing. Okay?"

(Sujject confirms. If not, the examiner should define the word SYNONYM and give an example. Define a synonym as a word that means the same thing, and give the Eollowing exanples.

EX.: Car--automobile man--male, him, he, gentleman, etc... end--stop, finish, period, etc...

(E) "Now let's try a few. Give me a synonym for HOP (jump, leap, etc...) Good, now let's try SILLY (ridiculous, laughable, goofy, funny, etc...). Okay, now let's do some others (Ex. proceeds to first item)."

Scoring: 2 = Abstract answer $I$ = Concrete answer $0=D K$ (Don't know), incorrect, or other answer

ex: "TEll me another word gor..........." 
1. EAST

(2) haste, accelerate, swift, hurry, quick, etc...

(I) run, speed, gallop, etc...

(0) DK, or other answer

2. LOUD

(2) noisy, blatant, bellow, deafen, etc...

(1) shout, clang, roar, racket, shrill, etc...

(0) silent, quiet, real, bang a drum, etc...

3. BEGIN

(2) start, initiate, onset, undertake, etc...

(1) first, change, open, etc...

(0) DK, start up, or other answer, etc...

4. RESPECT

(2) obey, esteem, honor, etc...

(1) self-respect, like, nice, etc...

(0) DK or other answer

5. LOOK

(2) see, observe, watch, etc...

(1) notice, study, examine, etc...

(0) DK or other answer

6. SOFT

(2) smooth, delicate, supple, tender, etc...

(1) furry, spongy, weak, flabby, plastic, etc...

( 0 ) hard, feels like..., rough, etc...

7. UNDER

(2) below, low, beneath, down, etc...

(1) downstairs, underground, etc...

(0) up, around, that way, etc...

3. DIFFERENT

(2) unusual, strange, odd, curious, etc...

(I) apart, another, various, bizarre, etc...

(0) similar, great, large, etc...

9. BEFORE

(2) preceed, front, lead, prior, etc...

(1) ahead, first, etc...

(0) last, end, behind, etc...

10. FINISH

(2) complete, end, terminate, conclude, final, etc...

(1) last, period, close, limit, etc...

(0) start, use, add, etc... 
I I. CIRCLE

(2) circumference, round, etc...

(1) wheel, compass, ball, etc...

(0) DK, square, box, round-a-bout, etc...

12. WORK

(2) job, task, employment, profession, etc...

(I) teacher, dentist, carpenter, factory, etc...

(0) DK, or other answer

13. GIGANTIC

(2) Iarge, huge, big, etc...

(1) giant, tall, monstrous, etc...

(0) DK, or other answer

14. IMPOSSIBLE

(2) difficult, absurd, unreasonable, etc...

(1) hard, can't do (Q), etc...

(O) won't do (Q), easy, crazy, etc...

15. REFUSE

(2) reject, deny, decline, etc...

(1) offend, grudge, etc...

(0) DK, give up, don't do, etc...

\section{SENTENCE REPEAT I}

(E) "Before we go on, I asked you to remember a sentence. Would you repeat it for me now?"

(I RODE THE BUS TO SCHOOL.)

Scoring: 2 = Total recall

$L$ = Partial recall

0 = No recall, or incorrect recall

SUBTEST III: DIGITS FORWARD/DIGITS BACKWARD

(See attached sheet "A" for items)

Directions (E): "I am going to say some numbers, and you are to say them right after me. okay? (S affirms) For example, if I say $1-6$, what would you say?

(Subject repeats. If he/she cannot, say, "I said 1-6. To repeat it, you would say 1-6. Let's try this group: 42." If subject still cannot repeat, go on to item one. )" 
Scoring: Give both sets $A$ and $B$. If $S$ only answers $A$ or $B$, score l. If both are repeated correctly, score 2. If neither are repeated, score 0 .

Directions (Digits Backwards) (E): "I am going to say a group of numbers that I want you to say backwards. For example, if I said 3-8, what would you say?"

(Subject repeats 8-3. If not, say, "Well,you would say 8-3. I said 3-8, so to say it backwards, you would say

8-3. Let's try another. Remember to say it backwards: 7-2." If $S$ answers correctly or incorrectly, proceed to item one.)

Scoring: Same as Digits Forward

\section{SUBTEST IV: DESIGN COPY}

(Designs placed on cards. Ex. gives the subject a plain piece of paper.)

Directions (E): "I am going to show you some cards with designs on them. All you have to do is draw them on your paper, okay? Good. Here is the first one."

(If $S$ does not understand, demonstrate the first item.)

Give all the cards to the subject.

Scoring (per item):

a. $0=$ complete distortion

b. 1 = the item is recognizable in shape, with a few angulation errors, distortions, rotations, Eragmentations, etc...

c. 2 = good reproduction

\section{SUBTEST $V$ : NONSENSE WORDS}

Directions (E): "I am going to give you a list of nonsense words tostudy for a few minutes. I will then give you another 1 ist of nonsense words. Simply circle the ones you remenber, okay? Good. Now here is the list."

Time: 60"

Items: (See SHEET "B". Ex. gives Subject SHEET B to study. Subject checks items off SHEET " $C$ ".) 
Ex. gives SHEET "C" to Subject and says, "Now, circle the ones you remember."

Scoring: The Subject is to identify all ten items for full credit.

a. $0-2=0$ points.

b. $3-4=1$ point.

c. $5-10=2$ points.

SUBTEST VI: VISUAL PATTERN MATCHING (See attached sheets "D"and "E".
Directions E: "I am going
designs. I will give you
Try to remember tinem so th
list. Okay? Good. Here a
(E shows the Subject the
(E): "Now, here is a grou
"E".) Simply circle the o
Note to (E): Give S Iist
Eor the Subject to circle
Scoring: $2=12-8$ correct
$1=7-3$ correct
$0=2-0$ correct 
DIGITS FORWARD

(SHEET "A")

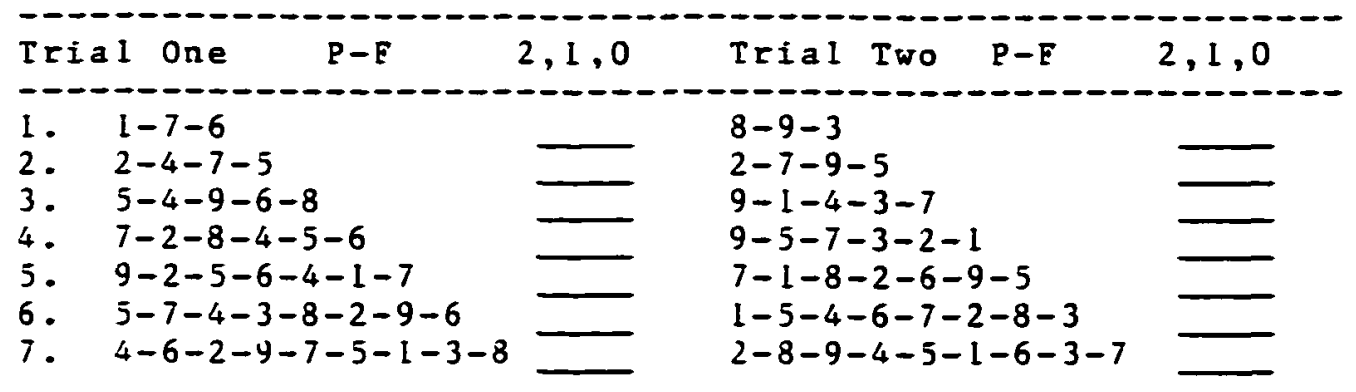

Toral Score:

\section{DIGITS BACKWARD}

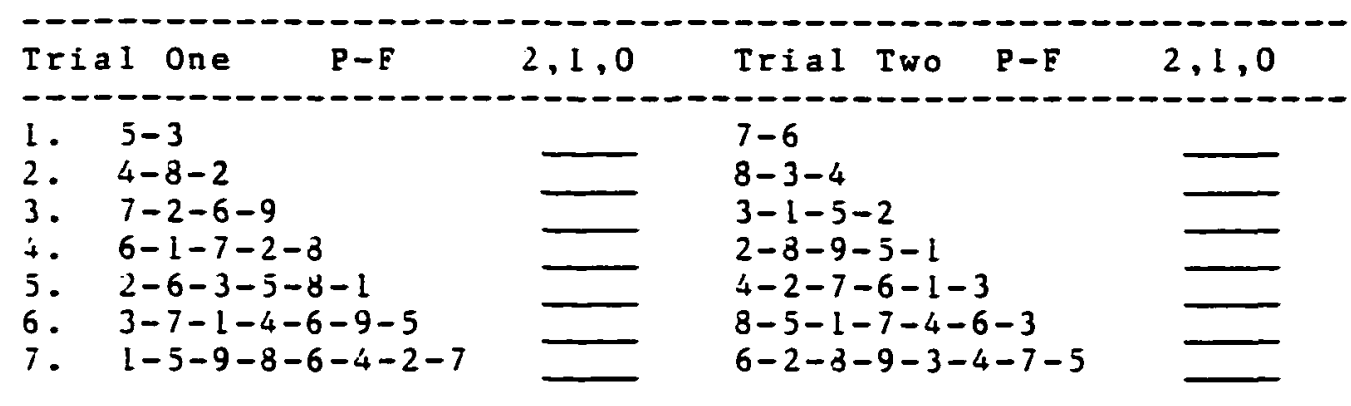

Total Score:

Reproduced with permission of the copyright owner. Further reproduction prohibited without permission. 
STIMULUS SHEET "B" (Nonsense Words)

I tems:

$\begin{array}{llll}\text { Campol Kevsuf } & \text { Gifmal } & \text { Bodin } & \text { Lustep } \\ \text { Polcam } & \text { Sufkev } & \text { Malgie } & \text { Linbod }\end{array}$

$\begin{array}{lccc}\text { RESPONSE SHEET "C" } & \text { (Nonsense Words) } \\ \text { Iasbuv } & \text { Lustep } & \text { Cagpos } & \text { Fapgen } \\ \text { Campol } & \text { Ieplus } & \text { Mibnuf } & \text { Poscag } \\ \text { Vocbem } & \text { Kevsuf } & \text { Bodlin } & \text { Pudzal } \\ \text { Polcan } & \text { Giplat } & \text { Gifmal } & \text { Bondut } \\ \text { Ketmaf } & \text { Kagnus } & \text { Sufkev } & \text { Fclis } \\ \text { Liabod } & \text { Diskug } & \text { Lekfam } & \text { Malgif }\end{array}$


Stimulus Sheet "D"
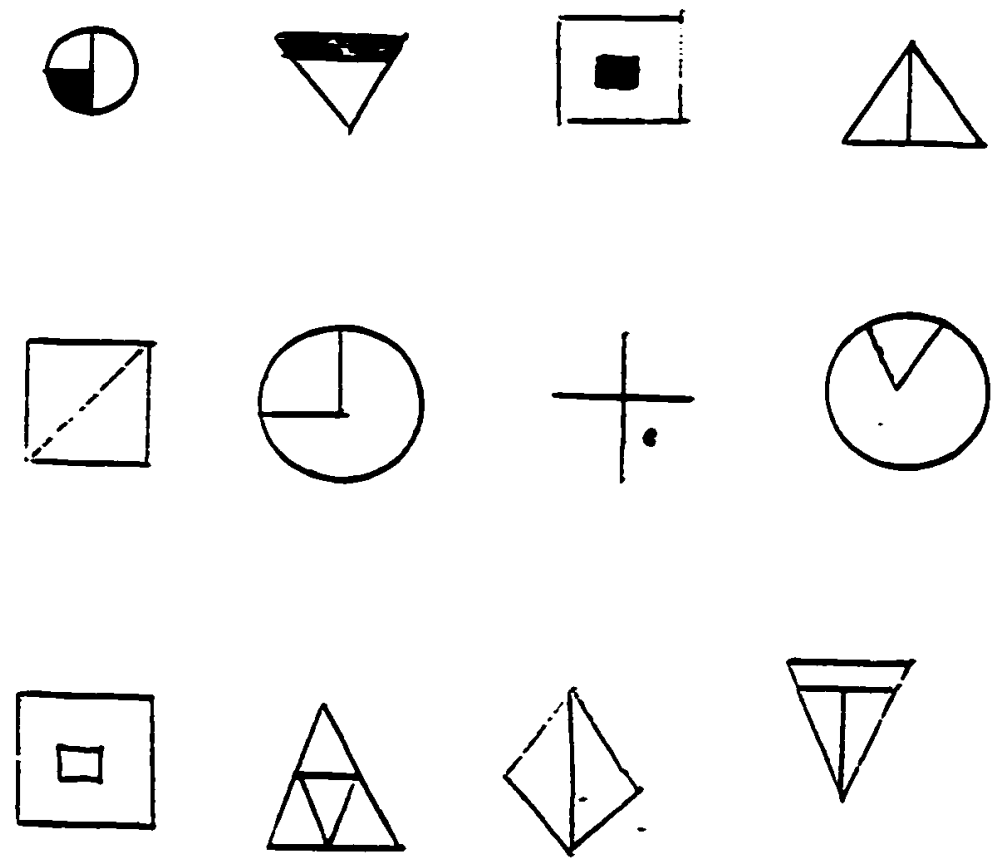

Reproduced with permission of the copyright owner. Further reproduction prohibited without permission. 
Stimulus Sheet "E"
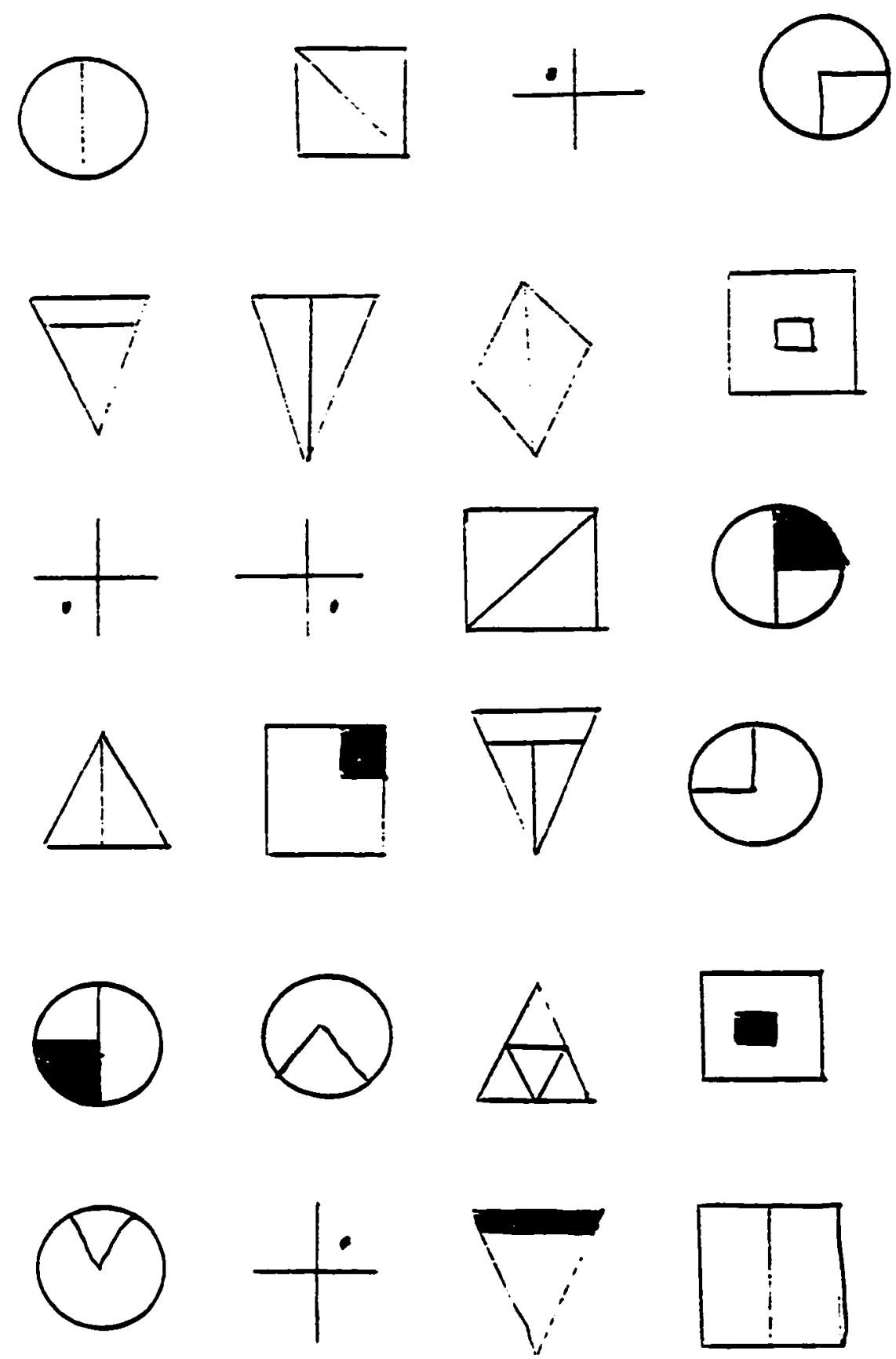


\section{1}

VISUAL PATIERN MATCHING:

STIMUUS FORMS

1.

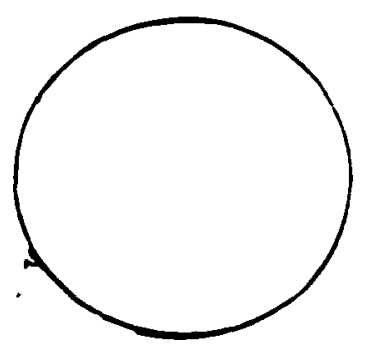

3.

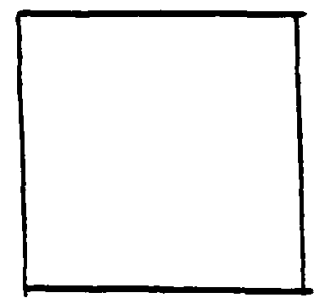

4.

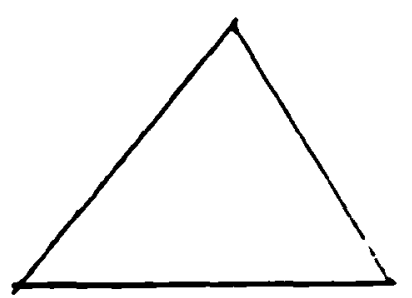

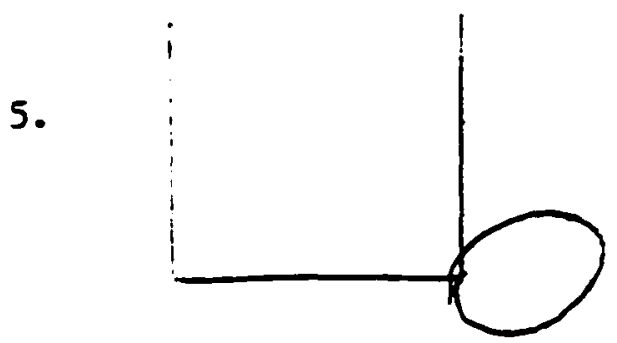

6.
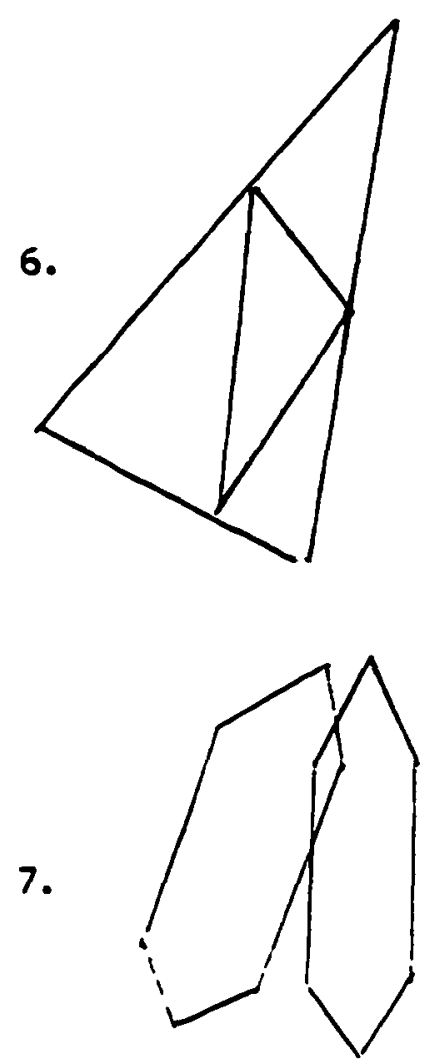

8.

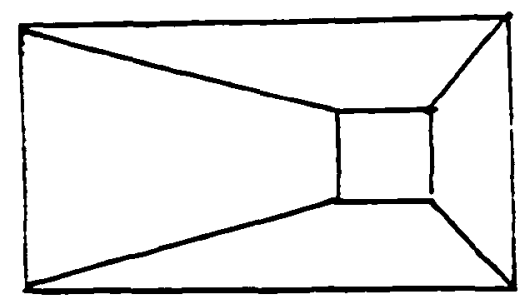

Reproduced with permission of the copyright owner. Further reproduction prohibited without permission. 
Subject

Group

RESPONSE SHEET:

Pilot Study

\section{SENTENCE REPEAT}

Directions (Comment):

Score:

Response:

\section{SYNONYMS}

Directions (Comment):

It em

Score

1. End

2. Loud

3. Right

4. Wrong

5. Duty

6. Soft

7. Under

8. Different

9. Before

10. Finish

11. Circle

12. Fact

13. Begin

14. Impossible

15. Refuse

Tot a I 
DIGITS FORWARD/BACKWARD

Directions (Comment):

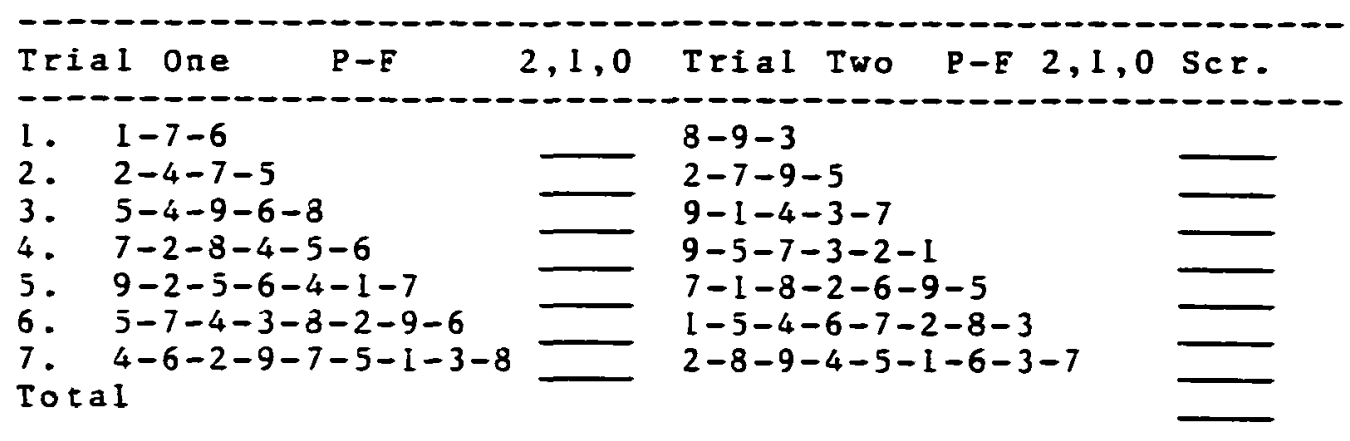

\section{DIGITS BACKWARD}

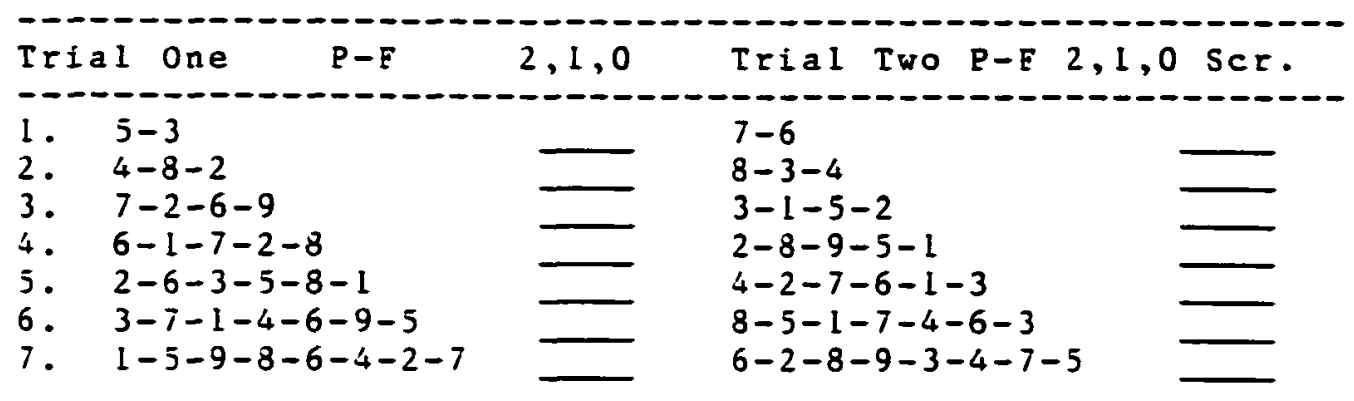

Total score:

$\frac{\text { DESIGN COPY }}{\text { Directions }}($ Comment):

Item Score

$\begin{array}{ll}1 . & \\ 2 . & \\ 3 . & \\ 4 . & \\ 5 . & \\ 7 . & \end{array}$

Total 
NONSENSE WORDS

Directions (Comment):

Score $(0-2=0 ; 3-4=1 ; 5-10=2)$ :

(Give STIMULUS SHEET A to subject. Time I $20 "$

Give STIMULUS SHEET B to subject after $120^{\prime \prime}$ to check off.)

VISUAL PATTERN MAICHING

Directions (Comment):

Score $(12-9=2 ; 8-5=1 ; 4-0=0):$

(Give Stimulus SHEET C to subject. Time $120 "$.

Give STIMULUS SHEET D to subject after $120^{\prime \prime}$ to check off

items.)

\section{SUMMARY SCORES}

Subtest

Total Score

Sentence Repeat

Synonyms

Digits Forward/Backward

Design Copy

Nonsense Words

Visual Pattern Matching

Total Score MPG 
STIMULUS SHEET A (Nonsense Words

Items:

$\begin{array}{llll}\text { Zrok } & \text { Simu } & \text { Bilo } & \text { Vron } \\ \text { Sawl } & \text { Delo } & \text { Misa } & \text { Trog } \\ \text { Rast } & \text { Kist } & \text { Grot } & \text { Seta } \\ \text { Jina } & \text { Tesa } & \text { Tiso } & \end{array}$

RESPONSE SHEET B (Nonsense Words)

Zrok Simu Bilo Acti Delo Misa Tiso Char Jrok

Bit Nicl Frin Jina Kelo Seta Vron Loki Wrek

Reil Grot Sawl Crui Jita Tuni Boli Trog Nija

Kroz Nirf Tesa Bosa Poti Kist Taci Rast Polt

Goti Wirt Riga Loni 
RESPONSE SHEET:

Final Revision

Michigan Patterned Gestalt

Time Start

Time End

Group :

SENTENCE REPEAT

(VLD/STD or control)

Response:

Score:

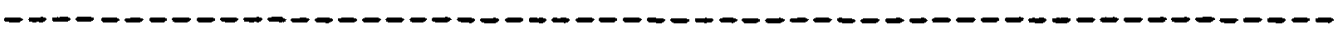

SYNONYMS

Directions (Comment):

Item

Response

Score

1. Fast

2. Loud

3. Begin

4. Respect

5. Look

6. Suft

7. Under

8. Different

9. Before

10. Finish

11. Circle

12. Work

13. Gigantic

14. Impossible

Reproduced with permission of the copyright owner. Further reproduction prohibited without permission. 


\section{Refuse}

\section{Total}

\section{DIGITS FORWARD/BACKWARD}

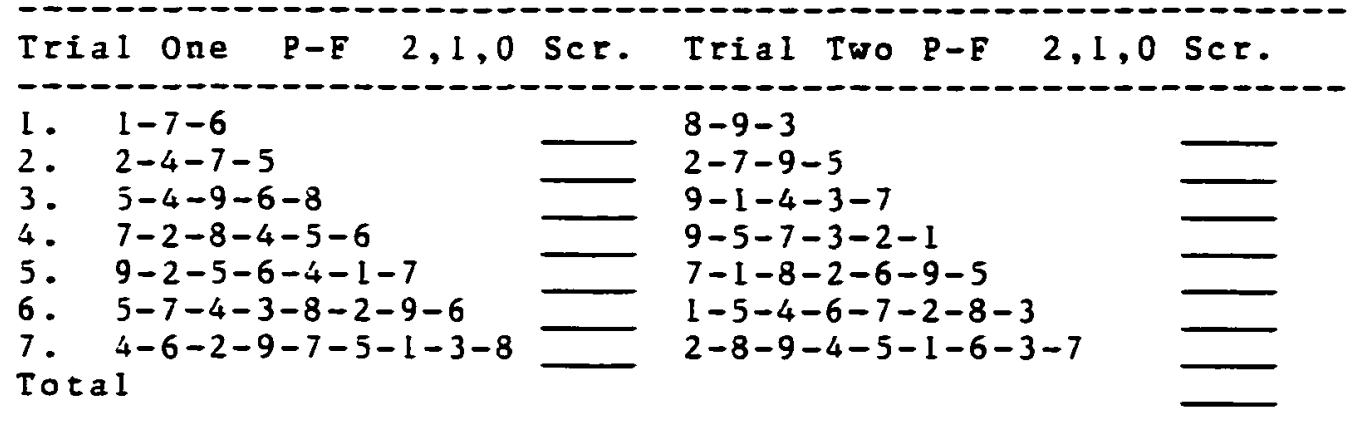

\section{DIGITS BACKWARD}

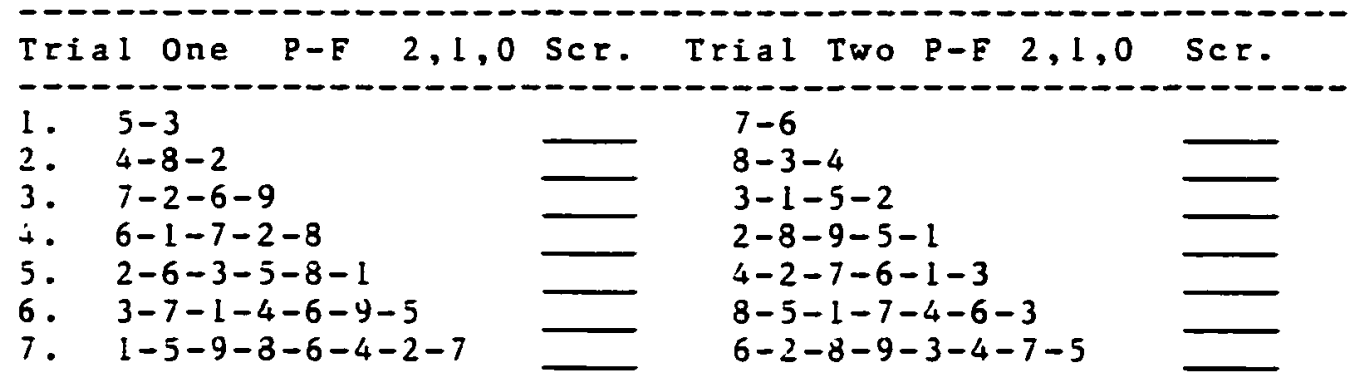

Total Score: 


\section{DESIGN COPY}

$\begin{array}{ll}\text { Item } & \text { Score } \\ 1 . & \\ 2 . & \\ 3 . & \\ 4 . & \\ 5 . & \\ 6 . & \\ 7 . & \end{array}$

Total

NONSENSE WORDS

Score $(0-2=0 ; 3-4=1 ; 5-10=2)$ :

(Give STIMULUS SHEET A to subject. Time 60". Give STIMULUS SHEET B to subject after 120 " to circle.)

VISUAL PATIERN MATCHING

Directions (Comment):

Score $(12-9=2 ; 8-5=1 ; 4-0=0):$

(Give Stimulus SHEET C to subject. Time 120".

Give STIMULUS SHEET D to subject after (20" to circle.)

SUMMARY SCORES

Subtest

Total Score

Sentence Repeat

Synonyms

Digits Forward/Backward

Design Copy

Nonsense Words

Visual Pattern Matching 
APPENDIX C

(Raw Data)

Reproduced with permission of the copyright owner. Further reproduction prohibited without permission. 


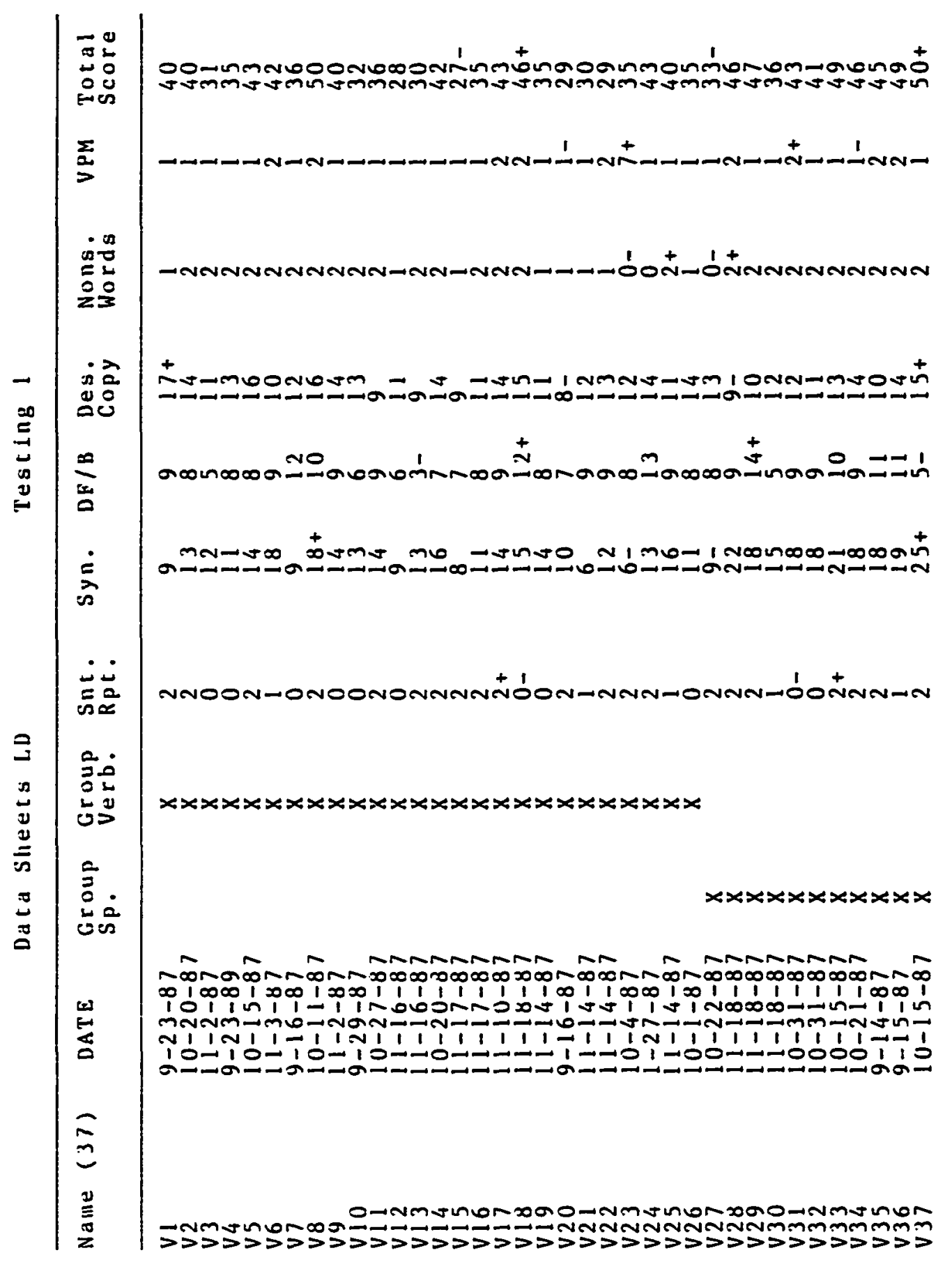

Reproduced with permission of the copyright owner. Further reproduction prohibited without permission. 


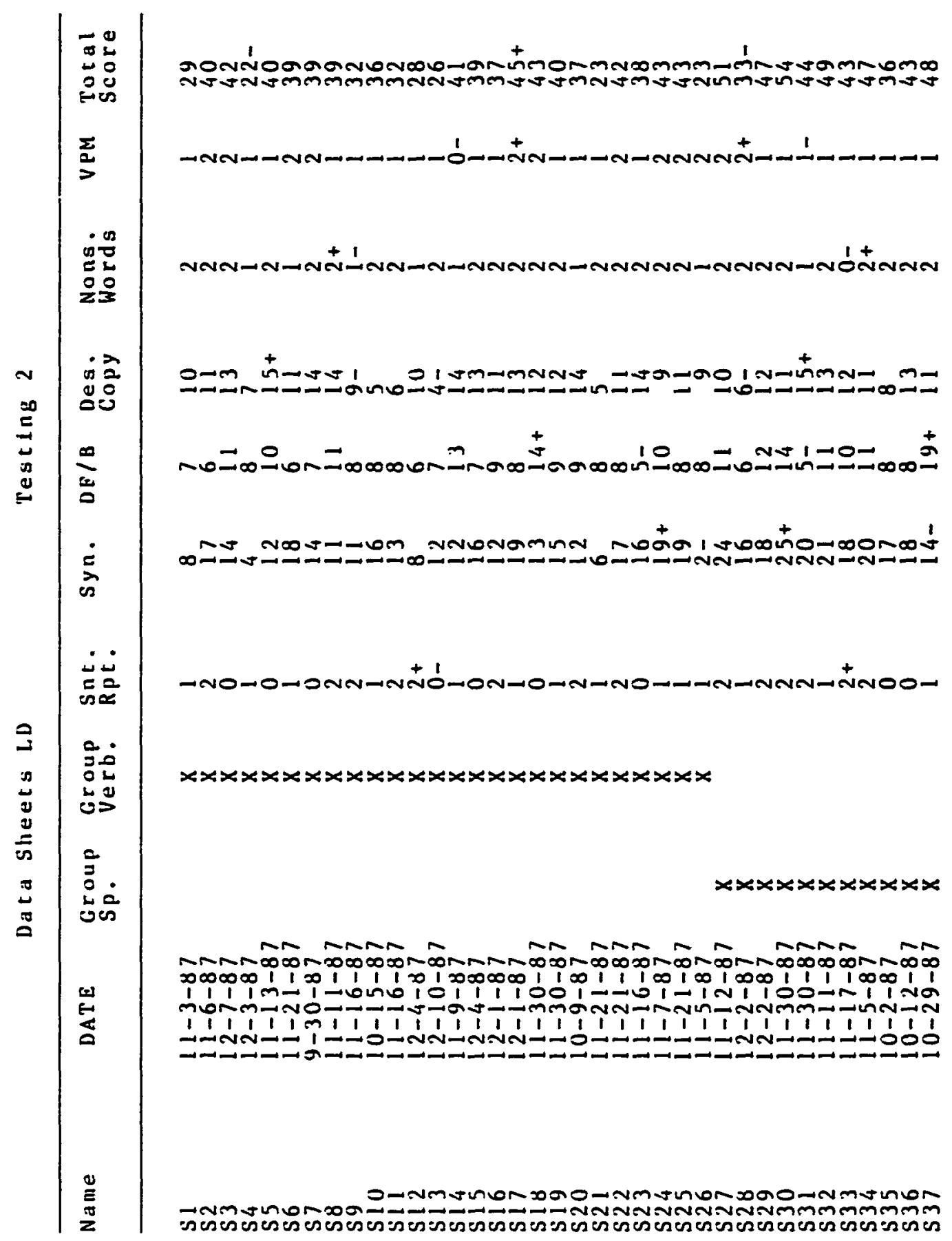

Reproduced with permission of the copyright owner. Further reproduction prohibited without permission. 


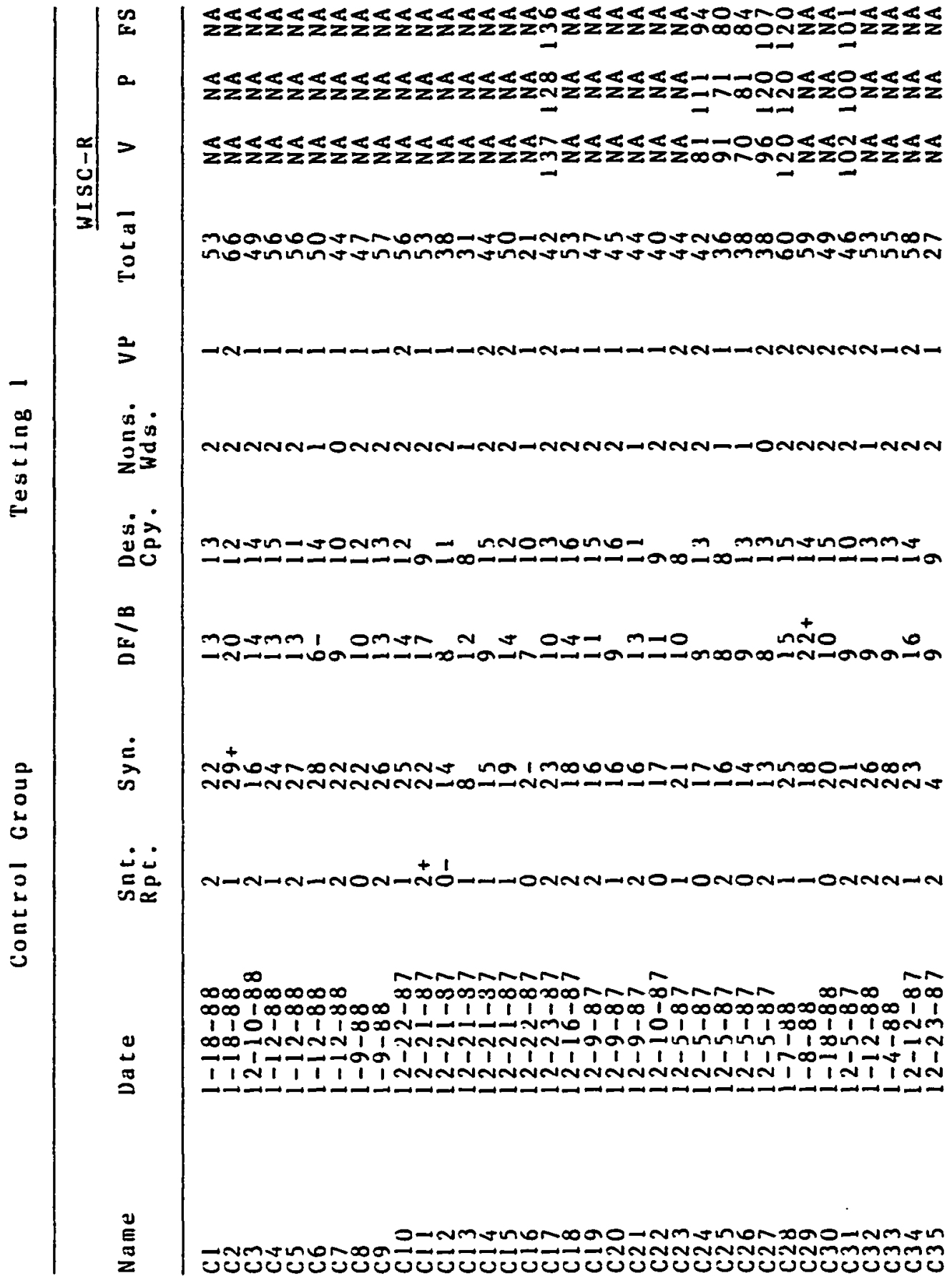

Reproduced with permission of the copyright owner. Further reproduction prohibited without permission. 


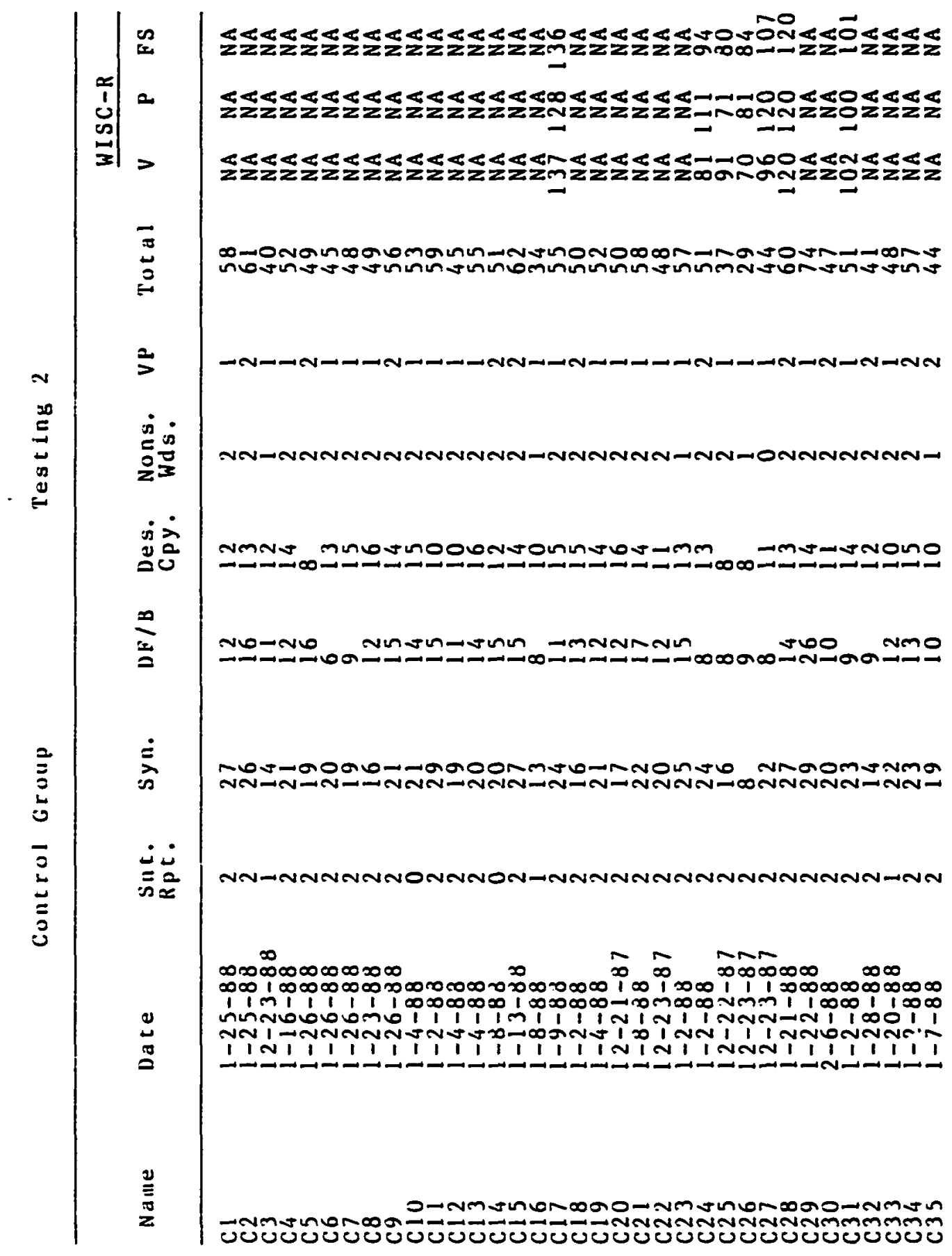

Reproduced with permission of the copyright owner. Further reproduction prohibited without permission. 


\section{AP PENDIX D}

TABLES NOT USED IN THE STUDY 
D) 1

Means and Standard Deviations For All Variables Post-

Test conditions

\begin{tabular}{|c|c|c|c|c|c|}
\hline \multirow[t]{3}{*}{ Subtest } & \multicolumn{3}{|c|}{ Group } & & \\
\hline & \multirow{2}{*}{$\begin{array}{l}\text { Verbally } \\
\text { Impaired } \\
\underline{x}\end{array}$} & \multirow{2}{*}{$\left(\underline{S}^{26)}\right.$} & \multirow{2}{*}{ 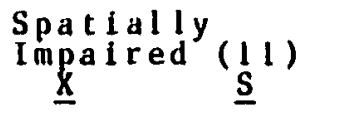 } & \multirow{2}{*}{\multicolumn{2}{|c|}{$\begin{array}{cr}\text { Control } & (35) \\
\underline{x} & \underline{s}\end{array}$}} \\
\hline & & & & & \\
\hline $\begin{array}{l}\text { Sentence Repeat } \\
\text { [Possible Range } 0-2 \text { l }\end{array}$ & 1.0385 & 0.774 & 1.3636 & 1.8000 & 0.531 \\
\hline $\begin{array}{l}\text { Synonyms } \\
\text { [Possible Range } 0-30 \text { I }\end{array}$ & 12.9231 & 4.525 & 19.1818 & 20.0857 & 4.683 \\
\hline $\begin{array}{l}\text { Digits Forward/ } \\
\text { Backwards } \\
{[\text { Possible Range 0-2] }}\end{array}$ & 8.4321 & 2.101 & 10.45453 .082 & 12.2571 & 3.665 \\
\hline $\begin{array}{l}\text { Design Copy } \\
\mid \text { Possible Range } 0-16 \mid\end{array}$ & 10.7692 & 2.984 & 11.0909 & 12.6001 & 2.329 \\
\hline $\begin{array}{l}\text { Nousense Words } \\
\text { [Possible Range } 0-2 \text { ] }\end{array}$ & 1.7308 & 0.452 & 1.7273 & 1.8007 & 0.473 \\
\hline $\begin{array}{l}\text { Visual Pattern } \\
\text { Matcning } \\
\text { [Possible Range } 0-2 \text { ] }\end{array}$ & 1.3462 & 0.562 & 1.1818 & 1.3429 & 0.482 \\
\hline
\end{tabular}


D 2

Corcelated Samples T-Test Pre-Post Test

Verbal Group Means

\begin{tabular}{|c|c|c|c|c|}
\hline Variable & $\begin{array}{l}\text { Pre-Test } \\
\text { Mean }\end{array}$ & $\begin{array}{l}\text { Post Test } \\
\text { Mean }\end{array}$ & I & $\mathbf{P}$ \\
\hline Sentence Repeat & I. 1923 & 1.0385 & 0.7001 & .490 \\
\hline synonyms & 12.2692 & 12.9231 & -0.7283 & .473 \\
\hline $\begin{array}{c}\text { Digies Forward/ } \\
\text { Backwards }\end{array}$ & 8.3077 & 8.4231 & -0.2239 & .825 \\
\hline Design Copy & 12.4231 & 10.7692 & 2.4680 & $.021 *$ \\
\hline Nonsense Words & 1.5385 & 1.7308 & -1.2243 & .232 \\
\hline $\begin{array}{c}\text { Visual Pattern } \\
\text { Matching }\end{array}$ & 1.4231 & 1.3462 & 0.2962 & .770 \\
\hline Total score & 37.1538 & 36.2308 & 0.7209 & .9231 \\
\hline
\end{tabular}

Reproduced with permission of the copyright owner. Further reproduction prohibited without permission. 
D 3

Correlated Samples T-Test Pre-Post Test

Spatial Group Means

\begin{tabular}{lcccc}
\hline Variable & $\begin{array}{l}\text { Pre-Test } \\
\text { Mean }\end{array}$ & $\begin{array}{l}\text { Post } \\
\text { Mean }\end{array}$ & I & P \\
\hline Sentence Repeat & 1.4545 & 1.3636 & 0.2654 & .796 \\
Synonyms & 18.2727 & 19.1818 & -0.4260 & .679 \\
$\begin{array}{l}\text { Digits Eorward/ } \\
\text { Backwards }\end{array}$ & 9.0909 & 10.4545 & -0.7988 & .443 \\
$\begin{array}{l}\text { Design Copy } \\
\text { Nonsense Words } \\
\text { Visual Pattern } \\
\text { Matching }\end{array}$ & 12.0909 & 11.0909 & 1.4015 & .191 \\
$\begin{array}{l}\text { Total Score } \\
\text { Sal }\end{array}$ & 1.8182 & 1.7273 & 0.3194 & .756 \\
\hline
\end{tabular}

Reproduced with permission of the copyright owner. Further reproduction prohibited without permission. 
D 4

Correlated Samples T-Test Pre-Post Test

Control Group Means

\begin{tabular}{lcccc}
\hline Variable & $\begin{array}{l}\text { Pre-Test } \\
\text { Mean }\end{array}$ & $\begin{array}{l}\text { Post Test } \\
\text { Mean }\end{array}$ & $T$ & $P$ \\
\hline Sentence Repeat & 1.2571 & 1.8000 & -3.4964 & $.001 *$ \\
Synonyms & 19.2286 & 20.6857 & -1.3402 & .189 \\
$\begin{array}{l}\text { Digits Forward/ } \\
\text { Backwards }\end{array}$ & 11.4857 & 12.2571 & -2.0521 & $.048 *$ \\
$\begin{array}{l}\text { Design Copy } \\
\text { Nonsense Words } \\
\text { Visual Pattern } \\
\text { Matching }\end{array}$ & 12.2571 & 12.6000 & -0.7281 & .472 \\
$\begin{array}{l}\text { Total Score } \\
\text { Sotal }\end{array}$ & 1.6857 & 1.8000 & -1.1604 & .254 \\
\hline
\end{tabular}

Reproduced with permission of the copyright owner. Further reproduction prohibited without permission. 
D 5

Analysis of Variance Postest

\begin{tabular}{lcc}
\hline Variable & $F$ & $P$ \\
\hline Sentence Repeat & 9.7243 & $.0002 *$ \\
Synonyms & 23.4866 & $.0000 *$ \\
Digits Fo-ward/Backwards & 10.5534 & $.0001 *$ \\
Design Copy & 4.0515 & $.0217 *$ \\
Nonsense Words & .1815 & .8344 \\
Visual Pattern Matching & .4877 & .6161 \\
Total Test & 25.3651 & $.0000 *$ \\
\hline
\end{tabular}

Reproduced with permission of the copyright owner. Further reproduction prohibited without permission. 
D 6

\section{Discriminant Function Post-Test}

\begin{tabular}{|c|c|c|c|c|}
\hline Variable & \multicolumn{2}{|l|}{ Name } & $\begin{array}{l}\text { Standard } \\
\text { Function }\end{array}$ & Discr. \\
\hline 1. & \multicolumn{2}{|c|}{ Sentence Repeat } & 4.5887 & (2) \\
\hline 2 . & \multicolumn{2}{|l|}{ Synonyms } & 7.8636 & ( I) \\
\hline 3. & \multicolumn{2}{|c|}{ Digits Eorward/Backwards } & 3.8821 & $(3)$ \\
\hline 4. & \multicolumn{2}{|c|}{ Design Copy } & .4136 & (6) \\
\hline 5 & \multicolumn{2}{|c|}{ Nonsense Words } & -1.5772 & (4) \\
\hline 6. & Visual & Pattern Matching & -1.3789 & (5) \\
\hline \multicolumn{2}{|c|}{$2=52.7324$} & \multicolumn{2}{|c|}{ Group } & ean \\
\hline \multicolumn{2}{|c|}{$D F=12$} & \multicolumn{2}{|c|}{ Spatially HCP'd } & 5.878 \\
\hline \multirow[t]{2}{*}{$P=$} & \multirow{2}{*}{.0000} & \multicolumn{2}{|c|}{ Verbally Hcp'd } & 3.922 \\
\hline & & \multicolumn{2}{|l|}{ Control } & 6.766 \\
\hline
\end{tabular}


D 7

Classification Matrix Post-Test

\begin{tabular}{lcccc}
\hline Group & Control & Verbal & Spatial & Total \\
\hline Control & 24 & 3 & 8 & 35 \\
Verbal & 0 & 13 & 3 & 26 \\
Spatial & 5 & 2 & 4 & 11 \\
Total & 29 & 28 & 15 & \\
\hline
\end{tabular}

Reproduced with permission of the copyright owner. Further reproduction prohibited without permission. 
REFERENCE LIST

Reproduced with permission of the copyright owner. Further reproduction prohibited without permission. 
Ackerman, P. T., Dykman, R. A., Oglesby, D. M. (1983). Sex and grade differences in reading and attention disordered children without hyperkinesis. Journal of Learning Disabilities, 16; $407-415$.

Ames, Lousie B. (1985). Learning disabilities--very big around here. Research Communication in Psychology, Psychiatry and Behavior, 10, 17-35.

Anastasi, Anne ( 1976 ). Psycholgocial Testing. New York: MacMillan Publishing Co., Inc.

Anderson, R. P., Holcomb, C. G., S Doyle, R. B. (1973). The measurement of attentional deficits. Exceptional Children, 39,534-539.

Aaron, P. G. (1981). Diagnosis and remediation of learning disabilities in children--A neuropsychological approach. In G. W. Hynd, J. E. obrzut, (Eds.), Neuropsychological assessment and the school-aged child. New York: Grune and stratton.

Aviezer, Y., \& Seymour, S. (1980, June/July). Variability and instability in perceptual and reading functions of brain-injured children. Journal of Learning Disabilities, $13,41-46$.

Ayres, A. (1972). Improving academic scores through sensory integration. Journal of learning disabilities, $\underline{5}, 339-343$.

Bakker, D. J. (1979). Hemispheric differences and reading strategies: Two dyslexias? Bulletin of the Orton Society, 29, 84-97.

Banbury, Mary M. (1986). What are learning disabilities? pamphlet: AFT Teacher's Network for Education of the Handicapped. Division of Personnel Preparation: U.S. Office of Special Education and Rehabilitative Services. 
Bennett, Randy E. ( 1980$)$. The use of grade and age equivalent scores in education assessment. Diagnostique, I, 139-145.

Benton, A. L., \& Pearl, D. (Eds.). (1978). Dyslexia: An appraisal of current knowledge. New York: Oxford University Press.

Benton, A. (1975). Developmental dyslexia: Neurological aspects. In W. J. Friedlander (Ed.), Advances in neurology. I New York: Raven Press.

Berk, R. A. ( $(1982)$. Verbal-performance IQ discrepancy score: A comment on reliability, abnormality, and validity. Journal of Clinical Psychology, 38 , 638-641.

Berk, R. A. ( 1983 ). The value of WISC-R profile analysis for the differential diagnosis of learning disabled students. Journal of Clinical Psychology 39, 133-136.

Bever, T. G. (1975). Cerebral asymetries in humans are due to the differentiation of two incompatible processes: holistic and analytic. In D. Aaronson and R. Rieber (Eds.), Developmental psycholinguistics and communication disorders. New York: New York Academy of Sciences.

Black, William F. ( 1976$)$. Cognitive, academic, and behavioral findings in children with suspected and documented neurological dysfunction. Journal of Learning Disabilities, $9,182-187$.

Bloom, A. S., \& Raskin, L. M. (1980). WISC-R verbalperformance IQ discrepancies: A comparison of learning disabled children to the normative sample. Journal of Clinical Psychology, 36 , $322-323$.

Bogen, J. E., Eischer, E. D., \& Vogel, P. J. í965, December). Cerebral commissurotomy: A second case report. Journal of the American Medical Association, 194, 1328-1329.

Bogen, J. E. ( 1969$)$. The other side of the brain I: Dysgraphia and dyscopia following cerebral commissurotomy. Bulletin of the Los Angeles Neurological Societies, 34, 73-105. 
Boll, Thomas J. (1978). Diagnosing brain impairment. In B. Wolman (Ed.), Diagnosis of mental disorders: A handbook 601-675 New York: Plenum Press.

Boll, Thomas J., \& Filskov, S. B. (I981). Handbook of cIinical neuropsychology. New York: John Wiley and Sons.

Boll, T. (1972). Conceptual versus perceptual versus motor deficits in brain damaged children. Journal of Clinical Psychology, 28, 157-159.

Boll, T. (1974). Behavioral correlates of cerebral damage in children aged 9-14. In R. Reitan and L. Davidason (Eds.), Clinical neuropsychology: Current status and applications (pp. 9I-120). Washington, DC: V.H. Winston and Sons.

Boll, T. J., \& Reitan, R. M. (1972). Comparative ability interrelationships in normal and brain-damaged children. Journal of Clinical Psychology, 28 , $152-156$.

Boll, T. J., \& Barth, J. T. (1981). Neuropsychology of brain damage in children. In S. B. Filskov and T. J. Boll, Handbook of clinical neuropsychology. New York: Wiley.

Bower, G. H., Hildegard, E. R. (1981). Theories of learning (5th ed.). Englewood Cifffs, NJ: Prentice-Hall.

Brazelton, T. B., Ironick, E., Adamson, L., Als, H., \& Weise, S. (1975). Early mother-infant reciprocity. In Parent-Infant Interaction. 22 CIBA Symposium. New York: Elsevier.

Broadbent, D. E. ( 1952$)$. Listening to one of two synchronus messages. Journal of experimental psychology, $44,5 \mathrm{i}-54$.

Broman, M. ( 1978$)$. Reaction-time differences between the left and right hemispheres for face and letter discrimination in cinildren and adults. Cortex, 14, $578-59 \mathrm{~L}$.

Brown, Ann L., \& Campione, J. C. (1986). Psychological theory and the study of learning disabilities. American Psychologist, 14, 1059-1068. 
Carmen, Amiram, Nashon, Israel, Starinsky, R. (I976, October). Developmental aspects of visual hemifield differences in perception of verbal material. Brain and Language, $\underline{3}, 463-469$.

Cherkes, M., \& Ryan, L. (1985). Bias inspecial education decision making. Academic Therapy, 20, 323-329.

Coles, Gerald. (1988, June/July). The learning mystique: A critical look at learning disabilities, 13, 41-

Corbalis, M. C. (1980, March). Laterality and myth. American Psychologist, 35, 284-295.

Cordoni, B. ((1982). A directory of college LD services. Journal of Learning Disabilities, 15, 529-534.

Costa, L. D. (1975). The relation of visuospatial dysfunction to digit span performance in patients with cerebral leisons. Cortex, $11,31-36$.

Coutts, R. L., Lichstein, L., Bermudez, J. M., Daigle, M., Mann, D. P., Charbonnel, I. S., Michaud, R., \& Williams, C. R. (1987). Treatment assessment of learning disabled children: Is there a role for Erequently repeated neuropsychological testing? Archives of Clinical Neuropsychology, $\underline{2}$, 237-244.

Culbertson, Wm. C., \& Doberty, Ed. M. (1982). Four-year reliability of a test of learning problems. Journal of Experimental Education, 50, I85187 .

Dean, R. S., Schwartz, N. H., \& S ith, L. S. (1981). Lateral preference patterns as a discriminator of learning disabilities. Journal of Consulting and Clinical Psychology, 49, 227-235.

Dee, H. L. (1970). Visuoconstructive and visuoperceptive deficit in patients with unilateral cerebral leisons. Neuropsychologia, $8,305-314$.

Dewolf, A. S. (1971). Differentiation of schizophrenia and brain danage with the WAIS. Journal of Clinical-Psychology, 27, 246-250.

Dictionary of Behavioral Sciences. (1973). New York: Van Nostrand. 
Duane, D. (1979). Theories about the causes of dyslexia and their implications. Pediatrics Annual, $\underline{8}$, $641-647$.

Dudley-Marling, C. C. (1985). Perceptions of the usefulness of the IEP by teachers of learning disabled and emotionally disturbed children. Psychology in the Schools, 22, 65-67.

Dumont, Joep J. (Dec. 1981). Learning disabilities: Definitions and critique. Vierteljahnesschrift fur heilpadagogik und ihre nachbargebiete, 50, 241252 .

Epstein, Michael H., Cullinan, D., \& Rosenier, R. (1983, Summer). Behavior problem patterns among the learning disabled: Boys aged 6-1 1 . Learning Disability Quarterly, 6, 305-311.

Erahart, C., Graham, F., Eichman, P., Marshal 1 , J., \& Thurstone, D. (1963). Brain injury in the preschool child: Some developmental considerations: II. comparison of brain injured and normal children. Psychological Monographs, 77, 17-33.

Eederal Register: Department of Health, Education, and Welfare: Office of Education. ( 1977 , August). Education of handicapped children: Implementation of Part $B$ of the Education of the Handicapped Act, P.L. $94-142$.

Fischer, Wyman, E., Dean, R. S., Rattan, G., Nickell, K. (1986). Neuropsychological reference groups for 9-through-14-year-old subjects with identified learning disabilities. Archives of Clinical Neuropsychology, $1,111-119$.

Fisk, J. L., \& Rourke, B. P. (1979). Identification of subtypes of learning-disabled children at three age levels: A neuropsychological, multivariate approach. Journal of Clinical Neuropsychology, 1 , $289-310$.

Fisk, J. L., \& Rourke, B. P. (1983). Neuropsychological subtyping of learning disabled children: History, methods, and implications. Journal of Learning Disabilities, 16 , 529-531. 
Galaburda, A. M., LeMay, M., Kemper, Thomas L., \& Geschwind, Norman. (1978, February). Right-left asymetries in the brain. Science, 199, 852-856.

Gasparrini, W., Shealy, C., \& Walters, D. (1980, october). Differences in size and spatial placement of drawings of left versus right hemisphere brain-damaged patients. Journal of Consulting and Clinical Psychology, 48, 673-674.

Gazzaniga, M. S. (1973). Brain theory and minimal brain dysfunction. Annals of the New York Academy of Sciences, 205, 89-92.

Gazzaniga, M. S. (1977). Consistency and diversity in brain organization. In S. J. Diamond and J. G. Beaumont (Eds.), Evolution and lateralization of the brain. Annals of the New York Acadamey of Science, 299, 415-423.

Gazzaniga, M. S. ( 1967 , August). The split brain in man. Scientific American, 217, 24-29.

Gazzaniga, M. S. (1970). The bisected brain. New York: Appleton-Century-crofts.

Geary, D.C., Jennings, S. M., Schultz, D. D., \& Alper, T. G. (1984). The diagnostic accuracy of the Luria-Nebraska Neuropsychological Battery Children's Revision for 9-12 year old LD children. School Psychology Review, 13, 375-380.

Geffin, G. (1978). The development of the right ear advantage in dichotic listening with focused attention. Cortex, 14, 169-177.

German, Diane. (1983). Analysis of word finding disorders on the Kaufman-Assessmenc Battery for Children (K-ABC). Evanston: (Reprint) Foster G. MeGraw Graduate Scinool.

Goldberg, H. K., \& Shiffman, G. B. (1972). Dyslexia. New York: Grune and Stratton.

Golden, Charles. (1978). Diagnosis and rehabilitation in clinical neuropsychology. Springfield: Charles C. Thomas. 
Goldstein, Gerald. (I984). Neurological aspects of learning disabilities. A training program in specific learning disability for rehabilitation psychologists. Department of Psychiatry: University of Pittsburgh School of Medicine, Western Psychiatric Institute and Clinic.

Graden, J. L. (1986). Referral and decision-making for learning disabilities: Implications for needed directions. Counterpoint, $7,4$.

Graham, F. K., Ernhart, C. B., Thurstone, D., \& Craft, M. (1962). Development three years after perinatal anoxia and other potentially damaging newborn experiences. Psychological Monographs, 76, Whole Number 522 .

Groff, C. V. (1986). A study of hemispheric preference as it relates to reading and recalling nonsense words Erom a card reader. Doctoral dissertation, Andrews University, Berrien Springs, MI.

Hamill, D. D., Leigh, J. E., McNutt, G., \& Larsen, S. C. (1982). A new definition of learning disabilities. Learning Disabilities Quarterly, 4 , 336-342.

Harris, W. J., \& King, D. R. (1982). Achievement, sociometric status, and personality characteristics of children selected by their teachers as having learning and/or behavior problems. Psychology in the Schools, 19, 452-457.

Hartlage, L. C., \& Telzrow, C. F. (1983). The neuropsychological bases of educational intervention. Journal of Learning Disabilities, $16,521-528$.

Hartiage, L. C., \& Telzrow, C. F. (1986). Neuropsychological assessment and intervention with children and adolescents. Sarasota: Professional Resource Exchange.

Herbert, M. (1964). The concept and testing of brain damage in cinildren: A review. OUB Journal of Child Psychology and Psychiatry, $5,197-217$.

Herron, J. (1980). Neuropsychology of left-handedness. New York: Academic Press. 
Highman, C., \& Morris, V. (I987, April). Linguistic stress judgments of language learning disabled students. Journal of Communication Disorders, 74, 93-103.

Holroyd, J., \& Wright, F. (1965). Neurological implications of WISC verbal-performance discrepancies in a psychiatric setting. Journal of Consulting Psychology, 29, 206-212.

Hynd, G. W., Hayes, F., Snow, J. (I982). veuropsychological screening with school age children: Rationale and conceptualization. Psychology in the Schools, $19,446-451$.

Indiana State Board of Education. (1978, June). Rule S1. State of Indiana.

Indiana Council of Administrators of Special Education. ( 1987 , February). Learning disability: Questions and responses to definition and eligibility criteria-guidelines for implementation.

Johnston, C. (1984). The learning disabled adolescent and young adult: An overview and critique of current practices. Journal of Learning Disabilities, 17 , 386-391.

Josciko, M., \& Rourke, B. P. (1985). Neuropsychological subtypes of learning-disabled children who exhibit the ACID pattern on the WISC. In B. P. Rourke (Ed.), Neuropsychology of learning disabilities: essentials of subtype analysis. New York: Guilford Press.

Kaufman, Alan S. (1979). Intelligence testing with the WISC-R. New York: John Wiley and Sons.

Kinsbourne, M., \& Hiscock, M. (1981). Cerebral lateralization and cognitive development: conceptual and methodological issues. In G. W. Hynd and J. E. Obrzut, Neuropsychological assessment of the school-aged child: Issues and procedures (pp. 125-152). New York: Grune and Stratton.

Koomar, J. A., Cermak, S. Q. ( 1981 , July). Reliability of dichotic listening using two stimulus format with normal and learning-disabled children. American Journal of Occupational Therapy, 35, 456463 . 
Kosc, L. ( 1987 , January/February). Learning disabilities: Definition or specification? A response to Kavale and Forness. RASE: Remedial and Special Education, 8, 36-4l.

Lawson, J. S., \& IngIis, J. (1984). Psychometric assessment of children with learning disabilities using the WISC-R. Journal of Learning Disabilities, $17,517-522$.

LD State Update: Minnesota. MN SEA/OSED Cooperative Agreement, Minnesota Dept. of Educationa, 1987 .

Leong, Che Kan. (1980). Laterality and reading proficiency in children. Reading and Research Quarterly, $15,18 \overline{5-202}$.

Leggett, Curtis L. Learning disabilities identification criterion. A proposal Submitted to the South Bend Community School Corporation, 1986.

Lerner, J. W. (1934). Learning disabilities: A field in transition. Chicago: Northeastern IIInois University. (handout)

Levitt, R. A. ( 1981 ). Physiological psychology, New York: Holt, Rinehart and Winston.

Lezak, Muriel D. ( 1976$)$. Neuropsychological assessment. New York: Oxford University Press.

Lezak, Muriel D. ( 1981 ). Neuropsychological assessment. New York: Oxford University Press.

Licht, Barbara D. (1983). Cognitive-motivational factors that contribute to the achievement of learningdisabled children. Journal of Learning Disabilities, $\underline{16}, 483-488$.

Lishman, W. A. (1978). Organic psychiatry: The psychological consequences of cerebral disorder. London: Blackwell Scientific Publishing.

Lubar, J.F., \& Deerinz, W. M. (1981). Behavioral approaches to neurology. New York: Academic Press.

Lyon, R., Stewart, N., \& Freedman, D. ( 1982$)$. Neuropsychological characteristics of empirically derived subgroups of learning disabled readers. Journal of Clinical Neuropsychology, 4 , 343-345. 
Matthews, C. G. (1974). Applications of neuropsychologial test methods in mentally retarded subjects. In R. M. Reitan \& L. A. Davidson, Clinical neuro-psychology: Current Status and applications. Washington D.C.: Winston.

Mauer, A. L. (1984). Various psychological/social characteristics of learning disabilities. (Handout)

McCue, M. (1984, May). Assessment and rehabilitation of learning-disabled adults. Rehabilitation Counseling Bulletin, pp. $28 \overline{1-290}$.

McFie, J. (1975). Assessment of organic intellectual impairment. London: Academic Press.

Mckeever, W. F. (1977). Lateralized tachistoscopic recognition, cerebral dominance, and dyslexia. Bulletin of the orton Society, 27, 26-36.

Mckinney, J. D. (1985). The search for subtypes of specific learning disabilities. Annual Progress in Child Psychiatry and Child Development, 73, 542-559.

McNeil, Malcom R., \& Hamre, C. E. (1974, June/July). A review of measures of lateralized cerebral hemispheric functions. Journal of Learning Disabilities, $7,375-436$.

Menkes, John H. (1980). Textbook of child neurology. (2nd ed.) Philadelphia: Lea and Febiger.

Meyer, V. (196I). Psychological effects of brain damage. In H. J. Eysenck (Ed.), Handbook of Abrormal Psychology. New York: Basic Books.

Meyer, V., \& Yates, A.J. (1955). Intellectual changes following temporal lobectomy for psychomotor epilepsy. Journal of Neurology, Neurosurgery, and Psychiatry, 13, 44-52.

Miller, Maurice. ( 1980 , June/July). On the at tempt to find WISC-R profiles for learning and reading disabilities. Journal of Learning Disabilities, $13,338-340$. 
183

Miller, M. ( $1978 \mathrm{~b})$. WISC subpatterns in two learning disabilities. Diagnostique, $3,10-12$.

Milner, B. (1958). Psychological defects with temporal lobe excision. In H. C. Solomon, S. Cobb, \& W. Penfield (Eds.), The brain and human behavior. Baltimore: Williams and Wilkin.

Mohr, J. O., Leicester, J., Stoddard, L. I., \& Sidman, M. ( 1971$)$. Rignt hemianopia with memory and colour deficits in circumscribed left fosterior cerebral artery territory infarction. Neurology, 21, 11041113.

Morris, Robin D. ( 1988$)$. Classification of learning disabilities: 0ld problems and new approaches. Journal of Consulting and Clinical Pyschology, 56, 789-794.

Morrison, D. C., Hinshaw, S. P., Carte, Estol T. (1985, January). Signs of neurobehavioral dysfunction in a sample of learning disabled children: Stability and concurrent validity. Perceptual and Motor Skills, 6I, 863-872.

Naglieri, J. A. (I935, April). Use of the WISC-R and the K-ABC with learning disabled, borderline mentally retarded, and normal children. Psychology in the Schools, 22, $133-141$.

National Joint Committee on Learning Disabilities. (1987). Learning disabilities: Issues on definition. Orton Dyslexia Society. Journal of Learning Disabilities, 20, 107-108.

Neff, W. D., \& Goldberg, J. M. (1960). Higher functions of central nervous system. Annual Review of Psychology, 22, 499 .

Newcomb, F. (1969). Missile wounds of the brain. Iondon: oxford University Press.

Nussbaum, Nancy L., \& Bigler, Erin D. (1986). Neuropsychological and behavioral profiles of empirically-derived subgroups of learning disabled children. International Journal of Clinical Neuropsychology, $8,82-89$.

ornstein, Robert F. ( 1977$)$. The psycholozy of consciousness. (2nd ed.). New York: Harcourt Brace Jovanovich. 
184

Pellegrino, J. W., Alderton, D. L., \& Shute, V. J. (1984, Eall). Understanding spatial ability. Educational Psychologist, 19, 239-253.

Petrauskas, R. J., \& Rourke, B. P. (1979). Identification of subtypes of retarded readers: A neuropsychological, multivariate approach. Journal of Clinical Neuropsychology, $1,17-37$.

Piaget, Jean. (1977). The origins of intelligence in children. New York: International Universities Press.

Pines, Maya. (9 September, 1973). We are left-brained or right-brained. New York Times Magazine, pp. 26 , $27,46-49$.

Pirozzolo, F. J. (1979). The neuropsychology of developmental reading disorders. New York: Praeger.

Pollak, J. M. (1986, Summer). Human Eigure-drawing performance of LD children: Research and clinical perspectives. Learning Disability Quarterly, $\underline{9}$, $173-181$.

Polloway, E. A., \& Smith, J. David. (1986). An investigation of date of birth in the incidence of learning disabilities. Special services in the Schools, $2,77-86$.

Prasse, D. P., Siewert, J.C., \& Breen, M. J. (1983, october). An analysis of performance on reading subtests from the 1978 Wide Range Achievement Test and the Woodcock Reading Mastery Test with the WISC-R for learning disabled and regular education students. Journal of Learning Disabilities, 16 , $458-460$.

Pressman, E, Roche, D., Davey, J., \& Firestone, P. ( 1986 , October). Patterns of auditory perception skilis in children with learning disabilities: A computer assisted approach. Journal of Learning Disabilities, $19,485-488$.

Prior, M., \& Sanson, A. (1986, May). Attention deficit disorder with hyperactivity: A critique. Journal of Child Psycinology and Psychiatry and Allied Disciplines, 27, 307-319. 
Proceedings of the 81 st Convention of the American Psychological Association, Montreal, CA.

Rapoport, Judith L., Donnelly, M., Zametkin, Alan, \& Carrougher, J. (I986, September). Situational hyperactivity in a U.S. clinical setting. Journal of Child Psychology and Psychiatry and Allied Disciplines, 27, 639-646.

Reitan, Ralph M. (Ed.) (1974). Clinical neuropsychology: Current status and applications. Washington, DC: Hemisphere Publishing Corp.

Rie, Herbert E., \& Rie, Ellen D. (1980). Handbook of minimal brain dysfunction: A critical view. New York: John Wiley and Sons.

Rourke, Bryon P. (1981). Neuropsychological assessment cf children with learning disabilities. In T. J. Boll and S. B. Filskov, Handbook of clinical neuropsychology. New York: John Wiley and Sons.

Rourke, Bryon P. (Ed.) (1985). Neuropsychology of learning disabilities: Essentials of subtype analysis. New York: Guilford Press.

Rourke, Bryon P., Bakker, Dirk S., Eisk, John L., \& Strang, John D. (1983). Child psychology: An introduction to theory, research, and clinical practice. New York: Guilford Press.

Rourke, Bryon P.; Eisk, John L.; \& Strang, John D. (1986). Neuropsychological assessment of children: A treatment-oriented approach. New York: Guilford Press.

Rourke, B. P., Yanni, D. W., MacDonald, G. W, \& Young, G. C. (1973). Neuropsychological significance of lateralized deficits on the grooved pegboard test for older children with learning disabilities. Journal of Consulting and Clinical Psychology, 41 , 128 .

Rourke, B. P., Young, G. C., Strang, J. D., \& Russell, D. L. (1986). Adult outcomes of central processing deficiencies in childhood. In I. Grant \& K. M. Adams (Eds.), Neuropsychological assessment of neuropsychiatric disorders. New York: Oxford Press. 
Rourke, B. P. ( 1975 ). Brain-behavior relationships in children with learning disabilities: A research program. American Psychologist, 30, 91 1-920.

Rutter, M. (1977). Brain-damage syndromes in childhood: Concepts and findings. Journal of Child Psychology and Psychiatry, $18,1-2$.

Sarason, S. B., \& Doris, J. (1979). Educational Handicap Public Policy, and Social History. New York: Macmilian.

Sarazin, F. B., \& Spreen, 0. (1986, June). Fifteen-year stability of some neuropsychological tests in learning disabled subjects with and without neurological impariments. Journal of Clinical and Experimental Neuropsychology, $\underline{8}, 190-200$.

Sattler, Jerome $M$. (1982). Assessment of children's intelligence (2nd ed.). Boston: Allyn and Bacon.

Sexton, L. C., \& Street, S. (1985). A comparison of WISC-R score profiles of students placed in special education and those referred, but not placed. Psyihology in the Schools, 22, 142-145.

Scull, John W., Brand, Linda H. ( 1980 , June/July). The WRAT and the PIAT with learning disabled children. Journal of Learning Disabilities 13, 64-66.

Selz, M., \& Reitan, R. M. (1979). Rules for neuropsychologial test performance of normal, LD, and brain injured children. Journal of Nervous and Mental Disease, 167, 298-302.

Shangraw, R. E., Seminer, Steven, J., \& Zarr, M. L. (1985, August). Attention deficit disorder, amphetamine, and pregnancy. Biological Psychiatry, 20, 926-927.

Shavwitz, S. E., Schnell, C., Shaywitz, B. A., \& Towle, V. R. (1986, September). Yale children's inventory (YCI): An instrument to assess children with attentional deficits and learning disabilities: I. Scaled development and psychometric properties. Journal of Abnormal Child Psychology, 14, 347-364. 
Silver, L. B. (198I). Tilk on children with learning disabilities at a conference in Nasiville, Tenn., Sept. I4, 1978: In J. F. Lubar, \&W. M. Deering, Behaviorial Approaches to Neurology (P. I56). New York: Academic Press.

Silverstein, A., Lehrer, G. AM., \& Mones, R. (1960). Relation of certain diagnostic features of carotoid occlusion to collateral circulation. Neurology, 10, 409-417.

SmaI l, Leonard. (1973). Neuropsychodiagnosis in psychotherapy. New York: Brunner/Mazel.

Snow, Jeffrey, \& Hynd, George W. (I985, Eall). Factor structure of the Luria-Nebraska Neuropsychological Battery--Children's Revision with learning disabled children. Journal of School Psychology, 23, $271-275$.

Spreen, 0., \& Haf, R. G. (1986). Empirically derived learning disabilities subtypes: A replication attempt and longitudinal patterns over 15 years. Journal of Learning Disabilities, 19, 170-180.

Steplen, L., \& Sherpinski, S. (1964). Impairment of recent memory after temporal lobe injuries in man. Neuropsychologia, 2, 499 .

Stevenson, L. P. (1985). WISC-R Analysis: Implications for diagnosis and intervention. Journal of Learning Disabilities: Essentials of Subtype Analysis. New York: Guilford Press.

Talley, Jack L. (1986). Memory in learning disabled children: Digit span and the Rey Auditory Learning Test. Archives of Clinical Neuropsychology, 1 , $315-322$.

Taylor, R. L., Partenio, I., \& Ziegler, E. W. (1983). Diagnostic use of WISC-R Subtest Scatter: A note of caution. Diagnostique, $\underline{9}, 26-31$.

Telzrow, C. F., \& harr, G. A. ( 1987 , Spring). Common variance among three measures of nonverbal cognitive ability: WISC-R Performance Scale, WJPBTCA Reasoning Cluster, and Halstead Category Test. Journal of School Psychology, 25, 93-95. 
Thompson, R. J. (1987). The diagnostic utility of Bannatyne's recategorized WISC-R scores with children referred to a developmental evaluation center. Psychology in the Schools, 18, 43-47.

Iravers, Robert M. W. (1967). Essentials for learning: An overview for students of education (2nd ed.). New York: Macmillan.

Tueber, H. L., \& Rudel, R. ( 1962 ). Behavior after cerebral leisons in children and adults. Developmental Medicine and Child Neurology, 4 ,

Tucker, D. M., Stensile, C. E., Roth, R. S., \& Shearer, S. L. (198I). Right frontal lobe activation and right hemispheric performance: Decrement during depressed mood. Archives of General Psychiatry, 38, $169-174$.

Vance, H. B., Singer, M. G. (1979). Recategorization of the WISC-R subtest scaled scores for learning disabled children. Journal of Learning Disabilities, $12,487-491$.

Vitale, J. H., Pulos, S. M., Wollitzer, A. 0., \& Steinhelber, J. C. (1974). Relationships of psychological dimensions to impairment in a population with cerebralvascular insufficiency. Journal of Nervous and Mental Disorders, 158, 456.

Wallace, W. P. ( 1980 , November). On the use of distractors for testing recognition memory. Psychological Bulletin, 88, 696-704.

Wallorown, Fred H., Blaha, John, \& Vance, Booney. ( 1980 , June/July). A reply to Miller's concerns about WISC-R profile analysis. Journal of Learning Disabilities, $13,340-345$.

Webster, R. E. (1985). The criterion-related validity of psychoeducational tests for actual reading ability of learning disabled children. Psychology in the Schools, 22, $152-159$.

Wiengarten, Merri, \& Anisfeld, Moshe. (1981, August). The syntagmatic-paradigmatic shift in dichotic istening. Journal of Experimental Child Psychology, 31, 27i-278. 
Williams, Moyra. (1979). Brain damage, behavior and the mind. New York: John Wiley and Sons.

Woo-Sam, J. (1971a). Location of injury and Wechsler indicies of mental deterioration. Perceptual Motor Skilis, 32, 223-238.

Woo-Sam, J. ( 197 lb). Lateralized brain damage and differential psychological effects: Parsons et al., re-examined. Perceptual Motor Skills, 33, 259 .

Wynne, M. E., \& Brown, R. T. (1984). Assessment of high incidence of learning disorders: Isolated measures with discriminative ability. School Psychology Review, $13,231-237$.

Ysseldyke, J. E., Algozzine, B., Epps, S. (I982). A logical and empirical analysis of current practices in classifying students as handicapped. Research Report No. 92. Minneapolis: University of Minnesota Institute for Research in Learning Disabilities.

Ysseldyke, J. E., Thurlow, M. L., Graden, J., Wesson, C.; Algozzine, B., \& Deno, S. (1983). Generalizations from five years of research on assessment and decision making. Exceptional Education Quarterly, 4, $75-93$.

Zantall, Sydney S., a Zentall, Thomas R. (1986, September). Hyperactivity ratings: Statistical regression provides an insufficient explanation of practice effects. Journal of Pediatric Psychology, $11,393-396$. 


\section{VITA}

\section{Personal Data}

Kenneth Matthew Paul Hanig was born May I8, 1950, in South Bend, Indiana, the son of Kenneth Arthur Joseph and Beradine Josephine lanig of 1951

Malvern Way, South Bend, Indiana.

\section{Education}

B.S. In Education, May 1972 from Indiana

University in Bloomington, Indiana

M.S. in Education, January 1976 from Indiana

University in Bloomington, Indiana

Doctoral candidate, 1989, for the Ph.D. dgree in Educational Psychology from Andrews University, Berrien Springs, Michigan

\section{Work Experience}

English teacher, 1972-1978, South Bend Commuity School Corporation, South Bend, Indiana

Staff Psychologist, 1978 to present, Department of Pupil Services, South Bend Communty School

Corporation, South Bend, Indiana

Adjunct Instructor in Psychology, 1985, Lake Michigan College, Niles, Michigan

QMRP Consultant, 1985 to present, Lakeland Manor, Warsaw, Indiana and Eremen Health Care Center, Bremen, Indiana

Organized private practice, 1987 to present, Behavioral Consulting Associates, South Bend and Elkhart, Indiana

Staff Psychologist-Consultant, 1988 to present, Behavioral Psychological Family Services, South Bend, Indiana 
Vita page 2

\section{Affiliations}

American Psychological Association (Divisions 1 , $15,16,40$ )

National Acadamy of Neuropsychologists

American Orthopsychiatric Association

New York Academy of Sciences

Psi Chi

Phi Sigma Kappa 